

\title{
Genetics and mechanisms leading to human cortical malformations
}

Delfina M Romero, Nadia Bahi-Buisson, Fiona Francis

\section{To cite this version:}

Delfina M Romero, Nadia Bahi-Buisson, Fiona Francis. Genetics and mechanisms leading to human cortical malformations. Seminars in Cell and Developmental Biology, 2017, 10.1016/j.semcdb.2017.09.031 . hal-01626222

\section{HAL Id: hal-01626222 \\ https://hal.sorbonne-universite.fr/hal-01626222}

Submitted on 30 Oct 2017

HAL is a multi-disciplinary open access archive for the deposit and dissemination of scientific research documents, whether they are published or not. The documents may come from teaching and research institutions in France or abroad, or from public or private research centers.
L'archive ouverte pluridisciplinaire HAL, est destinée au dépôt et à la diffusion de documents scientifiques de niveau recherche, publiés ou non, émanant des établissements d'enseignement et de recherche français ou étrangers, des laboratoires publics ou privés. 


\title{
Genetics and mechanisms leading to human cortical malformations
}

\author{
Delfina M. Romero ${ }^{1-3}$, Nadia Bahi-Buisson ${ }^{4-5}$, Fiona Francis ${ }^{1-3}$ \\ ${ }^{1}$ INSERM UMR-S 839, 17 rue du Fer à Moulin, Paris 75005, France. \\ ${ }^{2}$ Sorbonne Universités, Université Pierre et Marie Curie, 4 Place Jussieu, Paris 75005, \\ France. \\ ${ }^{3}$ Institut du Fer à Moulin, 17 rue du Fer à Moulin, Paris 75005, France. \\ ${ }^{4}$ Paris Descartes - Sorbonne Paris Cité University, Imagine Institute, Paris, France. \\ ${ }^{5}$ INSERM UMR 1163, Embryology and genetics of congenital malformations.
}

Corresponding author: Fiona Francis.

Institut du Fer à Moulin, INSERM UMR-S 839, 17 rue du Fer à Moulin, Paris 75005, France. E-mail address: fiona.francis@inserm.fr

\begin{abstract}
Cerebral cortical development involves a complex series of highly regulated steps to generate the laminated structure of the adult neocortex. Neuronal migration is a key part of this process. We provide here a detailed review of cortical malformations thought to be linked to abnormal neuronal migration. We have focused on providing updated views related to perturbed mechanisms based on the wealth of genetic information currently available, as well as the study of mutant genes in animal models. We discuss mainly type 1 lissencephaly, periventricular heterotopia, type II lissencephaly and polymicrogyria. We also discuss functional classifications such as the tubulinopathies, and emphasize how modern genetics is revealing genes mutated in atypical cases, as well as unexpected genes for classical cases. A role in neuronal migration is revealed for many mutant genes, although progenitor abnormalities also predominate, depending on the disorder. We finish by describing the advantages of human in vitro cell culture models, to examine human-specific cells and transcripts, and further mention non-genetic mechanisms leading to cortical malformations.
\end{abstract}

\section{Highlights}

Update in cortical development malformations (MCDs) involving single gene mutations. Comparative description of animal models of the main mutated genes.

Atypical rare mutations leading to neuronal migration phenotypes.

Genetics, mouse models and human cell models as tools to understand mechanisms of MCD.

Non-genetic mechanisms of MCD, the case of Zika virus infection.

\section{Keywords}

Neuronal migration; cortical malformations; lissencephaly; Tubulinopathies; heterotopia; microcephaly; polymicrogyria; atypical rare mutations; exome sequencing; human in vitro cultures; ZikaV.

\section{Cortical development in mammals - a short overview, rodent versus human}

\subsection{Principal cell neurogenesis}

A correctly functioning central nervous system (CNS) relies on the formation of neural circuits to control activity. For this, newborn neurons migrate, differentiate, form their dendrites and axons, and establish neuronal connections at the correct time and place in the CNS during embryogenesis [1,2]. 
In vertebrates, earliest stages of brain development involve segmentation of the neural tube into lineage-restricted compartments where a highly elaborated genetic program maintains the head-totail (anteroposterior; AP) and back-to-front (dorsoventral; DV) axes of the CNS [3]. After neural tube closure at around embryonic day (E) 30 or gestational week (GW4), neuroepithelial cells (NECs) convert into fate-restricted differentiated radial glial cells (RGCs), a process that in the mouse occurs at E9-10, and in human embryonic telencephalon at GW5-6. At these stages the ventricular zone (VZ) is the only proliferative region [4]. RGCs are polarized with an apical-basal orientation and show hallmarks of both astrocytes and NECs. RGC basal processes constitute the scaffold for migration of newly born neurons through the intermediate zone (IZ) to the cortical plate (CP). The RGC apical process allows attachment to the ventricular lining (VL) and also contains key elements of signaling pathways, such as the primary cilium and the centrosomes. Most neurons of the brain are derived, either directly or indirectly from RGCs [5]. These cells, expressing the marker Pax6, are either able to self-renew, generating two RGCs (symmetric cell division), or give rise by asymmetric cell divisions to basal or intermediate progenitors (BPs or IPs) which move basally to form the subventricular zone (SVZ). These cells are Tbr2-positive and in rodent give rise to post-mitotic neurons, thus indirectly from RGCs [6]. A more recently identified Pax6-positive VZ cell is the short neural precursor (SNP), which is similar to an RGC but has only a short basal process, and these cells generate post-mitotic neurons directly [7]. SVZ onset occurs at E12 in the mouse and at GW7-8 in humans [4], and neurogenesis in the SVZ contributes to the generation of upper-layer neurons [8], as well as other neurons in the deeper cortical layers [9].

In gyrencephalic species, apical RGCs divide asymmetrically to generate a more faterestricted type of RG progenitor. Thus, the SVZ is composed of several types of BP: basal or outer radial glial (bRG) cells, as well as intermediate progenitors (also called bIPs) [10]. This thickened SVZ and particularly its division into an expanded outer SVZ (OSVZ), is predominantly linked to neocortex evolution and expansion, as well as formation of folds and fissures [11]. OSVZ progenitors undergo expansive proliferative divisions which contrasts the rodent SVZ, where IP cells usually divide only once. These cellular mechanisms are hence associated with the evolutionary expansion of human neocortex [12].

At GW5 in human there is already evidence of the primordial plexiform layer (PPL) or preplate (PP), visible also by approximately E11 in the mouse. The earliest born neurons form this layer which is later divided (around GW7-8, and accomplished by approximately E13 in the mouse) into the more superficial marginal zone (MZ) and the deeper subplate (SP) by the emerging $\mathrm{CP}$ $[13,14]$. Later-born neurons arriving in the CP migrate past earlier born neurons, to generate a multilayered neocortex [8]. Post-mitotic cortical neurons migrate radially along RGC processes toward the pial surface, giving rise to pyramidal neurons [15-17]. After PP splitting, the subsequent waves of migrating neurons successfully form in an inverse manner layers II-VI in the mouse, with layerspecific connectivity, morphological and physiological characteristics. Different classes of projection neuron are thus born in overlapping temporal waves $[8,17]$.

In humans, the OSVZ forms at GW11, while the neuronal migration peak that in the mouse cortex takes place from E13-16, occurs from GW12-20 [12, 16]. The IZ, located above the SVZ (see Fig. 1), contains radially and tangentially migrating interneurons (IN), the latter derived from the ganglionic eminence (GE). Before beginning radial migration into the $\mathrm{CP}$, principal cells adopt first a multipolar morphology, basal to the VZ [18]. Then cells become bipolar, facilitated by different kinds of molecules that allow differentiation and locomotion along the basal process of RGCs towards the CP $[8,16,19]$. Extracellular guidance cues also promote the correct positioning of new-born neurons. The most well-known is the Reelin signaling pathway (see below). Reelin is secreted from CajalRetzius neurons to activate downstream factors within migrating neurons [16,20]. Cajal-Retzius cells are in place from very early corticogenesis [21].

\subsection{Gliogenesis}

Neurogenesis is generally followed by gliogenesis in the developing mammalian CNS, with the same progenitor domains switching the differentiation program to oligodendrocyte or astrocyte production [22]. Glia may constitute 50-90\% of the cells in the human brain, and glial numbers are thought to be essential for achieving increased brain complexity. This involves the expansion of glial 
pool size and increased long range conduction across white matter tracts [22]. RGCs in the developing mouse and human cortex hence give rise to two main types of glia, astrocytes and oligodendrocytes, which are produced both pre- and postnatally. The third major type of glia of different origin is the microglia population which constitute the macrophages of the CNS, mediators of neuroinflammation which can induce or modulate a broad spectrum of cellular responses.

Astrocyte dysfunction can lead to developmental and/or psychiatric disorders [23,24]. Mutation of the $\alpha$-2-delta subunit of the voltage gated calcium channel CACNA2D2 which is highly expressed in astrocytes and in the neocortex, has been linked with epileptiform activity in the mouse brain [25]. Mutations in this gene are also associated with polymicrogyria (PMG), global cortical atrophy, corpus callosum dysgenesis, intellectual disability (ID) and epilepsy in three non-related patients [26].

Furthermore, the role of glia in epilepsy has recently been reviewed, especially in association with cortical malformations [27]. These authors emphasize that gliosis is a common factor observed in histological brain samples from such patients. Glial uncoupling as a consequence of loss of expression of certain molecules which are normally expressed in glia could contribute to seizures, and targeting glial cell function in the treatment of epilepsy could be a key mechanism. Finally, these authors propose the hypothesis that glial dysfunction contributes to pathology through a local proinflammatory environment driven by abnormal gliovascular interactions. Further research efforts will elucidate glial contributions in this area.

\section{Human Malformations of Cortical Development (MCDs).}

ID in children comprises $2-5 \%$ of the general population $[28,29]$. This includes neuronal migration disorders caused by infectious, toxic or vascular events, as well as genetic disorders with Mendelian inheritance, reviewed here, caused by mutations in a single gene. Continual advances in genetic technologies allow a more general understanding of MCDs, and numerous new causative genes and mechanisms have been identified in MCD patients [30]. Nevertheless, many patients who present defined clinical features and likely genetic diseases cannot be diagnosed definitively. In addition, advances in neuroimaging technologies, particularly magnetic resonance imaging (MRI) and functional MRI (fMRI), allow a delineation of the type of brain malformation, but at the same time can make their classification complicated [31]. Therefore, the identification of the underlying genetic cause is also essential in order to diagnose and determine prognosis for the affected patients.

\subsection{Genetic methods for diagnosis of MCDs}

Clinical diagnosis involves standard practices for the identification of specific phenotypic or radiographic features, and the analysis of biopsies and metabolites. When there is a clear phenotype revealed by MRI, targeted Sanger sequencing of selected candidate genes may be performed (e.g. LIS1, DCX, FLNA, see below). Nevertheless, hypothesis-driven approaches based on the ability to recognize the most likely disorder associated with defined symptoms, often fails to reach a diagnosis. Targeted panels are frequently implemented [30]. Other genomic tests include G-band karyotype analysis, the identification of chromosomal abnormalities using fluorescence in situ hybridization (FISH) and array comparative genomic hybridization (array-CGH). Array-CGH (also known as chromosomal microarray analysis, CMA) has been developed as a method to identify and map submicroscopic deletions/duplications simultaneously onto the genome sequence [32]. Moreover, during the last decade, the implementation of Next Generation Sequencing (NGS) protocols has been an important tool for the diagnosis and classification of patients with rare Mendelian diseases [33]. This method is also key to understanding the molecular and cellular bases of certain disorders. Individual patients might be the sole cases showing mutations in a particular gene, although worldwide data sharing can allow the grouping of several patients, hence better validating these candidate genes.

For NGS, patient DNA samples are broken down into short fragments and amplified using polymerase chain reaction (PCR) or hybridization-based approaches. The regions that are amplified could include either a subset of genes (targeted approach) or all the genes in the genome. Sequencing all protein-coding regions of genes is referred to as whole exome sequencing (WES), whereas if the target is the entire genome, the method is called whole genome sequencing (WGS) [30, 34]. WES may 
also be extended to target functional non-protein coding elements (e.g., micro RNA, long intergenic noncoding RNA, etc.). While WGS has a greater sensitivity to detect pathogenic variations in a single individual gene (including outside of the coding region), WES is currently more accessible and powerful for novel disease gene discovery [35]. Sequences are processed bioinformatically, aligned and compared using a set of filters to determine the significance of the variants [36].

As different populations and ethnic groups differ in their genomic variations, databases containing common variants from healthy individuals are essential for determining the significance of a given variant. Some examples include dbSNP, 1000 Genomes project, Exome Aggregation Consortium (ExAC), and Exome Sequencing Project (ESP), although certain ethnicities are underrepresented in these databases [34]. WES has been shown to improve the diagnostic yield to $25 \%$ for patients affected with neurological disorders and/or congenital anomalies with Mendelian inheritance [33]. Indeed, WES has been shown to be very useful to discover new de novo mutations associated with epileptic encephalopathy or with severe IDs [37, 38]. However, there are some limitations on the use of WES, for instance some somatic variants may be missed if read depth or the alternate-allele read frequency is low [39]. Somatic mutations are post-zygotic events that lead to two or more populations of cells with distinct genotypes in an organism [40]. The better the sequence coverage, including the breadth and uniformity of the reads, the better is the probability and accuracy to find de novo variants. In the case of somatic variants, the use of WES with very high coverage aids their detection [39]. This is also the case with WGS which also has the advantage to identify structural and non-coding variants potentially associated with a disorder, although with a higher cost.

\subsection{Neuronal migration disorder classification and mutant genes}

MCDs can be diagnosed in utero, with the most severe disorders (lissencephaly, PMG and large heterotopia) detected during pregnancy with fetal ultrasound and fetal MRI [41]. For disorders detected after birth, children develop early MCD-related symptoms, such as developmental delay, epilepsy and ID, even during the first year of life depending on the severity of the malformation [42]. In some cases, additional extra-neurological features may be evident including facial dysmorphia and skin abnormalities. MRI is used as one criteria of classification and diagnosis, as well as karyotypes and molecular screens when there is a likely genetic origin of the pathology. As mentioned above, NGS is currently a key tool for the identification of mutated genes in patients, especially those cases remaining after screening for mutations in the known associated genes. Unraveling the genes involved in MCD has shown that each cortical disorder is heterogeneous with similar phenotypes explained by different mutated genes [30, 43].

MRIs from patients that do not respond to drug treatments for epilepsy have revealed a higherthan-expected prevalence of MCDs (8-14\% of cases) [44]. These are indeed often associated with recurrent seizures, due to the incorrect positioning of cortical neurons, or neuronal defects leading to alterations in cortical circuitry and a subsequent imbalance between excitatory (glutamatergic) and inhibitory ( $\gamma$-aminobutyric acid GABAergic) systems [45]. The latter system is involved in the normal regulation of electrical discharges, preventing spontaneous abnormal electrical discharges and seizures.

The severity of clinical manifestations in MCD patients correlates with the extent of the brain malformation. Neuronal migration disorders of the type I lissencephaly spectrum (including agyria, pachygyria and subcortical band heterotopia or $\mathrm{SBH}$ ) are grouped together based on MRI images and refer to partial or complete failure of newborn neurons to move correctly out of the proliferative zones, to cross the IZ and enter into the developing CP. It is also possible to distinguish generalized abnormalities of migration, mainly including lissencephalies (LIS) versus more localized abnormalities such as regions of heterotopia or cortical dysplasia. There are another set of abnormalities due to defects in the pial limiting membrane and/or terminal phases of migration (mostly type II 'cobblestone' lissencephaly, COB or polymicrogyria, PMG). These over-migration phenotypes may involve the detachment of basal processes of RGCs [16, 42] (see below). MCDs concerning apical abnormalities of the neuroependyma (related to the position where neurons start migrating), mainly include periventricular heterotopias (PVH).

We summarize here genetics and mechanisms of the most common neuronal migration MCDs in human, following the classification proposed by Barkovich and collegues [42]. Disorders are 
resumed in Fig 2 and corresponding mouse models in Tables 1-6. We mainly focus on single genes which when mutated have been shown to be involved in neuronal migration abnormalities. Future more optimal classifications may further involve pathways, linking together multiple mutant genes [42], and already the transitions between MCDs are being broken down by the identification of gene mutations spanning multiple linked malformations.

\subsubsection{Type 1 lissencephaly spectrum (LIS/SBH) and related disorders}

Classical (type 1) lissencephaly (cLIS, see Table 1), refers to a spectrum of related neuronal migration disorders which include a smooth, thickened and disorganized cortex without gyri (agyria or 'smooth brain'); simplified and abnormal gyri (pachygyria) and misplaced or ectopic neurons which form SBH (or double cortex) [42, 46]. Generally, agyria is characterized by the absence of deep sulci in more than one lobe, and a cortex thickness of 10-20 mm, while in pachygyria, gyri are simplified and wider than in the normal cortex, and the thickness of the cortex is 4-9 mm [31]. In SBH, a superficial cortex which may be grossly normal or show aberrant gyration, is separated by a thin layer of white matter from a band of grey matter.

It has been estimated that 40 to $75 \%$ of patients with cLIS including also Miller Dieker Syndrome (MDS, see below) have heterozygous mutations involving LIS1 (approximately to 60\%) or hemizygous $D C X$ mutations (12\%), meaning that many of lissencephaly patients have other mutations. Of these, rare cases of cLIS are for example, caused by mutations in TUBA1A [47, 48], and also in DYNC1H1 and KIF2A [49].

Irrespective of the causal gene, patients with cLIS typically demonstrate severe to profound hypotonia, intractable epilepsy and feeding problems [50]. The overall incidence of lissencephaly is rare and estimated around 1.2/100,000 births. Clinical presentation of cLIS may vary depending on the severity. The most severe cases, prenatally detected using ultrasound performed during the second trimester of the pregnancy, show an absence of primary sulci, confirmed by fetal cerebral MRI performed from $30 \mathrm{GW}$. Most patients present with hypotonia or severe neurological distress, or develop seizures during the first year of life [51].

Imaging studies for patients with cLIS also reveal a smooth surface brain with diminished white matter and a shallow vertically oriented Sylvian fissure. Remarkably, when the lissencephaly is not complete, the defects (agyria, or severe forms of pachygyria or SBH) are typically more severe in either anterior or posterior regions of the brain, e.g. parieto-occipital regions for LIS1-associated, and fronto-temporal regions for $D C X$-associated lissencephaly [52]. Thus, the neuroradiological appearance is often graded using a six-point grading system based on the severity and anteriorposterior gradient of the abnormalities. Only grade I actually deserves the name of lissencephaly; grades 2-4 are cases of pachygyria [42] and at the end of the spectrum, grades 5 and 6 apply to SBH.

According to Friocourt and colleagues [53], the first detailed neuropathological description of lissencephaly was reported in 1956 by Crome who introduced the notion of a "four-layered" cortex. On gross examination, brain weight is either normal or reduced. When the hemispheres are smooth, there are poorly defined central and Sylvian fissures. When present, gyri are broad, small in number and coarse, with a failure or a delayed operculization of the Sylvian fissure. The cortical ribbon is thicker than in a normal brain (10-20 mm vs. the normal $4 \mathrm{~mm}$ ) and poorly delineated from the white matter which is markedly reduced, leading to an inverted proportion between the white matter and the cortical ribbon [53]. On microscopic examination, the $\mathrm{CP}$ exhibits a characteristic four-layered pattern. The molecular layer I contains Cajal-Retzius cells located close to the pia. Layer II is composed of densely packed pyramidal neurons which are mainly observed in its upper part, and underlined by an irregular sheet of granular cells. Layer III consists of scattered fusiform, rounded or multipolar neuronal elements. Layer IV is particularly poorly delineated from the underlying white matter and composed of pleiomorphic neuronal cells, with misoriented pyramidal neurons. The reduced white matter contains multiple arrested post-mitotic neurons. The remaining subependymal cell layer is also poorly delineated from the deep white matter and sometimes contains PVHs. Moreover, anomalies of infratentorial structures and cortico-spinal tracts are also frequently observed, but these are typically less severe than found in cases of lissencephaly with cerebellar hypoplasia [54]. 
2.2.1.1a LIS1 (Platelet Activating Factor Acetylhydrolase 1b Regulatory Subunit 1, PAFAH1B1)

The first gene identified to be causative of lissencephaly was LIS1, localized on chromosome 17p13.3. LIS1 belongs to the non-catalytic alpha subunit of the intracellular Ib isoform of plateletactivating factor acteylhydrolase, which is a heterotrimeric enzyme that specifically catalyzes the removal of the acetyl group at the $\mathrm{SN}-2$ position of platelet-activating factor (identified as 1-O-alkyl2-acetyl-sn-glyceryl-3-phosphorylcholine) [55]. LIS1 also associates with microtubules (MTs) [56] (see below). This gene was found deleted in MDS patients [57], a contiguous gene deletion resulting from deletions of 17p13.3 including LIS1 [58-60]. cLIS can also occur as isolated forms due to other LIS1 mutations (isolated lissencephaly sequence or ILS, isolated SBH). MDS is more severe deleting LIS1 and adjacent genes, in particular 14-3-3E (YWHAE, tyrosine 3- monooxygenase/tryptophan 5monooxygenase activation protein, epsilon) [57]. The 14-3-3 $\varepsilon$ protein binds to phospho-serine containing proteins and mediates intracellular signal transduction. Approximately $80 \%$ of individuals with MDS have a de novo deletion and approximately $20 \%$ have inherited a deletion from one of the parents who presents a balanced chromosome rearrangement [61]. Heterozygous LIS1 mutations show an equal frequency in males and females, as expected from an autosomal disorder. Gene dosage is clearly very important, with these mutations leading to haploinsufficiency [56]. As well as MDS, it has also been proposed that $60 \%$ of the remaining mutations that cause the disorder involve the disruption of splicing of LIS1 variants [62]. Moreover, it has recently been shown that a recurrent LIS1 intronic mutation disrupts LIS1 transcript splicing and is responsible for cLIS of variable severity [63]. Other types of point mutations are observed e.g. [62] including cases of somatic mosaicism [39].

\subsubsection{1b Animal models and functional studies}

Mouse models of Lis1 (Pafahlb1) revealed that homozygous knockout (KO) mice died in embryogenesis soon after implantation suggesting an essential role of this gene in early embryonic development [64]. Brain abnormalities displayed by heterozygous (+/-) mutant mice mainly disrupt the hippocampus. However, 5\% of $\mathrm{Lisl}^{+-}$mutant mice die from seizures at 3-5 weeks of age. More severe defects are observed by lowering the amounts of Lis 1 further, by crossing with a hypomorphic allele [64]. In this case, the phenotype involves cortical, hippocampal and olfactory bulb disorganization resulting from delayed neuronal migration, by a cell-autonomous neuronal pathway. The Lis 1 phenotype is hence dosage-sensitive, and a critical role for Lisl in neuronal migration throughout the brain is suggested. The heterozygous phenotype in mice however, appears milder than the phenotype observed in patients with heterozygous LIS1 mutations.

Another Lis1 mouse model gave rise to a shorter Lis1 protein that initiates from the second methionine (M63) and elicits a different phenotype. In heterozygote mutant embryos ( $\mathrm{Lis} 1 / \mathrm{sLis}$ ), athough the $\mathrm{CP}$ does form in occipital regions, the process is slowed or delayed and as a consequence, the width of the CP is reduced at E14.5 [65]. The authors showed that these Lis1 mutants show no progenitor abnormalities in either cell cycle length or interkinetic nuclear migration (INM), despite the fact that the overall organization of RGCs seems affected. In both mouse models ( $\mathrm{Lisl}^{+/-}$and Lis 1/sLis 1), adult brain cortices are normal, but hippocampal abnormalities were observed only in Lis $1^{+/}$mice $[64,65]$. Altogether, dose-dependent disorganization of cortical layers, hippocampus, cerebellum and olfactory bulb due to cell autonomous neuronal migration defects is observed in mice with severely decreased levels of Lis1 [64]. 
In utero electroporation studies performed in rat embryos showed that down regulation of Lis 1 in neuronal progenitors induced the accumulation of multipolar progenitor cells within the SVZ of the neocortex. Moreover, a complete failure in progression from the multipolar to migratory bipolar state was observed. RGC proliferation failed and INM was abolished [66]. This is hence a severe phenotype generated by acute inactivation. In other studies, LIS1 was also shown to be important for cell proliferation during neurogenesis, as well as for neuronal migration and survival [67]. Furthermore, loss of Lis1 showed perturbed mitotic progression resulting in a prolonged cell cycle that induced anaphase onset delay in cKO mouse embryonic fibroblasts (MEFs) [68].

At the protein level, LIS1 has been shown to form a homodimer through $\mathrm{N}$ terminal associations [69], while it interacts through its C-terminal $\beta$-propeller with cytoplasmic dynein (DYNC1H1) and its regulatory partner dynactin (DCTN) [70-73]. DYNC1H1 belongs to a group of MT-activated ATPases that function as molecular motors, being the primary minus-end-directed MT motor protein. DCTN is involved in dynein-mediated retrograde transport of vesicles and organelles along MTs by recruiting and tethering dynein to them. Thus, DCTN binds to both dynein and MTs providing a link between specific cargos, assisting cargo loading and increasing processivity. In vitro studies in mammalian cells showed that dynein is important for LIS1's role in cell division [70], and for INM in mammalian neural progenitor cells. Indeed, dynein regulated by LIS1, is the force generator for nuclear movement in RGCs [74]. Additionally, experiments performed in migrating neural cells demonstrated that Lis 1 and dynein RNAi inhibit centrosomal and nuclear movement, whereas myosin II inhibition blocks only nuclear translocation [74].

LIS1 binds other proteins such as NDE1 [75] and its paralogue NDEL1 [76]. NDE1 is a spindle-associated gene and mutations in humans cause a severe microlissencephaly syndrome that reflects both morphological and quantitative defects in RGCs [76-79]. Blocking NDE1 self-association induced defective centrosomal duplication, and this defect was at least partially responsible for spindle mis-assembly [74]. Pawlisz and col. [80] showed that Nde1 null and Lis1 heterozygous double mutant mice have an $80 \%$ thinner and severely disorganized cortex, presenting reduced numbers of radial neuronal units, due to the loss of progenitors and a consequence of failures in mitotic spindle function. A dramatic increase in neuronal differentiation was shown at the onset of corticogenesis which in the mutant led to overproduction and abnormal development of early-born PP neurons and Cajal-Retzius cells, at the expense of progenitors.

Ndel 1 loss of function, like Lis 1 or dynein, impairs neuronal positioning and induces the uncoupling of the centrosome and nucleus. Shu and col. [81] showed that overexpression of Lis1 partially rescued the positioning defect caused by Ndel 1 RNAi but not dynein RNAi, whereas overexpression of Ndel1 was not able to rescue the phenotype induced by Lis 1 down-regulation, strongly suggesting that Ndel1 interaction with Lis1 is essential for dynein function. Lis1 and dynein colocalize at mitotic kinetochores, and microinjection of an anti-Lis1 antibody in mammalian cells was shown to interfere with the attachment of chromosomes to the metaphase plate, leading to chromosome loss and a delayed mitotic progression [70]. Ndel1 and Nde1 also colocalize with Lis1 at the MTOC in mitotic embryonic neuroblasts or fibroblasts [69] and were shown to interact directly with dynein $[71,81,83]$. Nde1 is hence required for targeting Lis1 to the cytoplasmic dynein complex to generate persistent motor forces [72], while Ndel1 has been implicated in the process of Lis1 recruitment to dynein, to act as a scaffold protein [81,84]. Lis1 also appears essential for precisely controlling mitotic spindle orientation via Lis1/Ndel1/dynein-mediated cortical MT capture [70,77]. This can help regulate symmetric versus asymmetric divisions of neural progenitor cells.

LIS1 and NDEL orthologs in Saccharomyces cerevisiae (Pac1 and Ndl1, respectively) were shown to be important for concentration of dynein at the plus ends of MTs [84,85]. This favors dynein at the cell membrane, where it positions the nucleus during cell division. Moreover, Lis 1 is required there for the proper distribution of three distinct dynein cargoes such as endosomes, peroxisomes and nuclei $[56,86]$.

Thus there are multiple roles for LIS1, intensively studied since its identification in 1993. Heterozygote LIS1 mutations in human reveal likely neuronal migration defects underlying disorganized cortical layers and gyral abnormalities. Abnormal neuronal migration can also be observed in mouse mutants. Varying Lis1 amounts in the mouse and in in vitro systems, reveals as well effects in dividing cells via multiple mechanisms. The human LIS phenotype might be due to a 
combination of LIS1 functions in nuclear positioning and organelle transport, as well as in mitotic spindle function and cell cycle progression. It should be noted that a proportion of LIS1 cases also exhibit microcephaly, and so it seems likely that certain mutations combined with particular genetic backgrounds will have a detrimental effect on progenitors, perhaps as well as during migration. It becomes important to dissect out these possible effects, potentially with the use of temporally and spatially controlled knockouts.

\subsubsection{2a Doublecortin (DCX)}

The $D C X$ gene is located on chromosome Xq22.3-q23, and mutations cause lissencephaly mostly in males (X-linked LIS or XLIS), whereas $D C X$ mutations in females frequently give rise to SBH [87,88]. A minority of males have SBH [52], often due to mosaic $D C X$ mutations. The product of $D C X$ is a cytosolic microtubule-associated protein (MAP) with two doublecortin domains (DC) which bind MTs and several potential regions for regulation by phosphorylation and protein interaction, such as proline and serine rich regions [89-91]. DCX nucleates and stabilizes MTs and is highly expressed in migrating and differentiating neurons, but appears to be little expressed in progenitors. This protein is potentially the best characterized of the neuronal migration classical MAPs [89,90,92-94].

In XLIS, neuronal migration in the cortex is severely disrupted, leading to the formation of an abnormal four-layered cortex. In hemizygous $D C X$-mutated males, the brain surface is agyric or pachygyric, the anterior areas being more severely affected, with hypoplasia of the frontal lobes (anterior-posterior gradient, [95]. The corpus callosum is variably affected, described as thick, thin or absent. The cortical ribbon is thick and poorly delimited from the white matter and generally recognized as 4-layered. However, with further investigation some $D C X$ brains have been described as having an ill-defined but six-layered cortex [53]. With a relatively normal layer I, layer II consists of a thin band containing an admixture of pyramidal and granular neurons. Layer III is poorly delimited and paucicellular and made up of granule and immature neurons. Within the superficial white matter, layer IV forms a thick ribbon of scattered, sometimes clustered pyramidal cells and immature neurons. The extra abnormal layers are adjacent in the white matter and composed of large nests of arrested migrating neurons, arranged in a radially and columnar pattern [96]. The cerebellum and the brainstem are macroscopically normal.

Most of missense mutations causing cLIS are located in the evolutionary conserved DC domains of DCX, suggesting the importance of MT binding for DCX function during brain development $[91,97,98]$. Mutations in $D C X$ have been found in families, with females presenting SBH and males presenting LIS. Also $80-90 \%$ of sporadic DCX mutations are found in females, versus $25 \%$ in males with $\mathrm{SBH}[31,99]$. De novo mutations show a higher proportion of nonsense and frameshift changes, and are likely therefore to lead to a more severely perturbed protein [98]. Indeed, maternal germline or somatic mosaicism may explain the difference between sporadic SBH and XLIS in males $[39,95,100]$. The $10 \%$ of SBH patients showing no $D C X$ mutations are likely to have mutations in other genes such as TUBAIA or occasionally LIS1 [101,102].

\subsubsection{2b Animal models and functional studies}

DCX is predominantly expressed in post-mitotic neurons and shows developmental regulation. In developing neurons Dcx has been shown to have a specific subcellular localization, enriched at the ends of neuritic and leading processes [89,103]. It has been shown to play a role limiting the number of leading processes during migration [92,94]. Mutations in MAPs which stabilize MTs, such as Dcx, Dclk, Tau, Map2 and Map1b, can impair cell polarization, formation of the leading process, neurite outgrowth and/or lead to excessive branching that hinders migration [16].

Like Lis 1 mutants, Dcx KO mutations in the mouse induce no major neocortical malformation although hippocampal lamination defects are observed [104,105]. $D c x^{-/ Y}$ mice show abnormally laminated CA3 hippocampal pyramidal cells, a dual or dispersed layer of pyramidal cell somata with potentially aberrant connectivity associated with mossy fibers [106]. Pyramidal cells displayed morphological abnormalities, as they were smaller with a reduced total dendritic length, and were more excitable than WT cells. In vitro hyperexcitability and spontaneous epilepsy are characteristic of this mouse model [107]. 
Lack of severe neocortical abnormalities suggests a functional redundancy with $D c x$-related genes, involving genetically redundant pathways [93,108]. However, acute down-regulation of $D c x$ in the developing rat cortex by RNAi led to disruption of radial migration [109]. In addition, Pramparo and col. [110] demonstrated by time-lapse video-microscopy in embryonic neocortical slices that $D c x$ ${ }^{/ Y}$ neurons do have defective migration velocities, similar to $\mathrm{Lis}^{+/-}$neurons, as well as multidirectional movements, abnormal morphology and increased branching [110]. This is similar to previous data showing the same defects in IN populations [92,94]. Pramparo and col. [110] also detected RGCs with abnormal spindle orientations in $D c x^{-/ Y}$ mutant mice, similar to Lis ${ }^{+/-}$cells, leading to mild proliferation defects in vivo and in vitro. Moreover, a genetic interaction in double mutant males $\left(L i s 1^{+/} ; D c x^{-/ Y}\right)$ was shown, resulting in severe defects of proliferation of neuronal precursors, neurogenesis and neuronal migration.

Dclk (Doublecortin-Like Kinase 1) is a protein kinase that belongs to the DCX family. Gene mutations cause no obvious migration abnormalities, although mice mutant for both $D c x$ and $D c l k$ show perinatal lethality, disorganized neocortical layering and hippocampi $[93,108]$. Dcx ${ }^{-/ y}$; $c l k^{-/-}$ mutants have axonal defects in the corpus callosum, anterior commissure, subcortical fiber tracts and the internal capsule. Lamination defects of the hippocampus observed in these animals were more severe than previously reported in Dcx KO mice [104] but appeared similar to hippocampal defects seen in $C d k 5$ KO mice $[108,111]$. In $D c x^{-/ Y} ; D c l k^{-/-}$animals, as in $C d k 5$ KO mice, hippocampal cells appeared to be less packed in the dentate gyrus, with a dispersion of neuronal cell bodies. The stratum pyramidale (SP) in fields CA3, CA2 and CA1 showed multiple, disorganized layers with an irregular influx of white matter in no consistent pattern. The cingulate cortex was also affected in contrast to $D c x$ and Dclk single KO mice, which show no apparent neocortical defects [108]. Double mutants of $D c x$ and $D c l k 2$ have also been generated, however in this case the hippocampus is the most affected structure [112].

Dcx mutations in mice have been shown to lead to defects in IN migration [92,94]. This was shown both during embryogenesis [92] and in the rostral migratory stream of the adult [94]. Videomicroscopy revealed morphological defects (excessive branching) during migration, expected due to the loss of a MAP. These defects lead to slowed neuronal migration. The down-regulation of $D c x$ in rat embryos also showed slowed IN migration during development [113], also observed with the down-regulation of $D c l k$, although branching defects were not observed in Dclk-mutant migrating INs [113]. Further information about Dcx and branching was obtained by the study of the stromal cellderived factor-1 (Sdf11), a modulator of IN migration speed and leading process branching in the mouse [114]. Sdf1 reduces IN branching frequency while promoting stream migration. The Sdf1 signaling pathway leads to the activation of the calpain protease which cleaves cortactin, reducing Arp2/3 activity, consolidating the actin network and leading to a reduced branch lifetime. Sdf1 signaling was however also shown to activate Dcx, favorising binding and bundling of MTs, stabilizing the MT array and reducing neuronal branches [115]. In addition to bundling MTs in processes, Dcx influences nuclear movement and also promotes MT elongation [89,90,94,97,116].

Transcriptome studies have also been performed in $D c x^{-/ Y}$ mice $[110,117]$. In the KhalafNazzal and col. study [117], an analysis of the abnormal double layer in the hippocampal CA3 region was performed, showing that one layer is likely to be due to migration of early born pyramidal neurons to abnormal superficial regions [117]. This is interesting since although all hippocampal neurons are deleted for Dcx, clearly they can be distinguished in two different populations, potentially related to different modes (Dcx dependent/ independent) of migration.

The $D c x$ mutant phenotypes showing abnormal neuronal migration can be associated with the required regulation of MTs by Dcx. An extensive clinical study also made the association of patient mutations with predicted effects on MTs [98]. In a separate study, the analysis of different $D C X$ patient mutations in vitro showed either loss-of-function or the activation of different cell pathways including increased autophagy [118]. Transcriptional studies also reveal increased cell stress [117]. Thus, $D C X$ alleles may cause dysfunction by different mechanisms [118]. This may help to explain variable severities in patients, including the small percentage $(\sim 15 \%)$ which also show microcephaly [98].

\subsubsection{3a Aristaless Related Homeobox (ARX) and interneuronopathies}


The ARX (aristaless-related homeobox) gene encodes a homeodomain transcription factor which is essential for brain development and patterning [119]. This gene is located in Xp22.3 and lossof-function mutations are associated with infantile spasms and X-linked lissencephaly with abnormal genitalia (XLAG) characterized by an unusual three-layered cortex and agenesis of corpus callosum, or alternatively X-linked non-syndromic ID.

Patients with XLAG present occipital-predominant lissencephaly, particularly anterior pachygyria and posterior agyria or a simplified gyral pattern, as well as agenesis of the corpus callosum, and abnormal basal ganglia [120]. In the most severe form of XLAG, patients show hydranencephaly with a large occipital cavity. Female carriers of $A R X$ mutations causing XLAG have a risk of agenesis of the corpus callosum with no cortical defects. In boys, abnormalities of external genitalia range from a hypoplastic penis or undescended testes to complete female appearance, while the karyotype is $46 \mathrm{XY}$. Patients with XLAG show intractable seizures soon after birth, suggesting major perturbations between excitatory projection neurons and inhibitory INs.

Approximately, 5-10\% of X-linked ID cases are associated with $A R X$ mutations [119]. Mutations in non-coding regions close to the $A R X$ gene have also been associated with ID and/or autism spectrum disorder (ASD) and infantile spasms [121]. Polyalanine expansions account for over half of all mutations in $A R X$. Missense and polyalanine expansions hence generate an extremely broad spectrum of phenotypes, associating malformation and non-syndromic cases, and showing a strong correlation between genotype and phenotype [120]. De novo mutations can give rise to the previously mentioned conditions, but in addition, hydraencephaly with abnormal/ambiguous genitalia, Proud syndrome (agenesis of corpus callosum with abnormal genitalia), West syndrome, X-linked myoclonic epilepsy with generalized spasticity and developmental delay, Partington syndrome, ASD, developmental delay with severe feeding problems, intracranial hemorrhage and seizures [122]. ARX has also been found mutated in atypical cases e.g. a boy presenting infantile spasms, PMG, PVH and cleft lip/ palate [123]. In particular, X-linked West syndrome, X-linked myoclonic epilepsy with spasticity and ID, Partington syndrome (ID, ataxia, and dystonia), and non-syndromic forms of ID have not been reported to present brain imaging abnormalities [124]. Poirier and col. [125] have also reported a patient presenting eye rolling combined with atypical hypsarrhythmia, severe ID and nonictal dyskinetic movements. Thus a huge variety of syndromic and non-syndromic phenotypes are possible.

Neuropathological reports for XLAG syndrome are rare [54,126-128]. In all reported cases, the cortical ribbon is of intermediate thickness (less than $10 \mathrm{~mm}$ ) and the corpus callosum is absent. Several diencephalic structures are not identified. With histological analysis, XLAG is characterized by a three-layered cortex with a global decrease in neuron number affecting massively INs. The molecular layer contains a few Cajal-Retzius cells lying under the pia. Layer II is composed of numerous densely packed pyramidal neurons. Layer III, whose thickness increases in the posterior lobes, is irregular in width and less cellular, and contains small-to-medium-sized neurons, with among them randomly dispersed pyramidal cells of various sizes. In the diencephalon, striatal and thalamic structures are disorganized. The caudate nuclei are markedly reduced in size and cellularity, and so are the putamen, the pallidum and the thalami. Most hypothalamic nuclei are not identified and their absence has been correlated with some clinical hallmarks of the disease.

Moey and col. [129] and Fullston and col. [121] have shown that certain missense variants early on in the $A R X$ gene induce a premature termination of the protein (amino acid residue 12 or 27) in patients with early-onset infantile spasms. In these cases they show that a reinitiation of translation is possible (e.g. at methionine residue 41) producing lower levels of an $\mathrm{N}$-terminal truncated protein. The authors conclude that low levels of the truncated protein are enough to improve the patients' phenotypes compared with severe loss-of-function XLAG patients. This is hence another way to account for certain variable phenotypes. Of note, heterozygous female carriers can show a variety of psychiatric conditions such as anxiety, depression and schizophrenia jointly with learning disability [130]. Genomic variations in $A R X$ have also been reported in some unaffected individuals [131]. Nevertheless, in general, different types of $A R X$ mutations lead to severe phenotypes.

A high proportion of GABAergic neocortical INs are generated in the medial ganglionic eminence (MGE) of the ventral telencephalon and reach the cortex by tangential migration, also 
termed non-radial cell migration. They migrate from the MGE to the cortex during embryonic development, guided by a combination of chemoattractive and repulsive cues [132]. IN dysfunction and perturbations of their migration have been associated with severe neurological and psychiatric illnesses, including epilepsy, ASD and schizophrenia [133]. Indeed, "interneuronopathies" is a term which refers to aberrant migration and differentiation of GABAergic INs which do not reach their proper destination in the neocortex [134]. This phenomenon also occurs mildly in human type-I cLIS, as well as relevant mouse models, although this is usually to a lesser extent, compared to XLAG $[16,46,96,134,135]$. Particularly, in $L I S 1$ and $D C X$ samples, defective migration was suggested by the presence of heterotopic calretinin- and calbindin-positive cells in the VZ/ SVZ or IZ. In addition, few GABAergic INs were detected in the CP. In comparison, an $A R X$ case in this study showed an almost complete absence of INs in the CP, as well as a paucity of Cajal-Retzius cells in layer I, suggesting that ARX is important for correct migration of several neuronal types [96]. Mutations in TUBA1A (see below) also can include GE abnormalities [136]. Thus, IN migration defects of different severities are frequent occurrences, also associated with MCDs.

\subsubsection{3b Animal models and functional studies}

Arx is expressed in several areas of the nervous system, and in the floorplate Arx together with FoxA2, directly induces Sonic hedgehog (Shh) expression through binding to an Shh floor plate enhancer (SFPE2) [137]. Nkx2.2, induced by Shh, then down-regulates Arx expression, showing hence a regulatory loop during vertebrate development. These data suggest that Arx plays a role as a context-dependent transcriptional activator, which may help explain how mutations in this gene are associated with a wide variety of phenotypes in affected patients. Different types of mutation also contribute to variability. Missense mutations found in patients in either the $\mathrm{N}$ - or C-terminal nuclear localization signal (NLS) regions lead to aggregates of ARX both in the peri-nuclear region of the cytoplasm and inside the nucleus [138]. These mutations did not prevent the interaction of ARX with Importin 13, a mediator of the nuclear import process, however they lead to inadequate accumulation and incorrect distribution of ARX [138].

Arx mutant mice die perinatally as a consequence of hypoglycemia related to pancreatic defects [139]. However, neuropathological analyses and study of Arx in the mouse show perturbed INs, confirming that this gene has an important role in their migration from the subpallium during brain development $[138,140]$. Mouse mutants also showed ectopic accumulation of neurons in ventral proliferative zones close to the ventricles [141], mimicking hence a ventral PVH phenotype. Arx KO mice also show hypoplasia of the olfactory bulbs, suggesting that IN migration routes are similarly perturbed in the adult [140].

During development Arx is also expressed in pallial VZ progenitors. Loss of Arx specifically from these cells $\left(A r x^{F / Y} ; E m x I^{C r e / C r e}\right.$ mice) resulted in less anxious, less social, hyperactive mice, resembling mildly affected human $A R X$ patients [142]. In addition, mice presented reduced cortical thickness, a hypoplastic corpus callosum and anterior commissure, consistent with perturbations in cortical projection neuron production and connectivity. Mutant mice were shown to have reduced size of brains and proliferation defects, especially affecting IPs [143]. This had an overall effect on upper layer neurons. Thus, Arx plays a role regulating pallial progenitors as well as being involved in subpallial mechanisms.

Conditional loss of Arx from developing INs in the neocortex and hippocampus induces a shift of these precursors to more ventral locations, which persists in the adult nervous system, leading to reduced numbers of INs in the cortex at early and late postnatal periods [144]. Conditional $A r x^{-/ y} ; D l x 5 / 6^{C I G}$ male mice and half of the $A r x^{-/+} ; D l x 5 / 6^{C I G}$ female mice exhibit different seizure types in early-life, including those that resemble infantile spasms which evolve throughout development. No specific anatomical defects were detected in this mouse model, although both male and female mutants showed a reduction of calbindin INs in the neocortex, as well as a more subtly reduced calretinin INs [145]. This study also found that 8/25 (32\%) human females heterozygous for $A R X$ mutations, had seizures, neurocognitive deficits, and/or agenesis of corpus callosum, suggesting that disruption of these IN subpopulations contributes to the pathogenesis of developmental epilepsy in both males and females.

\subsubsection{4a Reelin (RELN) and pachygyria}


Reln codes for a large extracellular glycoprotein, a serine protease, abundantly synthesized and secreted by Cajal-Retzius cells in the MZ, and involved in the positioning of post-mitotic neurons during migration in the developing cortex [146-148]. Cajal-Retzius cells are also localized in the hippocampus during embryonic development and disappear soon after birth (1-2 postnatal weeks), as soon as neuronal migration and layer formation are completed. Reln has multiple functions in the brain and also plays a role in neuronal morphology and synapse formation, e.g. in hippocampal connections during forebrain development, promoting the branching of axonal projections from the entorhinalhippocampal pathway [149].

Autosomal recessive mutations in Reelin $(R E L N)$ were identified in patients with a form of lissencephaly and cerebellar hypoplasia [150,151]. The association of cortical and cerebellar defects are also observed in patients with TUBAIA mutations and less commonly in patients presenting TUBB2B and CDK5 mutations [101,136,152-154]. The rare mutations in RELN or its receptor VLDLR (Very Low Density Lipoprotein Receptor) lead to frontal predominant mild lissencephaly (diffuse pachygyria) with severe hippocampal and cerebellar hypoplasia $[150,155]$. In rare cases, patients with RELN or VLDLR mutations may show pontocerebellar hypoplasia $(\mathrm{PCH})$, a neurodegenerative disorder with prenatal onset mainly affecting infratentorial structures, leading to combined pontocerebellar hypoplasia and atrophy at birth [156,157].

\subsubsection{4b Animal models and functional studies}

The spontaneous mouse mutant for Reln, reeler, is a well-studied model mimicking the human phenotype, with a disorganized, inverted lamination pattern in the cortex and hypoplastic cerebellum featuring a decreased number of Purkinje cells [148]. The reeler phenotype was observed in several original mouse mutants displaying either a complete loss of transcription of the gene [199] or Reln protein that lacks a C-terminal portion [64,158]. These mouse strains present neurological phenotypes including tremors, ataxia, cerebellar hypoplasia and malformation of cellular layers throughout the brain.

Another more recent mutant of Reln, a truncated variant containing a deletion of the Cterminal region (CTR), shows different cortical defects with no cerebellar hypoplasia [159]. This mutant (Reln $\left.{ }^{\text {CTRdel }}\right)$, carries a chemically induced splice-site mutation that truncates the Reln protein. This induces the intracellular accumulation of the mutant protein causing signaling defects. Interestingly, brains of Reln ${ }^{\text {CTRdel }}$ mice do not present an inversion of the cortical layers. However, some cortical neurons (Cux1-positive cells), over-migrate and are observed in the MZ, whereas other Cux1-positive cells migrate less and forms small ectopic clusters within the deep layers of the mouse cortex [159]. The differences in this mutant are likely to be related to the different signaling pathways initiated by Reln, involving either Vldlr or ApoER2. This particular mutation is likely to only affect binding to Vldlr.

Indeed, Reln binds both cell-surface receptors Vldlr and ApoER2 (apolipoprotein E receptor type 2) on migrating neurons, and induces clustering of the receptors and activation of the intracellular adaptor phosphoprotein Disabled-1 (Dab1). This is phosphorylated by Src family kinases (SFK) at different sites, which initiates a signaling cascade to induce neuronal migration [160], including Crk/Rap1 signaling affecting cell adhesion, and phosphatidylinositol-3 kinase PI3K/Akt and mTOR signaling $[161,162]$. Dab1 is then ubiquitinated leading to proteasome degradation, suggesting that this sequence of activation and shutoff may be crucial for the execution of multiple steps in neuronal migration [162]. During radial migration, neurons require Dab1 for glia-independent somal translocation, but not for glia-guided locomotion. During somal translocation, Dab1 function allows neuron translocation stabilizing their leading processes in a Rap1-dependent manner [162]. After binding to Vldlr on the cell surface, Reln has also been shown to be internalized into vesicles. ApoE has also been shown to reduce the level of Reln-induced intracellular tyrosine phosphorylation of Dab1 in mouse cortical neurons in vitro [163]. Vldlr and ApoER2 double mouse mutants have a reelerlike phenotype, involving inversed cortical lamination, hippocampal and cerebellar defects. Hence disruption of both pathways is required to lead to this severe cortical phenotype [159]. Dab1 mutants (one of which is known as scrambler), also have similar defects.

Reln canonical pathways, involving the activation of the ApoER2/Vldlr/Dab1 signaling, appear to mediate many Reln-dependent functions during pre- and postnatal brain development and 
function [160]. However, SFKs that are central in Reln signal transduction allow the activation of two distinct branches: PI3K-Akt- and MEK-Erk1/2- dependent signaling cascades, which converge on downstream effectors, as was reported in cortical neurons in vitro [161]. A non-canonical pathway is hence known, involving the induction of Erk1/2, p90RSK, and immediate early genes and was suggested to mediate at least some postnatal functions of Reln signaling [161] which may also be related to neuropsychiatric disorders.

Reln also binds to the extracellular domain of ephrin Bs, which interact at the membrane with Vldlr and ApoER2 in neurons [164]. Clustering of ephrin Bs leads to the recruitment and phosphorylation of Dab1, which is necessary for Reelin signaling. Compound mouse mutants $\left(\operatorname{Reln}^{+/}\right.$; $E f n b 3^{-/-}$or Reln $^{+-}$; Efnb2 $2^{-/}$) and triple ephrin B1, B2, B3 KOs show neuronal migration defects that recapitulate the ones observed in the neocortex, hippocampus and cerebellum of the reeler mouse [165]. Loss of function of ephrin Bs severely impairs Reelin-induced Dab1 phosphorylation. Dab1 activates additionally other signaling pathways, eg involving PI3K. Interestingly, the activation of ephrin Bs can rescue the phenotype of neuronal migration defects in reeler slices, allowing neurons to reach layers II-III [165]. Ephrin B induces the formation of a macromolecular complex required for Src recruitment/activation and Reln signaling. Sentürk and col. [165] concluded that ephrin Bs are essential components of the Reln receptor/signaling pathway controlling neuronal migration during nervous system development.

Interestingly, $\mathrm{He}$ and col. [166] demonstrated that during cortical development, sister excitatory neurons progressively and selectively develop gap junctions with each other while they migrate. This accurate electrical synapse formation depends on inside-out radial migration. Indeed, inactivation of Reln or knockdown of Dab1 disrupted clonal inside-out neuronal migration and impaired electrical synapse formation between sister neurons. Moreover, elevated levels of EfnA/EphA-mediated signaling, which was shown to laterally disperse clonally related excitatory neurons, also prevented electrical coupling. Mutations in the Reln pathway are hence key for the elucidation of such mechanisms.

The Rho family of small GTPases, RhoA, Rac and Cdc42, are significant contributors for orchestrating neuronal development including many cellular processes, such as cytoskeleton stability during neurite outgrowth and branching, cell polarity and vesicle trafficking [167-169]. Leemhuis and col. [169] showed that Reln-treated neurons have increased growth cone motility and these are enlarged with abundant filopodia. This stimulated motility occurred via ApoeR2, activating Cdc42 through the PI3K cascade, which resulted in axonal filopodia formation [169]. More recently, Clasp2 (cytoplasmic linker associated proteins), an MT plus-end tracking protein that specifically accumulates in the growth cone, was also shown to be a key cytoskeletal effector downstream of the Reln activation pathway, orchestrating cytoskeletal dynamics during neurite extension and motility during brain development [170].

Reelin activation of the PI3K/Akt/mTOR pathway may not normally play a crucial role in the early events leading to layer formation and corticogenesis. However, the activation of a specific AKT isoform, AKT3, in focal MCDs was shown to be responsible for local, non-cell autonomous cortical migration defects, leading to drug-resistant epilepsy [171]. In this study it was shown that restricted cells exhibiting postzygotic brain-specific somatic mosaic AKT3 mutations showed activation of the PI3K-AKT-mTOR pathway. Importantly, mutation-expressing neural progenitors in the mouse brain showed misexpression of Reln, due to a derepression of reelin transcription, involving Foxg1. These mechanisms are hence involved in perturbed migration of restricted mutated and surrounding cells, leading to this focal malformation. De novo heterozygous mutations in FOXG1 can also lead to cortical malformations associated with Rett-like symptoms, postnatal microcephaly and abnormalities of the corpus callosum [172].

Reln is clearly a potent, multi-functional protein with different receptors and signaling pathways, expressed in several cell types and even in the adult brain. Signaling pathways involving this protein revealed mutations in patients for several components, representing one of the first examples of an assembled biochemical 'pathway' for MCDs, identified via 'phenocopy' mouse mutants and biochemical studies [146,148,163]. Putting together pathways is now being made easier with the use of NGS technologies in patients with similar disorders. 


\subsection{2a. Tubulinopathies}

In recent years it has been shown that mutations in certain cytoskeletal proteins are viable in the heterozygote state, causing a range of of MCDs now grouped together 'functionally' as tubulinopathies. MT function in particular has been revealed as highly vulnerable during cortical developmen [232]. MTs have multiple functions, they are essential components of the mitotic spindle in dividing cells and during neurogenesis, they are constantly remodeled during neuronal migration, and once neurons reach their final position, helping to generate and stabilize axonal processes to mediate cell communication via synaptogenesis [139]. Tubulin-related cortical dysgeneses, (see Table 2 ), refer to MCDs involving mutations in tubulin genes: $\alpha$-tubulin (principally TUBA1A), $\beta$-tubulin (TUBB2B, TUBB2A, TUBB3, TUBB(TUBB5)) and $\gamma$-tubulin (TUBG1) $[47,49,152,153,174,175]$. MCDs present in most individuals with mutations of tubulin or tubulin motor genes include a wide spectrum of morphological abnormalities with overlapping characteristics of LIS and PMG by brain imaging and neuropathological examinations $[49,176]$.

Mutations in the tubulin $\alpha-1 A$ (TUBA1A) gene have been found in patients presenting a wide spectrum of MCDs [49,136,176-179]. As well as the cLIS spectrum, brain malformations include lissencephaly with cerebellar hypoplasia, or with corpus callosum agenesis, and centrally predominant pachygyria, PMG-like cortical dysplasia, generalized PMG-like cortical dysplasia, simplified gyral pattern with areas of focal PMG, and microlissencephaly often in combination with dysplastic basal ganglia, corpus callosum abnormalities, and hypoplasia or dysplasia of the brainstem and cerebellum $[47,175,177,178]$. Clinical features include motor and intellectual disabilities, epilepsy and ocular impairments. It has been shown that $1 \%$ of children with cLIS present a recurrent mutation in the TUBA1A gene, and $30 \%$ of children with lissencephaly and cerebellar hypoplasia ( $\mathrm{LCH})$ also present TUBAIA mutations [136].

Mutations in $T U B B 2 B$ were first linked to asymmetric PMG, and originally 5 different heterozygous mutations were found in this gene [153]. Two disease-associated mutations were shown to lead to impaired formation of tubulin heterodimers. Patient manifestations included seizures and severe neuromotor impairment, and PMG was associated with dysmorphic basal ganglia, agenesis of corpus callosum, cerebellar dysplasia and brainstem hypoplasia. Moreover, neuropathological examination of a fetus showed absence of cortical lamination with ectopic neurons in the white matter and in the leptomeningeal spaces as a consequence of breaches in the pial basement membrane [153]. $T U B B 2 B$ mutations were also identified in symmetric PMG and pachygyria, complex malformations of cortical development, and lissencephaly [176,180]. The analysis of somatic mutations performed by Jamuar and col. [39] in a cohort of 158 patients with MCDs, also found a patient with a pathogenic mutation in $T U B B 2 B$ presenting frontal pachygyria, parietal, occipital and temporal PMG, a small dysplastic cerebellum, hypoplastic pons and hypoplastic optic nerves. In addition, this gene was associated with fetal akinesia deformation sequence with microlissencephaly [181]. TUBB2A mutations found in two patients are associated with simplified gyral patterning and infantile-onset epilepsy [174].

Clinical manifestations of patients with $T U B B 3$ mutations are different and milder compared to patients with TUBA1A mutations [182,183]. Originally, TUBB3 gene mutations were shown to be associated with various neurological syndromes which all have in common an ocular motility disorder, congenital fibrosis of the extraocular muscle type 3 (CFEOM3). However, missense mutations in $T U B B 3$ were also found in nine patients with cortical disorganization, axonal abnormalities associated with pontocerebellar hypoplasia, but with no ocular motility defects [182]. Indeed, MRI of patients showed a common complex cortical dysgenesis with frontally predominant microgyria or gyral disorganization and simplification, dysmorphic and hypertrophic basal ganglia, cerebellar dysplasia, hypoplastic brainstem and hypoplastic corpus callosum. The mutated $\beta$ III-tubulin results in a reduction of heterodimer formation, suggesting that mutated MTs are less stable than control ones.

Breuss and col. [184] reported that mutations in TUBB5 cause microcephaly with structural brain abnormalities in three patients. Certain mutations showed a diminished yield of heterodimer formation, or failed to incorporate. The E401K mutation has been the most studied (see below) and FLAG-tagged variants of Tubb5 containing this mutation failed to incorporate into the MT cytoskeleton in Neuro2A cells [184]. 
It is known that all mutations identified in the tubulin isotypes (TUBA1A, TUBB2B, TUBB3 and $T U B B 5)$ are heterozygote missense mutations. This could suggest dominant-negative phenotypes through abnormal protein function, which in addition to haploinsufficiency, may contribute to the mechanisms underlying MCDs [183]. Indeed, MTs with altered characteristics could have an impact on multiple mechanisms during migration including nuclear-centrosome coupling, leading process stabilization, the growth of new processes and growth cone navigation.

\subsection{2b Animal models and functional studies}

An N-ethyl-N-nitrosourea (ENU) mutagenesis screen allowed the identification of a mouse mutant with a mutation (S140G) in the guanosine triphosphate (GTP) binding pocket of $\alpha-1$ tubulin (Tubala) affecting tubulin heterodimer formation in vitro. Mice showed abnormalities in the laminar architecture of the hippocampus with subtle abnormalities in the neocortex, coherent with impaired neuronal migration [152]. Heterozygous mice $(\mathrm{Jna} /+)$ were hyperactive, weighed $\sim 30 \%$ less and brain size was also proportionally smaller. It was through the identification of this mouse mutant, that TUBA1A was proposed as a candidate gene for LIS. Hippocampal disorganization included an additional layer of pyramidal cells in the stratum oriens throughout the pyramidal cell subfields into the subiculum, most marked in the CA3 region where the neurons were loosely packed. Subtle abnormalities were also detected in the neocortex, related to wavy layers in the visual, auditory and somatosensory cortices, with motor and retrosplenial cortices unaffected. The phenotype was rescued by Tubala expression in a BAC clone (Jna/+/BAC mice) [152].

Downregulation of tubulin beta-2b (Tubb2b) by shRNAs electroporated into progenitor cells in the VZ of E15 rat neocortices showed a significant arrest of cells within the SVZ/IZ at E20. This neuronal migration defect was rescued by overexpression of a resistant Tubb2b [153]. In vitro studies of plasmids expressing missense mutations identified in patients showed defective formation of functional alpha/beta-tubulin heterodimers that were compromised in their ability to properly assemble into well-defined MTs [153]. A separate ENU mutagenesis screen allowed as well the identification of a mouse mutant (also called the brain dimple ( $B r d p)$ mutation) with a $T u b b 2 b$ missense mutation at a highly conserved residue (N247S) [185]. Homozygous mutant mice die soon after birth, and presented brains which were severely reduced in size, with expanded ventricles, and reduced olfactory bulbs, midbrain and cerebellum, and with thinning of the cortical epithelium. Within the cortex, brdp mutants have wave-like perturbations in the $\mathrm{CP}$ and a hypoplastic, irregular VZ. Analysis of the brain also showed an increase in RGC proliferation but a reduced CP suggesting an increase of neuron cell death, which was then confirmed by a TUNEL assay.

Tubb3 knockdown experiments in the developing mouse cortex showed as well a significant arrest in radial migration in which the majority of neurons were blocked in the IZ with only a few neurons found in the CP [183]. Defects in numbers of progenitor cells were also observed, especially the Tbr2+ population. Although TUBB3 overexpression leads to the rescue of the shRNA migration phenotype, the overexpression of other $\beta$ tubulin subunits (TUBB1, TUBB2B and TUBB4A) does not completely rescue the migration phenotype [183]. These results support the non-functional redundancy of these $\beta$-tubulins during cortical development and the functional specificity of Tubb3.

In order to analyze the effects of TUBB5 (also termed TUBB) during cortical development, the generation of two conditional Tubb5 transgenic mouse lines were reported: a conditional knock-in of the E401K patient mutation and a conditional KO [186]. Both lines were generated by crossing with Nestin-Cre mice to drive expression in progenitors. Heterozygous Tubb5 $5^{E 40 I K /+}$; Nestin-Cre mice showed no significant reduction in brain size compared to controls (Tubb5 $5^{E 401 K /+}$ ), although

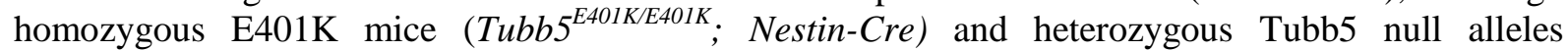
$\left(T u b b 5^{f l /+}\right.$;Nestin-Cre), both presented significant reductions in total brain and cortical volume. Other brain regions were also affected, including the corpus callosum, cerebellum, hippocampus and putamen [186]. No major defects in the laminar structure of the cortex were detected, despite a significant reduction in Cux1-positive superficial neurons. Ectopic Sox2+ progenitors and an increased mitotic index were also detected in the homozygous E401K mutant mouse. Defects in spindle orientation have been attributed to the ectopic localization of progenitors, in some cases leading to the depletion of the progenitor pool and premature production of postmitotic neurons, which has been proposed to be the underlying cellular mechanism in microcephaly. However, the authors conclude 
that the spindle orientation defects in the knockin model do not majorly affect the number of progenitors, and are hence unlikely to account for the severe microcephalic phenotype observed in adulthood. Indeed, mitotic progression defects were also observed only in homozygous E401K mutant animals, suggesting that the dosage of functional Tubb5 is important for the phenotype. Finally, the authors conclude that $\mathrm{E} 401 \mathrm{~K}$ mutation acts by a complex mechanism, involving subtle gain-offunction effects, and distinct defects during mitosis leading to p53-dependent apoptosis resulting in a smaller brain size in $T u b b 5$ mutant mice.

Finally, the ablation of Tubgl cause embryonic lethality in mice [187]. Therefore, to study the effects of this gene on neuronal migration in utero electroporation at E14.5 was performed in mouse embryos [49]. Downregulation of $\gamma$-tubulin arrested cell migration and this phenotype was substantially rescued by a WT human cDNA, suggesting that proper levels of Tubgl are essential for normal MT behavior and neuronal migration.

\subsection{3. a Periventricular nodular heterotopias $(P V H)$ and ventricular lining $(V L)$ abnormalities}

During normal human brain development, from the $6^{\text {th }}$ to the $24^{\text {th }}$ week of pregnancy, neurons formed close to the ventricles migrate outward to form the cortex in six layers (see section 1). In PVH, some neurons fail to migrate to their proper position and form nodules of grey matter located around the walls of the lateral ventricles, associated with breaks of the VL, disrupting the integrity of the neuroependyma [188]. Amongst neuronal migration MCDs, PVH may represent up to $31 \%$ of cases [189]. This disorder can occur as an isolated malformation or associated with other brain malformations, such as e.g. temporo-occipital PVH with hippocampal malformation and cerebellar hypoplasia, or associated with fragile-X syndrome, with Ehlers-Danlos syndrome (EDS) and with microcephaly, amongst others [190,191]. Clinical manifestations are heterogeneous, but learning difficulties and seizures are included as the most common features [43].

Mutations in two genes, FLNA and ARFGEF2 (see below), were previously associated with this pathology (see Table 3 ) [16,190]. FLNA encodes a large $(280 \mathrm{kDa})$ cytoplasmic actin-binding protein that crosslinks actin filaments and links them to membrane glycoproteins. This protein is involved in remodeling the cytoskeleton to allow changes in cell shape and migration. Mutations in FLNA are associated with classical X-linked bilateral PVH [87,173,190]. Hemizygous males are rarely observed and assumed to be frequently embryonic lethal. PVH hence generally manifests in females, also associated with cardiovascular complications and Ehlers-Danlos syndrome [188,190,192]. FLNA mutations have been reported in all familial cases and in approximately $40 \%$ of sporadic patients $[39,192]$.

A rare autosomal recessive form of $\mathrm{PVH}$ due to ARFGEF2 gene mutations has also been reported in children with microcephaly, severe developmental delay and early-onset seizures [193]. Frameshift, missense and nonsense mutations were identified. ARFGEF2 encodes the brefeldin A inhibited guanine exchange factor-2 (BIG2), a protein kinase A anchoring protein (AKAP) which regulates Golgi-vesicle trafficking through its Sec7 domain [193]. The congenital microcephaly observed in ARFGEF2 PVH patients might suggest progenitor defects rather than post-mitotic neural migration impairments [193,194].

Rare mutations in several other genes were also found in PVH, accounting for a small number of patients. Mutations in two cell adhesion molecules were identified, specifically FAT4 (atypical cadherin 4, a member of the protocadherin family) and DCHS1 (dachsous 1, cadherin-related 1) [195]. Patients reported with biallelic mutations in DCHS1 and FAT4 present as a consequence Van Maldergem syndrome-2 which includes PVH [195]. Moreover, a role of the heterotrimeric G-protein (Gai2) was recently suggested in cortical development, and the encoding gene (GNAI2) was found mutated in a single PVH patient [196]. Another candidate gene playing a role in this cortical malformation is C6orf70 (ERMARD, for ER-membrane associated RNA degradation), found mutated in a patient with PVH [197].

\subsection{3b Animal models and functional studies}

Flna KO male mice die by E14.5 and present several vascular and cardiac abnormalities, including an abnormally thickened and malformed outflow tract valve and a single ventricle, which 
demonstrate that Flna plays an important role in cardiac morphogenesis. Analysis of the brains showed a normal distribution of $\alpha$-catenin, $\beta$-catenin, zonula occludens-1 and F-actin, unlike VE-Cadherin (Cadherin 5), which was abnormally located in Flna KO progenitors [198]. Apical complex integrity is essential for the correct positioning of RGCs, as well as their cell polarity and division at the VZ [5,199]. The analysis of Flna KO mutant males at E14.5 showed a smaller but grossly normal brain presenting a thinner $\mathrm{CP}$ that was normally positioned, with no migration deficits or arrested neurons in the VZ. Conditional KO male mice (Cre recombination performed in ES cells) died at birth, showing cardiac abnormalities similar to Flna KO mice, although less severe [198].

A recent study in the mouse developing cortex showed however, that conditional deletion of Flna in neuronal progenitor cells highly resembles PVH in humans [200]. Loss of the mitogenactivated protein kinase kinase kinase 4 (Mekk4 or Map3K4) in mice, a regulator of FlnA phosphorylation, leads to a similar phenotype [201]. Double mutant mice $\left(F \ln a^{\text {flox/y; Emx1Cre+ }} ; F^{-1 n} b^{-/-}\right)$ reveals periventricular nodules, variable in size, number and distribution, present in both cerebral hemispheres, and containing mixed neurons and glia cells. Mouse phenotypes were consistent with radiological and pathological studies in FLNA patients, and suggested that PVH caused by Flna loss is a condition in which additional neurons are generated without compromising production and migration of neurons destined for the neocortex [200]. Indeed, this work demonstrated that the Flna-phenotype primarily results from an increased neurogenesis of mislocalized IPs present in the periventricular space. The expanded IP pool increases neuronal production without affecting cell fate. Interestingly, other factors contribute in a non-cell-autonomous manner to this phenotype, an EMT (epithelialmesenchymal transition)-like event was observed in RGs, changing the extracellular environment, as well as increased local angiogenesis and vascular activity. Through an interaction with $\beta$-arrestin, Flna normally blocks the excessive communication between blood vessels and neural progenitors by attenuating growth signals and acting as a cell signaling modulator [200]. This block is lost in the cKO of Flna, contributing to the phenotype.

In another study, FLNA was shown to form a functional complex with Meckelin (MKS3/TMEM67), a protein that directs centriole migration to the apical membrane and is involved in the formation of the primary cilium [202]. Particularly, a patient was described with Meckel-Gruber syndrome (MKS)-like ciliopathy with both MKS and cerebellar heterotopia, presenting an unusual inframe deletion mutation in the meckelin C-terminus. The mutation disrupted the meckelin-Flna interaction, leading to impaired cilia formation and reduction of RhoA activity. Flna was shown to be necessary for optimal cilia formation and for the correct positioning of the basal body in patientderived fibroblasts and murine epithelial cell line (inner medullary collecting duct, IMCD3). Moreover, meckelin distribution at the apical cell surface and ventricles was disrupted in the Flna ${ }^{\text {Dilp2 }}$ mouse [202,203]. Finally, loss of meckelin or Flna causes a deregulation of Wnt signaling, as was previously reported in the pathogenesis of ciliopathies [204]. Authors hence suggested that some of the features of PVH caused by FLNA mutation may be due to impaired ciliogenesis. These data further suggest a role for FLNA in progenitor cell fate and proliferation [202].

A null mouse model for Arfgef2 is embryonic lethal, and heterozygous mutants did not reveal abnormalities [205]. However, Sheen and col. [193] previously demonstrated that Big2, the Arfgef2 encoded protein, plays a role in vesicle and membrane trafficking from the trans-Golgi network. Inhibition of Big2 perturbed adhesion molecules such as E-cadherin and $\beta$-catenin by preventing their transport from the Golgi to the cell surface. Furthermore, treatment with Brefeldin A (BFA) inhibited migration of cerebellar granule cells and inhibited spreading of cells derived from the SVZ, suggesting that Arfgef 2 function is required for neuronal migration [193]. Using a gene-trap line with vector integration in the Arfgef2 gene, reporter gene expression is activated in 4-cell stage embryos suggesting that this gene is essential for early embryonic development [205]. In addition, it was shown that Arfgef 2 function is not compensated by Arfgef 1 . It remains difficult to know the exact function of this gene and conditional KO mice are required. Nevertheless, via membrane trafficking, it is likely Big2 plays a role regulating cell adhesion and cell-cell junctions which could be important in progenitor zones.

Finally, in rare mutation cases, reducing the expression of Fat4 and Dchs 1 in the mouse cortex induces an increase in progenitor cell number and reduces the differentiation to neurons, resulting in an ectopic accumulation of Pax6-positive cells close to the ventricles [195]. More recently, mutations were also found in several patients in the $N E D D 4 L$ gene, which codes for the E3 ubiquitin ligase. This 
work suggested that disruption of mTOR and AKT signaling pathways is involved in the neurodevelopment of this pathology [189]. Defects in progenitor cells, neuronal positioning and terminal translocation were identified by in utero electroporation. Furthermore, down-regulation of the $\alpha$ subunit, Gai2, or C6orf70, affects neuron morphology and induces migration defects during corticogenesis in rodents [196,197].

Thus, by the study of multiple genes, there are indications of changed progenitor cell fate which re-occur linked to this pathology. Neuronal migration defects are also identified, although these may in some cases be secondary to RGC defects. For other more rarely mutated genes, acute gene knockdown by in utero electroporation has revealed either progenitor and/or neuronal migration defects. Progenitor defects most probably cannot be excluded in the latter models.

\subsection{4. a Type II lissencephaly (cobblestone)}

Cobblestone lissencephaly (COB-LIS) is a severe brain malformation in which so-called 'overmigration' of neurons and glial cells into the arachnoid space results in the formation of cortical dysplasia, including dysmyelination, cystic cerebellar dysplasia and brainstem hypoplasia [206]. Disorganized cerebral and cerebellar cortices and multiple coarse gyri with agyric regions arise due to breaks of the basement membrane (BM). COB-LIS patients may have a broader spectrum of conditions referred to as Walker-Warburg syndrome (WWS), muscle-eye-brain disease (MEB) and Fukuyama congenital muscular dystrophy (FCMD) [43,207].

The gene dystroglycan (DAGl) codes for a major extracellular matrix receptor in muscle, and in the CNS it is present in RG basal endfeet (also known as the glia limitans), making a link with laminin in the basal lamina. Rare mutations have been identified in this gene in WWS [208,209]. Dystroglycan (DG) is subjected to a post-translational cleavage to generate the peripheral membrane protein $\alpha$-DG, and the transmembrane protein $\beta$-DG. Then the $\alpha$-DG undergoes O-linked mannosylations mediating the binding to extracellular matrix proteins such as laminin, agrin, neurexin, pikachurin and perlecan. $\beta$-DG interacts with the actin cytoskeleton via dystrophin, utrophin, plectin and together, $\alpha$-DG and $\beta$-DG link the cytoskeleton to the extracellular matrix [210]. Indeed, these DG complexes are necessary for the deposition of other BM proteins and in the organization and turnover of the BM [211]. MEB, FCMD and WWS (see Table 4) have been associated with aberrant glycosylation of $\alpha$-DG [207,212-214].

Symptoms are present at birth and may vary within a wide spectrum, usually with severe structural brain findings (including lissencephaly and ventriculomegaly), various developmental abnormalities of the eyes (e.g., unilateral or bilateral microphthalmia and retinal dysplasia), hypotonia, progressive muscle weakness and degeneration, delayed speech and motor functions as well as seizures [215]. This spectrum of disorders is associated with a poor perinatal prognosis depending on the severity of the malformation.

COB-LIS has most often been associated with mutations in genes which are required for the maturation of $\alpha$-DG into a functional receptor and are consequently identified as causing secondary dystroglycanopathies, the most common form of congenital muscular dystrophies. These genes include POMT1, POMT2, POMGNT1, FKTN, FKRP, LARGE, ISPD, GTDC2, TMEM5, POMK, B4GAT1, B3GALNT2 (see Table 4) [212, 213,215-225]. Other mutations are rare, described in only a few patients with WWS, and include genes encoding BM constituents, such as LAMB1, LAMC3 and COLAA1, and the transmembrane and tetratricopeptide repeat containing 3 gene, TMTC3 [215,218,226], coding for a protein for which its link is currently unclear.

In addition, GPR56 (G protein-coupled receptor) mutations have been reported in 14 patients with bilateral frontoparietal PMG (see below), and the phenotypes associated with these mutations were proposed as COB-like cortical dysgeneses due to the pathophysiological similarities with COBLIS [227]. Indeed, homozygous or biallelic mutations in the GPR56 ligand, COL3A1 were also recently found associated with a COB-like malformation [228]. Nevertheless, one third of the studied COB-LIS cases has not been genetically linked to any mutation and remain unexplained [215,218]. Non-genetic causes are still recognized for COB-LIS, including prenatal vascular problems and viral infections [43].

\subsection{4b. Animal models and functional studies}


Targeted loss of DG or mutations of enzymes involved in the glycosylation of $\alpha$-DG in the developing brain, have been shown to recapitulate many aspects of WWS and MEB, indicating DG as central to disease pathogenesis (See Table 4) [210,229-232].

Two mouse models with a deficiency in fukutin-related protein (FKRP) were generated, the first one with a missense mutation and a neomycin cassette, FKRP-Neo ${ }^{\text {Tyr307Asn }}$ (FKRP KD) and the second with the $F K R P^{T y r 307 A s n}$ mutation alone [210,232]. $F K R P^{T y r 307 A s n}$ homozygous mice have a gross brain and heart anatomy indistinguishable from controls. On the other hand, homozygous animals for FKRP-Neo ${ }^{\text {Tyr307Asn }}$ die at or soon after birth. In addition, FKRP KD mice present a reduced muscle mass and hypoglycosylation of $\alpha$-DG. Mutant mice showed a disruption of the neuronal layering of the cortex and partial fusion of the intrahemispheric fissure. Defects in the pial BM were also observed, including laminin $\gamma 1$, perlecan and collagen IV disorganization. The RGC scaffold was highly disorganized, which correlated with both the degree of dyslamination and an absence of glycosylated $\alpha$-DG. Thus, this mouse model recapitulates some of the features of MEB, displaying a marked reduction in the glycosylation of $\alpha$-DG at the pial BM, associated with BM defects and a neuronal migration disorder [210,232]. Moreover, Booler and col. [210] showed in FKRP KD embryonic mouse brains (E12.5), that the multifocal disruption to the BM was associated with disorganization of the PP and its failure to split.

Booler and col. [210] made a comparative study analyzing the brain defects present in different mouse models of dystroglycanopathies. This study demonstrated that the mislocalization of Cajal-Retzius cells was correlated with a rostro-caudal and medio-lateral gradient of the lesions and the severity of the brain phenotype, where FKRP KD mice exhibit the most severe brain phenotype and Large $e^{m y d}$ mice the mildest. Indeed, there is no apparent CP or MZ in FKRP KD mice, whereas in Pomgntl KO mice, the CP and MZ are apparent below a substantial extracortical layer. The Large ${ }^{\mathrm{myd}}$ mice, on the other hand present a relatively organized $\mathrm{CP}$, but neurons from the $\mathrm{CP}$ apparently migrate through the MZ and the pial BM. Other brain regions were also found affected [210]. Moreover, disruption to the RG scaffold was present in all of the mouse models, the glia limitans being disrupted to a variety of degrees, and most extensively affected in FKRP KD mice.

Mutant mice of the integrin-related family, such as FAK (focal adhesion kinase) [233] and Ilk (integrin-linked kinase) [235], have been associated with features that resemble human COB-LIS, including cortical migration and basal lamina integrity defects, but mutations of these genes have not been identified in human patients.

Finally, several genes related to human mutations or downregulation of dystroglycanopathies have been assayed in morpholino (MO) injected Zebrafish or Drosophila models (See Table 4, e.g. FKRP, FKTN, ISPD, POMK, B4GAT1, B3GALNT2, POMGNT2). The vast majority of these models showed characteristics that resemble the human pathology, such as hypoglycosylation of $\alpha$-DG, embryos with small heads, hydrocephalus, incomplete brain folding, reduced eye size, delayed ocular development, retinal degeneration, defects in muscle fibers and severely impaired motility $[221,224,225,235,236]$. These are hence useful models for revealing defects related to individual genes.

\subsection{5a Polymicrogyria $(P M G)$}

PMG refers to an excessive number of abnormally small gyri that produce an irregular cortical surface with a lumpy aspect, associated with abnormal neuronal migration [237]. PMG can affect part of the brain or the whole brain, and there can be overlapping features with COB-LIS as mentioned above [227]. PMG exist also as an isolated malformation or it may be associated with other brain malformations, such as corpus callosum agenesis and hypogenesis, cerebellar hypoplasia, PVH and SBH in patients that may present microcephaly, normocephaly or macrocephaly [237].

PMG can occur as a result of both genetic and environmental factors $[16,43,237]$. The exact mechanisms causing this heterogeneous disorder remain to be elucidated, indeed some genes identified in PMG patients have been found to be involved in migration, others in progenitors, as well as centrosome function and cilia location (see below and Table 5). Clinical presentations include a high incidence of epilepsy, ID and there is a variable age of onset [16,43,237]. 
Only in a small minority of patients, mainly represented by consanguineous families, has a defined genetic cause been identified, e.g. associated with autosomal recessive mutations in GPR56, RTTN (rotatin) and PRICKLE1 (Prickle Planar Cell Polarity Protein 1) genes (see Table 5) $[176,227,238,239]$. The most severe outcomes of PMG occur in children with severe microcephaly (-3 SD or smaller). Patients with severe congenital microcephaly and PMG have for example, shown mutations in WDR62 (WD repeat-containing protein 62), NDE1, RTNN and RAB3GAP1/2 and RAB18 [240-242]. PMG with microcephaly or normal brain size, corpus callosum dysgenesis and cerebellar hypoplasia may also be related to tubulin and MT-motor gene mutations such as KIFIB binding protein, TUBA1A, TUBB, TUBB2B, TUBB3, and DYNC1H1 (see Tables 1 and 2) [156,199,237].

Mutations in PIK3R2, PIK3CA, AKT3, CCND2 and MTOR, involved in the mTOR pathway, have also been associated with PMG [243-249]. Mutations in these genes also cause hemimegalencephaly (HMG), which is a developmental disorder characterized by the enlargement and malformation of a cerebral hemisphere [250]. Other genes including the transcription factor PAX6 [251] are recognized in PMG (see also Table 6). Furthermore, copy-number variants have also been shown associated with PMG, showing deletions in a wide number of chromosomes [43].

As mentioned above, mutations in GPR56 can also give rise to bilateral frontoparietal PMG, as well as cerebellar and white matter abnormalities [227,252,253]. Bae and col. [254] also found a mutation in a non-coding region of the gene, present in five individuals with PMG (and see below).

\subsection{5b Animal models and functional studies}

PMG is often described as abnormal late cortical organization and is inconstantly associated with abnormal neuronal migration, overmigration of cells, thickening and duplication of the pial collagen layers and increased leptomeningeal vascularity [237]. Indeed, the maintenance of pial integrity is essential for the proper anchoring of the basal RGC endfeet, ensuring the correct migratory scaffold for neurons. Certain mouse models have contributed to these ideas. Concerning non-coding mutations present in GPR56, the mutated element normally contains two copies in tandem of 15- base pair (bp), but all affected individuals have a homozygous deletion of one 15-bp repeat, and the parents are heterozygous with no obvious clinical signs. The GPR56 transcript variants differ between mice and humans, and this regulatory element apparently directs lateral cortical expression. This was shown by generating a transgenic mouse with the 23-kb human GPR56 upstream region (WT and mutant) driving green fluorescent protein (GFP) expression. The 15-bp deletion shows no lateral cortex expression in the mouse and is likely to disrupt perisylvian GPR56 expression in human. GPR56 also interacts with various regionally expressed transcription factors, and controls progenitor proliferation in different brain regions. Reduced proliferation occurs when Gpr56 is absent, while overexpression enhances proliferation and progenitor number. Furthermore, in Gpr56 KO mice, neurons over-migrate through breached pial BM, or under-migrate forming irregular cortical layers. Gpr56 was shown to stabilize the BM of RGCs and it localizes to the basal processes [253], where it was shown to bind to extracellular matrix proteins (eg. collagen type III) [255]. The histopathology of BFPP hence strongly resembles a COB-LIS malformation [253]. Both conditions are hence linked to abnormal progenitors. Alternative promoters and regional interactors in PMG help explain expression and function in particular brain regions and hence specific MCD phenotypes.

The fact that PMG can be associated with primary microcephaly (MCPH) also suggests that progenitor abnormalities could contribute to this MCD. Mutations in ASPM (abnormal spindle-like microcephaly-associated) and WDR62 represent more than half of all MCPH cases [256]. Both Aspm and Wdr62 are genetically and biochemically tightly linked. In mice lacking Wdr62, Aspm, or both, gene dose-related centriole duplication defects were detected during cell division that parallel the severity of the microcephaly. Disrupted apical complexes and increased ectopic basal progenitors are also observed, suggesting premature delamination of RGCs from the VZ [257]. These proteins, share a common localization during interphase at mother centrioles, where they physically interact, and with other microcephaly proteins converge on CENPJ/CPAP/Sas-4 as a final common target [257]. WDR62 mutations can also give rise to PMG [258-260], whereas ASPM mutations have been associated with anterior predominant pachygyria and simplified gyral pattern [261,262]. Wdr62 down-regulation in rat embryos reveals neuronal migration abnormalities, as well as RGC mitotic defects and depletion [263]. 
As mentioned previously, NDE1 is localized at the centrosome and interacts there with other proteins, such as LIS1, as part of a multiprotein complex that regulates dynein function, highly important during neuronal migration and in progenitors [71,76]. Mutations of this gene were found in patients with very severe form of microcephaly, ACC and fetal brain disruption (FBD)-like cortical malformation, profound ID and early onset seizures [78,264]. The effect of NDE1 on cortical thickness is due to alterations in neuronal progenitor fate [80]. Particularly, the loss of NDE1 increases the number of differentiated PP cortical neurons and Cajal-Retzius cells which are produced during early corticogenesis, depleting the neuroepithelial cells and RGC pool for neuron production at later stages of development. This is a consequence of failures in the assembly and orientation of the mitotic spindle which requires NDE1 function [77,80,264]. On the other hand, loss of its paralogue NDEL1 prevents the migration of neurons into the $\mathrm{CP}$, although the motility within the IZ or SVZ is not affected [264,265]. NDE1 mutations also give rise to rare cases of PMG, it remains unclear how this arises, but RGC perturbations are also likely to affect basal endfeet attachment at the BM. De novo missense mutations in $\mathrm{DYNClH1}$ have also recently been associated with PMG $[39,266]$. Thus although this MCD is less well-known in terms of mechanisms, some common themes are emerging.

\section{Atypical rare cases, consanguineous families and contribution of recent NGS studies.}

Patients showing MCDs such as SBH, pachygyria, lissencephaly with or without microcephaly, congenital microcephaly, or PMG, and sometimes syndromic forms, were also reported with mutations in genes other than the classical ones described for a particular disorder. In some cases, the spectrum of phenotypes for a particular gene was widened by identifying unexpected mutations in other MCDs. Cases are often atypical, sometimes exhibiting de novo sporadic mutations, or alternatively, homozygous mutations were identified in consanguineous families. Some examples are EML1, CRADD, ACTG1 and KATNB1 (see Table 6) [267-271]. Related genes, such as $\alpha$-E-catenin, Ccdc85C, Rapgef2/Rapgef6, Afadin and RhoA induce similar, severe phenotypes (e.g. SBH or PVHlike phenotypes) in the mouse when they are down-regulated or suppressed during cortical development (see Table 6) [195,272-276]. However, no mutations in these latter genes have been reported in human, and in some cases constitutive phenotypes are lethal in the mouse (See Table 6). Conditional mutant Afadin and RhoA mice resemble the HeCo phenotype, with mutations in the Eml 1 gene.

Echinoderm Microtubule Associated Protein-like 1 (EML1), a MT binding protein, was shown to be mutated in the spontaneously arisen HeCo (Heterotopic Cortex) mouse presenting bilateral SBH. Mutations were subsequently identified in two non-related families with giant ribbonlike heterotopia [267]. Human EML1 mutations are thus associated with a severe and atypical giant form of SH, epilepsy and ID. HeCo mice show ectopic progenitors and EML1 has a cell cycledependent localization, it is enriched on spindle MTs and in midzone regions of mitotic neuronal progenitors. HeCo mice show an increased proportion of oblique mitotic spindle orientations in apical RGs, which may favor asymmetric inheritance of apical membrane, leading to detached ectopic progenitors which divide in the region that the heterotopia develops [267]. Early and late born neurons are perturbed in their migration due to an abnormal migration substrate (RG basal processes), laterborn neurons become trapped within the white matter forming the heterotopia in mutant mouse brains. The detailed molecular mechanisms leading to the production of ectopic progenitors and SBH in this model have not yet been identified, although it seems clear that migration perturbations are secondary to the progenitor abnormalities [267].

More recently, an interesting study identified a mild variant of lissencephaly, after review of more than 1,400 LIS phenotype patients [268]. The phenotype was referred to as TLIS or "thin" lissencephaly, and is characterized by anterior-predominant pachygyria with shallow and unusually wide sulci, a mildly thick cortex $(5-7 \mathrm{~mm})$ in at least the frontal regions and megaencephaly. Patients present mutations in the $C R A D D$ gene, which encodes a protein containing a caspase-recruitmentdomain and death domain (DD), required for activation of caspase-2-mediated apoptosis. The phenotype includes mild to moderate ID and in some cases epilepsy. Cradd KO mice recapitulate the human phenotype. These data suggest that CRADD/caspase-2 signaling is required for normal development of the human neocortex and for normal cognitive function. Decreased caspase-2mediated apoptosis during human development results in this MCD [268]. 
Deleterious mutations in the KATNBI gene were found in ten patients of consanguineous parents with a spectrum of MCD disorders, including microcephaly co-occurring or not with LIS, microlissencephaly, or less severe abnormalities such as PVH or SBH [271,277]. The encoded protein is the p80 regulatory subunit of the MT-severing enzyme Katanin. Katanin is composed of catalytic p60 (KATNA1), and regulatory p80 (KATNB1) subunits, and acts by disrupting contacts within the MT polymer lattice. The C-terminal region of KATNB1, is known to interact with the p60/KATNA1 catalytic subunit and NDEL1, while the N-terminal region, is known to interact with the molecular motor protein Dynein and LIS1 [262]. Loss of KATNB1 orthologs in zebrafish (katnb1) and flies (kat80) results in microcephaly, recapitulating one of the human phenotypes. Indeed, kat80 loss of function affects asymmetrically dividing neuroblasts, which display supernumerary centrosomes and elicit spindle abnormalities during mitosis, leading to cell cycle progression delays and reduced cell numbers [271]. Severe brain abnormalities in patients are likely to be explained at least in part by loss of the ability of p80 to regulate MTs. Hu and col. [277] showed that patient-derived cells had decreased levels of both p80 and p60 proteins, as well as mitotic and signaling abnormalities. More recently, it was demonstrated that p80 regulates MT remodeling in combination with its interacting partner NuMA (nuclear mitotic apparatus protein) and cytoplasmic dynein, and that p80 is essential for aster formation and maintenance in vitro [278]. Notably, patient mutations in KATNB1 were unable to elicit aster formation. In the same study, it was shown that $\mathrm{p} 80$ and/or NuMA down-regulation induces neural progenitors to exit the proliferation phase and prematurely commit to neuronal differentiation, in addition to delaying neuronal migration in the mouse embryonic brain [278].

Mutations in SRPX2 (Sushi Repeat Containing Protein, X-Linked 2) give rise to rolandic epilepsy, speech dyspraxia and ID, and in rare cases have been also linked to bilateral perisylvian PMG (BPP) (See table 6). SRPX2 is expressed at various embryonic stages from the proliferative VZ/SVZ to the CP. Srpx2 downregulation lead to altered position of projection neurons in the developing rat cerebral cortex [279]. It was demonstrated that Srpx2 influences acetylation of alphatubulin in vitro, where the expression of Srpx2 induced an increase in the acetylation activity and the silencing had the opposite effect. Moreover, the migration deficit was improved by prenatal administration of tubacin, a specific inhibitor of tubulin deacetylase HDAC6, and prevented the epileptiform activity caused by Srpx2 silencing in utero [279].

Of note as well, a recent study revealed two male siblings with a mutation in FLNA, predicted to lead to a loss of function caused by protein truncation, although other mutations are typically lethal in males [280]. However, the patients did not present PVH, but other health complications including visceral abnormalities. Functional studies demonstrated that the mutation (4 bp insertion) induced inframe skipping of the mutated exon, leading to a mutant FLNA missing an internal region of 41 amino acids, but its capacity to induce focal adhesions was comparable to those of the wild-type protein. This is hence likely to explain the ameliorated symptoms of these affected male patients [280]. A further atypical phenotype for FLNA mutations was revealed by studying alternative splicing [281]. Using RNA-seq and the 'mixture-of-isoforms' (MISO) model, a percentage spliced in (PSI) value was assigned to each exon by estimating its abundance compared to adjacent exons [281]. The results of this study suggest that most splicing switches occur between neural progenitors in the VZ and neurons in the $\mathrm{CP}$, and cytoskeleton genes such as $F \ln A$, have differentially spliced exons in mouse and human. Indeed, differentially spliced exons lead to protein domain alterations, changes in subcellular localization and interactions with other proteins. Interestingly, this study shows that a highly conserved exon of $F \ln A$ is normally skipped in E14.5 neural progenitors (VZ) and most adult tissues, but included in mRNAs from E14.5 neurons, in adult cortex and cerebellum. Moreover, a particular intronic mutation in FLNA causing a PVH phenotype in both males and females of an affected family, promotes abnormal exon inclusion ('poison' exon) in neural progenitors, creating a cell-type- and tissue-specific FLNA partial loss of function and an atypical PVH syndrome. The inclusion/exclusion of 'poison' exons in the developing cortex was shown to be antagonistically regulated by Ptbp 1 and Rbfox 1/2/3 factors, which are expressed in neural progenitors and neurons, respectively. Rbfox1/2/3induced splicing causes Ninein to be translocated from the centrosome in progenitors to noncentrosomal loci in neurons, although Ptbp1 expression is required for apical RG position by maintaining Flna and Flnb expression in progenitor cells [281].

Finally, a good example of the high power of WES for clinical diagnosis is the recently published work from the Deciphering Developmental Disorders (DDD) team (DDD Study, 2017) [35]. 
This project aimed to deeply analyze all genomic data from the UK National Health Service and the Republic of Ireland to try and find a diagnosis for as many affected children as possible. The DDD study recruited 4,293 individuals with severe undiagnosed developmental disorders, and most of them were the only affected family member. Using WES analysis of trios, this study allowed the identification of 94 genes enriched in damaging de novo mutations (DNMs), including fourteen new genes that were not previously statistically compelling for DD causation: CDK13, CHD4, CNOT3, CSNK2A1, GNAI1, KCNQ3, MSL3, PPMID, PUF60, QRICH1, SET, KMT5B, TCF20 and ZBTB18. Moreover, several new disorders were identified linked to known DD-associated genes, but with different modes of inheritance or molecular mechanisms. Interestingly, of the 285 individuals with truncating or missense DNMs in known seizure-associated genes, $56 \%$ of individuals had no coded terms related to seizures and/or epilepsy. However, nearly three times as many individuals with seizures had a DNM in a seizure-associated gene compared to individuals without seizures. These data illustrate the power of studying a large sample size. This work also showed that a much higher proportion of truncating than missense DNMs affected known DD-associated genes. DNMs are associated with approximately half of severe DDs, and are split roughly equally between loss of function and altered function. Finally, this study allowed an estimation of the mean birth prevalence of dominant monogenic DDs to be around 1 in 295, which is greater than trisomies 13, 18 and 21. This study is clearly important, and large, collaborative MCD cohorts in the future could be analyzed in a similar integrated manner.

\section{Stem cell models as tools for the study of MCD mechanisms.}

Stem cells (SC) cells are specialized cell types with hallmark properties of self-renewal and the ability to differentiate into other cell type(s) [282]. In 2007, Takahashi and Yamanaka described the induction of pluripotent SC properties from mouse embryonic and adult fibroblasts by the transfer of four factors (Oct3/4, Sox2, c-Myc and Klf4) under ES cell culture conditions. These cells were named induced pluripotent stem cells (iPSCs). The same is true for adult human fibroblasts, giving rise to human iPSCs after the introduction of the same or similar factors [283,284]. Human iPSCs were found similar to human ES cells in many features [283].

Human SCs (hESCs) are also a valuable model. Both hESCs and iPSCs during neuronal differentiation undergo morphogenetic changes characterized by the formation of neuronal rosettes, which are radially organized columnar epithelial cells [285,286]. These are the 2D neural tube structures which recapitulate the apical-basal polarity similar to that of the neural tube, useful for the study of brain development [287]. On the other hand, neurospheres are aggregates of neural SCs (NSCs) that can be used to address the self-renewing capacity but are likewise not well organized and thus, limited to model certain characteristics of brain development [287]. Neurospheres represent very early characteristics of neurogenesis, whereas brain organoids, 3D structures exhibiting multiple cell types [287], recapitulate the cellular and molecular events comparable to the first-trimester of fetal neocortex development, which may include forebrain, midbrain, and hindbrain regions with functional electrophysiological properties, gene expression, progenitor polarity and cortical layering [288,289]. One advantage of 3D culture over monolayer cultures is the capacity of cells to differentiate and selforganize into epithelia, as they would in the embryo. The potential application of organoid systems are many $[287,288]$. This includes the possibility of analyzing species-specific cellular processes and one example of this is that bRG-like cortical cells can be produced from human, but not mouse, iPSCs [288,290,291].

From the perspective of this review, iPSC-derived cell investigations have been key to further study and characterize neurodevelopmental events during early embryogenesis, as well as to study molecular bases of human pathologies (e.g. MCDs such as microcephaly) in human in vitro models. Patient-derived iPSCs have also been shown to be useful for screening drug candidate libraries [293]. Moreover, a transcriptome-wide profiling study of single cells showed that cerebral organoids are able to recapitulate many of the molecular pathways that control normal human cortical neurogenesis [289]. Interestingly, the use of iPSCs and cerebral organoids in the study of the mechanisms that give rise to severe microcephaly-induced by ZIKV (Zika virus), has lead to amazing advances for the characterization of the mechanisms involved in the development of such a pathology (see below) [292, 294-297]. 
An interesting study previously mentioned in section 3, focuses on the molecular bases of microcephaly and lissencephaly involving the gene KATNB1 (p80) [278]. In this work, brain organoids were generated from human iPSCs from microcephaly patients carrying mutations in this gene. Mutant brain organoids showed fewer Tuj1+ neurons, and these neurons failed to migrate compared to controls [278]. Another interesting study involved the generation of patient-derived iPSCs to study the molecular bases of MDS, as previously mentioned, a severe LIS MCD characterized by nearly absent cortical folding often associated with reduced brain size, craniofacial dysmorphisms, ID and intractable epilepsy (see section 2.2.1) [298]. In this work cerebral organoids derived from control and MDS-iPSCs showed apoptosis of NECs leading to a reduced size, consistent with the clinical manifestation of the patients' microcephaly. A more frequent incidence of horizontal vs vertical cleavage planes and a significantly reduced average cleavage angle was observed in the MDS neuroepithelium (implying inappropriate progenitor divisions), as well as defective radial migration of cortical neurons was observed in 5 week organoids compared to control. Defective neuronal migration was rescued with a ring chromosome containing a compensatory copy of the chromosome 17 [298]. It was also shown that MDS bRG cells remained in mitosis for prolonged periods prior to cytokinesis and thus, authors suggest the possible involvement of bRG cell dysfunction in the pathogenesis of human LIS [298]. A second study has also used patient-specific forebrain-type organoids to study MDS pathology [299]. Premature neurogenesis was found to reduce the expansion of MDS patient-specific organoids, characterized with a panel of parameters. A switch from symmetric to asymmetric cell division of apical RGCs was observed, as well as alterations of the $\mathrm{N}$-Cadherin/ $\beta$-Catenin signaling pathway, showing that a reduction of Wnt activity leads to premature neurogenesis. These alterations in MDS-derived organoids were rescued by Wnt activation [299]. Thus, these studies highlight the potential of organotypic cell-culture models to contribute to the understanding of developmental mechanisms underlying MCDs.

\section{Non-genetic origins of MCDs (illustrated by Zika virus infection) - highjacking the same pathways, use of the same models.}

Congenital microcephaly is due to reduced neuronal production or increased cell death $[16,42,46,199]$. A large proportion of microcephaly cases remain unexplained as they have not been linked to any genetic origin. Possible explanations for some of these cases may include exposure to certain infections during pregnancy, the so called TORCHS factors, such as toxoplasmosis, rubella, cytomegalovirus, herpes virus, and syphilis; as well as severe malnutrition, exposure to harmful substances, such as alcohol, certain drugs, toxic chemicals or interruption of the blood supply during development [300,301]. Zika virus (ZIKV) carried by mosquitos, now joins the list of viral TORCH pathogens [302].

Crescent reports of a possible association between ZIKV infection and increased incidence of microcephaly and lissencephaly among neonates and Guillain-Barré syndrome (GBS) in Americas attracted global attention [303,304]. Vertical transmission from infected mothers was supported by the detection of ZIKV in the amniotic fluid of two pregnant women whose fetuses were diagnosed with microcephaly [305]. ZIKV was found in fetal brain tissue presenting microcephaly with almost complete agyria, hydrocephalus, together with multifocal dystrophic calcifications in the cortex and subcortical white matter [306]. Moreover, ZIKV infection has been reported to induce not only atrophy of the cortex and brainstem, but also cerebellar hypoplasia, macrocephaly, hydranencephaly, brain and spinal cord inflammation, arthrogryposis, ventriculomegaly, pulmonary hypoplasia, and architectural distortion of the spinal cord presenting severe neuronal loss and microcalcifications among others features [307,308].

$\mathrm{Li}$ and col. [309] demonstrated that ZIKV infects mainly progenitor cells in the mouse, leading to smaller brain sizes 5 days after the infection (E18.5), cell-cycle dysregulation, neural progenitor cell (NPC) defects in differentiation and increased active caspase-3 positive cells. Moreover, ZIKV infects human NPCs derived from iPSCs, increases cell death and deregulates cell-cycle progression, resulting in attenuated hNPC growth [297]. RNA-seq analysis showed downregulation of cell-cyclerelated genes as well as upregulation of genes associated with transcription, protein transport, and catabolic processes, consistent with increased caspase-3 activation [297]. Similarly, ZIKV infection in 
human NSCs growing as neurospheres and brain organoids reduces their viability and growth through caspase 3/7-mediated cell death [295].

Based on the role of NSCs in other forms of microcephaly, Nowakowski and colleagues [296] hypothesized that human RGCs may selectively express proteins that facilitate the entry and infectivity of ZIKV during neurogenesis. Using single-cell RNA-seq they found a candidate viral entry receptor, AXL (Receptor Tyrosine Kinase), which is highly expressed by human RGCs, among other cell types and conserved in developing mouse and ferret cortex and in human cerebral organoids.

Analyzing human NES cells in organotypic fetal brain slices, and a ZIKV-infected microcephalic brain, it was shown that ZIKV infects both neocortical and spinal NES cells as well as RGCs, causing disrupted mitoses, super-numerary centrosomes, structural disorganization, and cell death. NES cells and RGCs presented centrosomal depletion and mitochondrial sequestration of phospho-TBK1 during mitosis, a phosphorylated TANK binding kinase 1 (pTBK1), involved in antiviral innate immunity and cell proliferation [310]. These authors also demonstrated that antiviral nucleoside analogs, such as Sofosbuvir, inhibit ZIKV replication and cytopathology in NES cells, unraveling some components of the cellular mechanisms that may be involved in ZIKV pathogenesis. Related to this, organoids treated with ZIKV showed a significant decrease in the neuroepithelium and overall organoid size, and the innate immune receptor Toll-like-Receptor 3 (TLR3), expressed in NPCs, was found upregulated in cerebral organoids and neurospheres [294]. These authors conclude that TLR3-activation triggers multiple genetic cascades regulating axogenesis, cell proliferation and anti-apoptotic pathways within NPCs and neurons which may strongly contribute to the ZIKVmediated microcephaly phenotype.

More recently, the ZIKV strains isolated in the last outbreak (H/PF/2013 (ZIKV-AS) and FBGWUH-2016 (ZIKV-AM)) were characterized by Gabriel and col. [311], showing that ZIKV targets and replicates in proliferating NPCs, leading to premature differentiation associated with centrosome perturbation, NPC depletion, disruption of the VZ, impaired neurogenesis and cortical thinning. Altogether, recent evidence linking microcephaly with ZIKV infection through targeted-NPCs and the huge amount of research dedicated to the study of the effects of this virus and mechanisms of action, not only contributed to the development of an effective antiviral vaccine that could prevent ZIKV effects, but also provided potential fundamental clues of cortical development impairment under other pathological conditions which lead to MCDs.

\section{Conclusions and perspectives}

The development of the human neocortex is a complex and dynamic process that occurs over a period of many weeks. Any disruption to the normal process can lead to severe MCDs. The disruption of neuronal migration, differentiation and cell fate can lead to abnormalities of gyration. Abnormal layering of the cortex, as well as heterotopia (PVH, SBH or double cortex formation) are almost always associated with epilepsy. Disruption of progenitor number and function leads to microcephaly, but also increasingly progenitor abnormalities are associated with PVH and PMG. BM defects due to detachment of RGC basal endfeet also lead to COB-LIS, these disorders in patients are characterized by severe infant epilepsy, ID and behavioral deficits.

As described here, NGS techniques sometimes lead to some surprises. We have reviewed several cases where a defined MCD is linked with a mutation in a particular gene which is already known for its association with a different MCD phenotype (e.g. ASPM, see Table 6). These occurrences are indeed increasing, and the spectrum of phenotypes linked to single genes are widening because of such data. This phenotype variability is currently hard to explain, however genetic background is likely to play a strong role. Patient mutations revealed in large cohorts e.g. in epilepsy genes, can occur even if no epilepsy has yet been recorded in that patient. Future work should search for genetic backgrounds which may protect against these pathologies. There are also further cases where a particular expected mutation was not identified $[35,39,312]$. All scenarios hence exist. This latter situation may suggest MCDs that might be associated with non-coding or regulatory sequence mutations. This represents a new focus for mutation identification.

Animal models of these disorders have helped us understand the role of many MCD genes and the mechanisms in which they act during normal cortical development. Interestingly, acute downregulation using in utero electroporation often shows severer phenotypes than mouse KOs. In some 
cases off-target effects may aggravate the phenotype [171], in other cases functional compensation in KOs may have occurred, as suggested by severer phenotypes observed with double gene KOs (e.g. $[94,108])$. The reasons for these mouse-human differences remain unknown. These issues complicate the analyses, and in many cases phenotypes do not resemble those of human patients. For cLIS-related genes, defects are firmly linked to MT dysfunction [173]. Indeed, the LIS phenotype is mainly caused by mutations in genes which encode MT binding-proteins, cytoskeleton subunits including tubulin, but also actin, and motor proteins. The requirement for an intact MT cytoskeleton is likely to be related to the dynamic nature of the migration process, involving extensive changes in cell morphology. A question which remains concerning these genes is their involvement or not in other cell types and in particular progenitors. RGC progenitor defects will also likely have a secondary impact on migrating cells which is a confounding factor. Transplantation experiments in animal models can help clarify primary roles, although it still remains a mystery concerning which cell populations are affected in the human brain. In vitro human cell models and the use of gyrencephaly species such as the ferret may help clarify mechanisms.

The Reln gene when mutated in the mouse reveals a phenotype which appears to mimic well the human disorder. Its highly constrained expression in Cajal-Retzius cells during development shows that these cells are critical and highly conserved. Type II COB-LIS genes are numerous, and biochemical pathways are becoming clearer related to the BM. These disorders are described as overmigration phenotypes, with a distinction that they do not affect the migration of neurons themselves, but instead the cortical boundaries, including mis-localization of Cajal Retzius cells. COB-LIS mechanisms affecting basal endfeet of RGCs can also perhaps be likened to PVH mechanisms affecting the apical aspects. On the other hand, PVH genes may also play a role during neuronal migration itself. Perturbing either end of RGCs can also impact the other extremity, presumably via a global detachment process, combined with the retraction of both apical and basal processes (e.g. observed in the cKO of RhoA, [273]). These phenotypes should hence be systematically assessed. It is also interesting that COB-LIS phenotypes often also involve hydrocephaly, and this malformation can arise by multiple mechanisms. One thing is however clear, defects in highly specialized RGCs spanning the cortical wall can potentially account for a large proportion of these MCDs.

Common PMG mechanisms still need to be clarified, although once again progenitor cell defects are prominent. This is interesting related to the fact that this MCD as well is often described as a post-migration, cortical organization phenomenon, related to the aspect of the multiple small gyri and fused shallow sulci, giving the brain a lumpy appearance, which is sometimes difficult to distinguish from COB-LIS on MRI. Overlap between these MCDs is indeed observed eg due to mutations in GRP56 [227]. Other gene mutations giving rise to PMG, are associated with different progenitor mechanisms (eg perturbed centrioles, spindles and primary cilia). Mechanisms still however, need to be further elucidated, as well as how the multiple small gyri actually develop which still remains a mystery. As PMG has been associated with environmental factors, it would be interesting to address the interaction of environment with specific mutations which have not been described to generate any phenotype in animal models, but have strong effects in humans. Indeed, this could particularly be interesting in cases where the same gene is mutated in different MCDs. Another important point to be mentioned is that many MCDs described here are characterized by the presence of seizures in humans, nevertheless most of the animal models lack this characteristic. Human/ rodent differences in this respect need to be better understood.

Although animal models have provided valuable insights into the pathogenesis of $\mathrm{MCD}$, there are still many cases where they have not reproduced many of the features observed in the corresponding human conditions (see Table 1). One possible explanation for this observation could be the low proportion of bRGCs in lissencephalic animal models such as mice and rats [11,298,313-315]. Particularly, there is a known debate on the use of lissencephalic species in the study of abnormalities of gyration presented in humans. Gene expression studies have shown that at the molecular level proliferative zones present differential profiles among lissencephalic (eg. mouse) and gyrencephalic species (e.g. the ferret and humans), particularly related to the SVZ [316-320]. Furthermore, differentially expressed genes within the developing human brain may have an elevated substitution rate in humans and in other species, particularly in conserved non-coding sequences (CNSs) [321], which may also help explain some human disorders. Human-specific non-coding regions of DNA, 
including human-accelerated CNSs (HACNSs), have also been shown to play important roles in human brain development by regulating genes having key roles in temporal and spatial dynamics compared to the mouse [322,323]. These differences need to be further studied to have the best chance of understanding human conditions.

Finally, during the last decade, the use of new technologies such as the generation of brain organoids from patients' samples have allowed incredible advances in the study of the molecular mechanisms leading to MCD. One example has been intense studies related to the recent ZIKV outbreak. The use of these models have provided further insights into the understanding how this virus could infect specifically RGCs and the mechanisms that lead to RGC death, giving rise to microcephaly and lissencephaly in affected individuals. Increasing use of these models is expected in the future.

\section{Acknowledgement}

We thank members of our laboratories for support.

\section{Funding}

We are grateful for financial support from INSERM, the CNRS and UPMC, the European Union (EUHEALTH-2013), the ANR (13-BSV4-0008-01, ANR-16-CE16-0011-03), the JTC 2015 Neurodevelopmental Disorders and the ANR for NEURON8-Full-815-006 STEM-MCD and the Région Ile-de-France. FF's group is associated with the BioPsy Labex project and the Ecole des Neurosciences de Paris Ile-de-France network.

\section{Captures}




\section{A. Human cortical development}

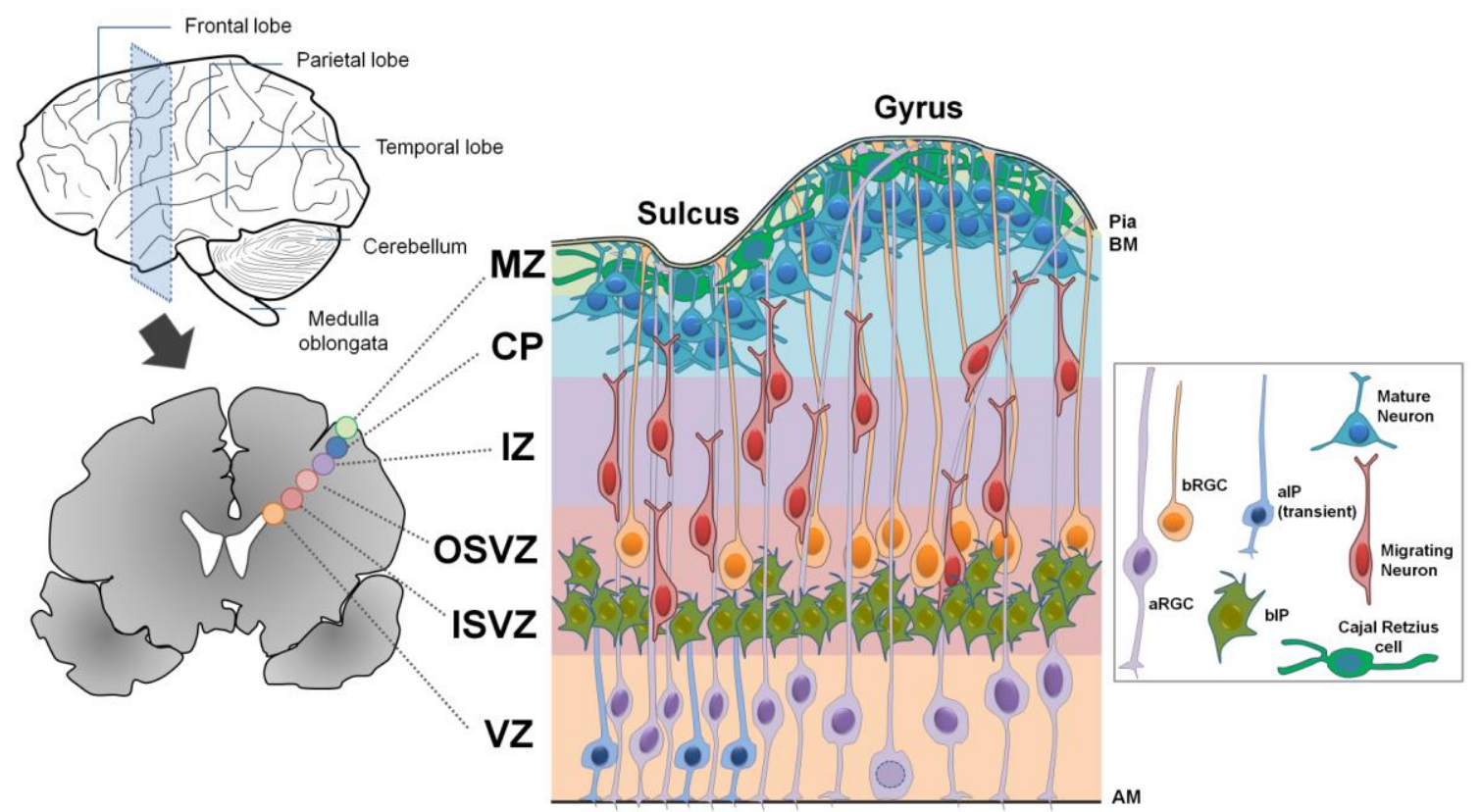

B. Mouse cortical development
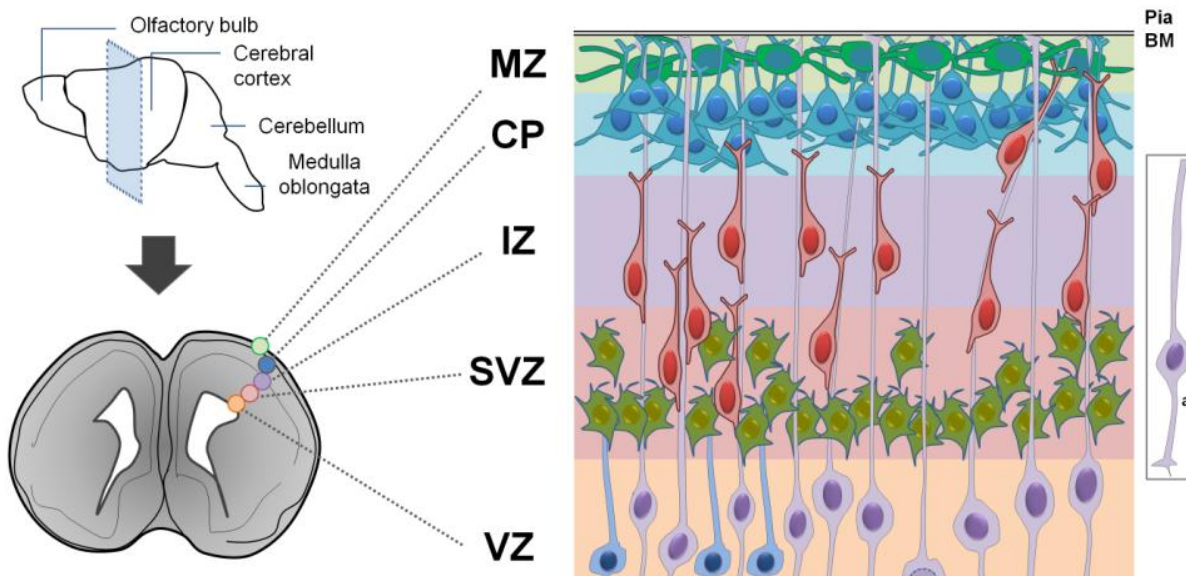

IZ



VZ

Figure 1. Comparison between cortical development in gyrencephalic and lissencephalic brains

A. Lateral view of an adult gyrencephalic brain (top left) and a developing brain slice (coronal view, lower left). The different color circles represent each developing cortical region (indicated on the right). The location and prototypical cell-types present in each region are illustrated (right panels). The basal radial glial cells (bRGCs) are mainly present in gyrencephalic species and they are localized within the outer subventricular zone (OSVZ).

B. Lateral view of an adult lissencephalic brain (top left) and a developing brain slice (coronal view, lower left). Each developing cortical region is differentially colored and indicated on the right. The location and prototypical cell-types of each region are illustrated (right panels).

In both figures the interkinetic nuclear migration of RGCs in the ventricular zone (VZ) and neuronal migration are represented. The division of the subventricular zone (SVZ) into an inner (ISVZ) and outer (OSVZ) region, and the presence of sulci and gyri, are the main organizational differences between the human and mouse brains. 


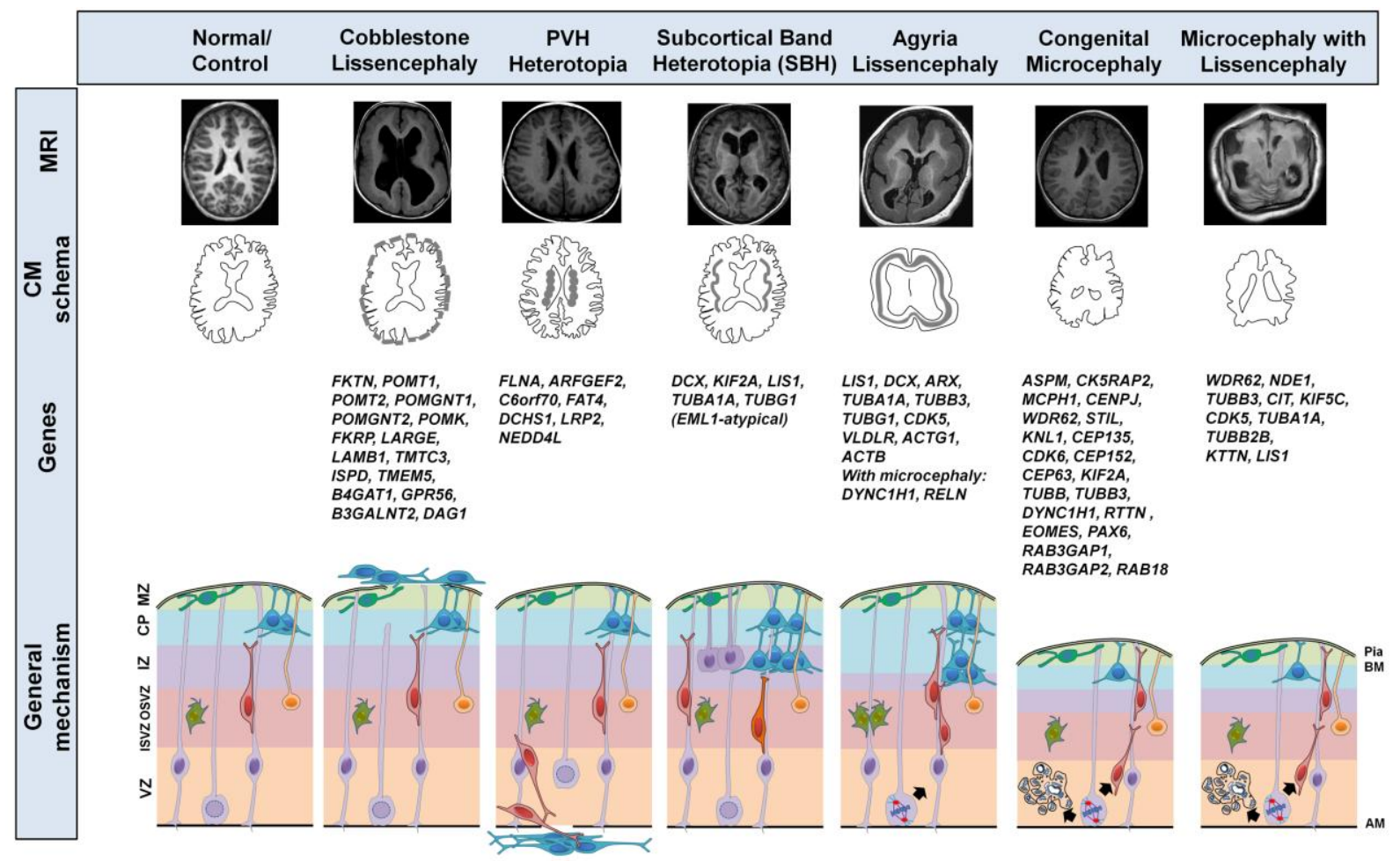

Figure 2. Comparison of human brain malformations of cortical development (MCDs).

Magnetic resonance imaging (MRI) images of patients with different brain cortical malformations are shown: Control, cobblestone lissencephaly (COB-LIS), periventricular heterotopia (PVH), subcortical band heterotopia (SBH), agyria/lissencephaly (LIS), congenital microcephaly and the most severe phenotype, lissencephaly with microcephaly. Schematic representation of MCDs are included below the MRI images. For each MCD, the main genes mutated are shown. Schematic representations of the general mechanisms leading to each MCD and main genes mutated are shown below. Control: interkinetic nuclear migration of RGCs (grey) and migration of immature neurons (red) are represented. Cortical plate (CP) contains mature neurons (blue) and the marginal zone (MZ), CajalRetzius cells (green). The SVZ contains IP cells (light green). COB-LIS: over-migration of neurons through a disrupted pial basal membrane (BM) forms the cobblestone phenotype. PVH neurons are produced and escape through the ventricular lining forming nodules. SBH: defects in neuronal migration (orange neuron) lead to the accumulation of ectopic cells that form an extra cortical layer below the normal cortex (note the double cortex). RGC detachment and ectopic proliferation can also lead to SBH. Agyria/LIS: The same neuronal migration defects are also observed in LIS. Defects in the mitotic machinery, IPs or bRGs also cannot be ruled out. Congenital microcephaly: an increased apoptosis of RGCs, premature differentiation to neurons, and defects in spindle formation are the main causes of the microcephaly phenotype. LIS with microcephaly: mainly due to increased apoptosis of RGCs, premature neuronal differentiation and defects in spindle formation.

\section{References}

[1] H. Komuro, P. Rakic, Distinct modes of neuronal migration in different domains of developing cerebellar cortex, J. Neurosci. Off. J. Soc. Neurosci. 18 (1998) 1478-1490.

[2] A.R. Kriegstein, S.C. Noctor, Patterns of neuronal migration in the embryonic cortex, Trends Neurosci. 27 (2004) $392-399$. doi:10.1016/j.tins.2004.05.001.

[3] D.H. Rowitch, A.R. Kriegstein, Developmental genetics of vertebrate glial-cell specification, Nature. 468 (2010) $214-222$ doi:10.1038/nature09611. 
[4] N. Zecevic, Y. Chen, R. Filipovic, Contributions of cortical subventricular zone to the development of the human cerebral cortex, J. Comp. Neurol. 491 (2005) 109-122. doi:10.1002/cne.20714.

[5] M. Götz, W.B. Huttner, The cell biology of neurogenesis, Nat. Rev. Mol. Cell Biol. 6 (2005) 777-788. doi:10.1038/nrm1739.

[6] B.E. LaMonica, J.H. Lui, X. Wang, A.R. Kriegstein, OSVZ progenitors in the human cortex: an updated perspective on neurodevelopmental disease, Curr. Opin. Neurobiol. 22 (2012) 747-753. doi:10.1016/j.conb.2012.03.006.

[7] E.K. Stancik, I. Navarro-Quiroga, R. Sellke, T.F. Haydar, Heterogeneity in ventricular zone neural precursors contributes to neuronal fate diversity in the postnatal neocortex, J. Neurosci. Off. J. Soc. Neurosci. 30 (2010) 7028-7036. doi:10.1523/JNEUROSCI.6131-09.2010.

[8] B.J. Molyneaux, P. Arlotta, J.R.L. Menezes, J.D. Macklis, Neuronal subtype specification in the cerebral cortex, Nat. Rev. Neurosci. 8 (2007) 427-437. doi:10.1038/nrn2151.

[9] P. Gao, K.T. Sultan, X.-J. Zhang, S.-H. Shi, Lineage-dependent circuit assembly in the neocortex, Dev. Camb. Engl. 140 (2013) 2645-2655. doi:10.1242/dev.087668.

[10] E. Taverna, M. Götz, W.B. Huttner, The cell biology of neurogenesis: toward an understanding of the development and evolution of the neocortex, Annu. Rev. Cell Dev. Biol. 30 (2014) 465-502. doi:10.1146/annurev-cellbio-101011-155801.

[11] M. Florio, V. Borrell, W.B. Huttner, Human-specific genomic signatures of neocortical expansion, Curr. Opin. Neurobiol. 42 (2017) 33-44. doi:10.1016/j.conb.2016.11.004.

[12] D.V. Hansen, J.H. Lui, P.R.L. Parker, A.R. Kriegstein, Neurogenic radial glia in the outer subventricular zone of human neocortex, Nature. 464 (2010) 554-561. doi:10.1038/nature08845.

[13] M. Marin-Padilla, Dual origin of the mammalian neocortex and evolution of the cortical plate, Anat. Embryol. (Berl.). 152 (1978) $109-126$.

[14] N. Zecevic, F. Hu, I. Jakovcevski, Interneurons in the developing human neocortex, Dev. Neurobiol. 71 (2011) 18-33. doi:10.1002/dneu.20812.

[15] R. Ayala, T. Shu, L.-H. Tsai, Trekking across the brain: the journey of neuronal migration, Cell. 128 (2007) $29-43$. doi:10.1016/j.cell.2006.12.021.

[16] M.A. Stouffer, J.A. Golden, F. Francis, Neuronal migration disorders: Focus on the cytoskeleton and epilepsy, Neurobiol. Dis. 92 (2016) 18-45. doi:10.1016/j.nbd.2015.08.003.

[17] G. Meyer, J.P. Schaaps, L. Moreau, A.M. Goffinet, Embryonic and early fetal development of the human neocortex, J. Neurosci. Off. J. Soc. Neurosci. 20 (2000) 1858-1868.

[18] H. Tabata, K. Nakajima, Multipolar migration: the third mode of radial neuronal migration in the developing cerebral cortex, J. Neurosci. Off. J. Soc. Neurosci. 23 (2003) 9996-10001.

[19] B. Nadarajah, J.E. Brunstrom, J. Grutzendler, R.O. Wong, A.L. Pearlman, Two modes of radial migration in early development of the cerebral cortex, Nat. Neurosci. 4 (2001) 143-150. doi:10.1038/83967.

[20] Y. Jossin, J.A. Cooper, Reelin, Rap1 and N-cadherin orient the migration of multipolar neurons in the developing neocortex, Nat. Neurosci. 14 (2011) 697-703. doi:10.1038/nn.2816.

[21] F. Bielle, A. Griveau, N. Narboux-Nême, S. Vigneau, M. Sigrist, S. Arber, M. Wassef, A. Pierani, Multiple origins of Cajal-Retzius cells at the borders of the developing pallium, Nat. Neurosci. 8 (2005) 1002-1012. doi:10.1038/nn1511.

[22] M.R. Freeman, D.H. Rowitch, Evolving concepts of gliogenesis: a look way back and ahead to the next 25 years, Neuron. 80 (2013) 613-623. doi:10.1016/j.neuron.2013.10.034.

[23] H. Tabata, Diverse subtypes of astrocytes and their development during corticogenesis, Front. Neurosci. 9 (2015) 114. doi:10.3389/fnins.2015.00114.

[24] A. Araque, M. Navarrete, Glial cells in neuronal network function, Philos. Trans. R. Soc. Lond. B. Biol. Sci. 365 (2010) $2375-$ 2381. doi:10.1098/rstb.2009.0313

[25] L.C. Faria, F. Gu, I. Parada, B. Barres, Z.D. Luo, D.A. Prince, Epileptiform activity and behavioral arrests in mice overexpressing the calcium channel subunit $\alpha 2 \delta$-1, Neurobiol. Dis. 102 (2017) 70-80. doi:10.1016/j.nbd.2017.01.009.

[26] S. Vergult, A. Dheedene, A. Meurs, F. Faes, B. Isidor, S. Janssens, A. Gautier, C. Le Caignec, B. Menten, Genomic aberrations of the CACNA2D1 gene in three patients with epilepsy and intellectual disability, Eur. J. Hum. Genet. EJHG. 23 (2015) 628-632. doi:10.1038/ejhg.2014.141.

[27] M. Kielbinski, K. Gzielo, Z. Soltys, Review: Roles for astrocytes in epilepsy: insights from malformations of cortical development, Neuropathol. Appl. Neurobiol. 42 (2016) 593-606. doi:10.1111/nan.12331.

[28] H.H. Ropers, Genetics of early onset cognitive impairment, Annu. Rev. Genomics Hum. Genet. 11 (2010) 161-187. doi:10.1146/annurev-genom-082509-141640.

[29] E. Sheridan, J. Wright, N. Small, P.C. Corry, S. Oddie, C. Whibley, E.S. Petherick, T. Malik, N. Pawson, P.A. McKinney, R.C. Parslow, Risk factors for congenital anomaly in a multiethnic birth cohort: an analysis of the Born in Bradford study, Lancet Lond Engl. 382 (2013) 1350-1359. doi:10.1016/S0140-6736(13)61132-0.

[30] S.S. Jamuar, C.A. Walsh, Somatic mutations in cerebral cortical malformations, N. Engl. J. Med. 371 (2014) 2038 doi:10.1056/NEJMc1411784.

[31] M. Kato, Genotype-phenotype correlation in neuronal migration disorders and cortical dysplasias, Front. Neurosci. 9 (2015) 181. doi:10.3389/fnins.2015.00181.

[32] D. Pinkel, R. Segraves, D. Sudar, S. Clark, I. Poole, D. Kowbel, C. Collins, W.L. Kuo, C. Chen, Y. Zhai, S.H. Dairkee, B.M Ljung, J.W. Gray, D.G. Albertson, High resolution analysis of DNA copy number variation using comparative genomic hybridization to microarrays, Nat. Genet. 20 (1998) 207-211. doi:10.1038/2524.

[33] Y. Yang, D.M. Muzny, J.G. Reid, M.N. Bainbridge, A. Willis, P.A. Ward, A. Braxton, J. Beuten, F. Xia, Z. Niu, M. Hardison, R. Person, M.R. Bekheirnia, M.S. Leduc, A. Kirby, P. Pham, J. Scull, M. Wang, Y. Ding, S.E. Plon, J.R. Lupski, A.L. Beaudet, R.A. Gibbs, C.M. Eng, Clinical whole-exome sequencing for the diagnosis of mendelian disorders, N. Engl. J. Med. 369 (2013) 15021511. doi:10.1056/NEJMoa1306555.

[34] S.S. Jamuar, E.-C. Tan, Clinical application of next-generation sequencing for Mendelian diseases, Hum. Genomics. 9 (2015) 10. doi:10.1186/s40246-015-0031-5.

[35] Deciphering Developmental Disorders Study, Prevalence and architecture of de novo mutations in developmental disorders, Nature. 542 (2017) 433-438. doi:10.1038/nature21062.

[36] L.G. Biesecker, B.B. Biesecker, An approach to pediatric exome and genome sequencing, Curr. Opin. Pediatr. 26 (2014) 639-645. doi:10.1097/MOP.0000000000000150.

[37] J. de Ligt, M.H. Willemsen, B.W.M. van Bon, T. Kleefstra, H.G. Yntema, T. Kroes, A.T. Vulto-van Silfhout, D.A. Koolen, P. de Vries, C. Gilissen, M. del Rosario, A. Hoischen, H. Scheffer, B.B.A. de Vries, H.G. Brunner, J.A. Veltman, L.E.L.M. Vissers, Diagnostic exome sequencing in persons with severe intellectual disability, N. Engl. J. Med. 367 (2012) 1921-1929. doi:10.1056/NEJMoa1206524. 
[38] Epi4K Consortium, Epilepsy Phenome/Genome Project, A.S. Allen, S.F. Berkovic, P. Cossette, N. Delanty, D. Dlugos, E.E. Eichler, M.P. Epstein, T. Glauser, D.B. Goldstein, Y. Han, E.L. Heinzen, Y. Hitomi, K.B. Howell, M.R. Johnson, R. Kuzniecky, D.H. Lowenstein, Y.-F. Lu, M.R.Z. Madou, A.G. Marson, H.C. Mefford, S. Esmaeeli Nieh, T.J. O’Brien, R. Ottman, S. Petrovski, A. Poduri, E.K. Ruzzo, I.E. Scheffer, E.H. Sherr, C.J. Yuskaitis, B. Abou-Khalil, B.K. Alldredge, J.F. Bautista, S.F. Berkovic, A. Boro, G.D. Cascino, D. Consalvo, P. Crumrine, O. Devinsky, D. Dlugos, M.P. Epstein, M. Fiol, N.B. Fountain, J. French, D. Friedman, E.B. Geller, T. Glauser, S. Glynn, S.R. Haut, J. Hayward, S.L. Helmers, S. Joshi, A. Kanner, H.E. Kirsch, R.C. Knowlton, E.H. Kossoff, R. Kuperman, R. Kuzniecky, D.H. Lowenstein, S.M. McGuire, P.V. Motika, E.J. Novotny, R. Ottman, J.M. Paolicchi, J.M. Parent, K. Park, A. Poduri, I.E. Scheffer, R.A. Shellhaas, E.H. Sherr, J.J. Shih, R. Singh, J. Sirven, M.C. Smith, J. Sullivan, L. Lin Thio, A. Venkat, E.P.G. Vining, G.K. Von Allmen, J.L. Weisenberg, P. Widdess-Walsh, M.R. Winawer, De novo mutations in epileptic encephalopathies, Nature. 501 (2013) 217-221. doi:10.1038/nature12439.

[39] S.S. Jamuar, A.-T.N. Lam, M. Kircher, A.M. D’Gama, J. Wang, B.J. Barry, X. Zhang, R.S. Hill, J.N. Partlow, A. Rozzo, S. Servattalab, B.K. Mehta, M. Topcu, D. Amrom, E. Andermann, B. Dan, E. Parrini, R. Guerrini, I.E. Scheffer, S.F. Berkovic, R.J. Leventer, Y. Shen, B.L. Wu, A.J. Barkovich, M. Sahin, B.S. Chang, M. Bamshad, D.A. Nickerson, J. Shendure, A. Poduri, T.W. Yu, C.A. Walsh, Somatic mutations in cerebral cortical malformations, N. Engl. J. Med. 371 (2014) 733-743. doi:10.1056/NEJMoa1314432.

[40] L.G. Biesecker, N.B. Spinner, A genomic view of mosaicism and human disease, Nat. Rev. Genet. 14 (2013) 307-320. doi: $10.1038 / \mathrm{nrg} 3424$.

[41] G. Malinger, D. Kidron, L. Schreiber, L. Ben-Sira, C. Hoffmann, D. Lev, T. Lerman-Sagie, Prenatal diagnosis of malformations of cortical development by dedicated neurosonography, Ultrasound Obstet. Gynecol. Off. J. Int. Soc. Ultrasound Obstet. Gynecol. 29 (2007) 178-191. doi:10.1002/uog.3906.

[42] A.J. Barkovich, R. Guerrini, R.I. Kuzniecky, G.D. Jackson, W.B. Dobyns, A developmental and genetic classification for malformations of cortical development: update 2012, Brain J. Neurol. 135 (2012) 1348-1369. doi:10.1093/brain/aws019.

[43] R. Guerrini, W.B. Dobyns, Malformations of cortical development: clinical features and genetic causes, Lancet Neurol. 13 (2014) 710-726. doi:10.1016/S1474-4422(14)70040-7.

[44] S.M. Sisodiya, Surgery for malformations of cortical development causing epilepsy, Brain J. Neurol. 123 ( Pt 6) (2000) 1075-1091.

[45] R.J. Leventer, R. Guerrini, W.B. Dobyns, Malformations of cortical development and epilepsy, Dialogues Clin. Neurosci. 10 (2008) 47-62

[46] F. Francis, G. Meyer, C. Fallet-Bianco, S. Moreno, C. Kappeler, A.C. Socorro, F.P.D. Tuy, C. Beldjord, J. Chelly, Human disorders of cortical development: from past to present, Eur. J. Neurosci. 23 (2006) 877-893. doi:10.1111/j.14609568.2006.04649.x

[47] N. Bahi-Buisson, K. Poirier, F. Fourniol, Y. Saillour, S. Valence, N. Lebrun, M. Hully, C.F. Bianco, N. Boddaert, C. Elie, K. Lascelles, I. Souville, LIS-Tubulinopathies Consortium, C. Beldjord, J. Chelly, The wide spectrum of tubulinopathies: what are the key features for the diagnosis?, Brain J. Neurol. 137 (2014) 1676-1700. doi:10.1093/brain/awu082.

[48] K. Poirier, Y. Saillour, F. Fourniol, F. Francis, I. Souville, S. Valence, I. Desguerre, J. Marie Lepage, N. Boddaert, M. Line Jacquemont, C. Beldjord, J. Chelly, N. Bahi-Buisson, Expanding the spectrum of TUBA1A-related cortical dysgenesis to Polymicrogyria, Eur. J. Hum. Genet. EJHG. 21 (2013) 381-385. doi:10.1038/ejhg.2012.195.

[49] K. Poirier, N. Lebrun, L. Broix, G. Tian, Y. Saillour, C. Boscheron, E. Parrini, S. Valence, B.S. Pierre, M. Oger, D. Lacombe, D. Geneviève, E. Fontana, F. Darra, C. Cances, M. Barth, D. Bonneau, B.D. Bernadina, S. N'guyen, C. Gitiaux, P. Parent, V. des Portes, J.M. Pedespan, V. Legrez, L. Castelnau-Ptakine, P. Nitschke, T. Hieu, C. Masson, D. Zelenika, A. Andrieux, F. Francis, R. Guerrini, N.J. Cowan, N. Bahi-Buisson, J. Chelly, Mutations in TUBG1, DYNC1H1, KIF5C and KIF2A cause malformations of cortical development and microcephaly, Nat. Genet. 45 (2013) 639-647. doi:10.1038/ng.2613.

[50] J. Aicardi, The agyria-pachygyria complex: a spectrum of cortical malformations, Brain Dev. 13 (1991) 1-8

[51] R. Guerrini, T. Filippi, Neuronal migration disorders, genetics, and epileptogenesis, J. Child Neurol. 20 (2005) 287-299. doi:10.1177/08830738050200040401.

[52] D.T. Pilz, J. Kuc, N. Matsumoto, J. Bodurtha, B. Bernadi, C.A. Tassinari, W.B. Dobyns, D.H. Ledbetter, Subcortical band heterotopia in rare affected males can be caused by missense mutations in DCX (XLIS) or LIS1, Hum. Mol. Genet. 8 (1999) 17571760 .

[53] G. Friocourt, P. Marcorelles, P. Saugier-Veber, M.-L. Quille, S. Marret, A. Laquerrière, Role of cytoskeletal abnormalities in the neuropathology and pathophysiology of type I lissencephaly, Acta Neuropathol. (Berl.). 121 (2011) 149-170. doi:10.1007/s00401010-0768-9.

[54] M.S. Forman, W. Squier, W.B. Dobyns, J.A. Golden, Genotypically defined lissencephalies show distinct pathologies, J. Neuropathol. Exp. Neurol. 64 (2005) 847-857.

[55] M. Hattori, H. Adachi, M. Tsujimoto, H. Arai, K. Inoue, The catalytic subunit of bovine brain platelet-activating factor acetylhydrolase is a novel type of serine esterase, J. Biol. Chem. 269 (1994) 23150-23155.

[56] O. Reiner, T. Sapir, LIS1 functions in normal development and disease, Curr. Opin. Neurobiol. 23 (2013) 951-956. doi:10.1016/j.conb.2013.08.001.

[57] O. Reiner, R. Carrozzo, Y. Shen, M. Wehnert, F. Faustinella, W.B. Dobyns, C.T. Caskey, D.H. Ledbetter, Isolation of a MillerDieker lissencephaly gene containing G protein beta-subunit-like repeats, Nature. 364 (1993) 717-721. doi:10.1038/364717a0. W.B. Dobyns, C.J. Curry, H.E. Hoyme, L. Turlington, D.H. Ledbetter, Clinical and molecular diagnosis of Miller-Dieker syndrome, Am. J. Hum. Genet. 48 (1991) 584-594.

59] C. Lo Nigro, C.S. Chong, A.C. Smith, W.B. Dobyns, R. Carrozzo, D.H. Ledbetter, Point mutations and an intragenic deletion in LIS1, the lissencephaly causative gene in isolated lissencephaly sequence and Miller-Dieker syndrome, Hum. Mol. Genet. 6 (1997) $157-164$.

[60] M. Rossi, R. Guerrini, W.B. Dobyns, G. Andria, R.M. Winter, Characterization of brain malformations in the Baraitser-Winter syndrome and review of the literature, Neuropediatrics. 34 (2003) 287-292. doi:10.1055/s-2003-44666.

[61] W.B. Dobyns, S. Das, LIS1-Associated Lissencephaly/Subcortical Band Heterotopia, in: R.A. Pagon, M.P. Adam, H.H. Ardinger, S.E. Wallace, A. Amemiya, L.J. Bean, T.D. Bird, N. Ledbetter, H.C. Mefford, R.J. Smith, K. Stephens (Eds.), GeneReviews(®), University of Washington, Seattle, Seattle (WA), 1993. http://www.ncbi.nlm.nih.gov/books/NBK5189/ (accessed May 12, 2017).

[62] Y. Saillour, N. Carion, C. Quelin, P.-L. Leger, N. Boddaert, C. Elie, A. Toutain, S. Mercier, M.A. Barthez, M. Milh, S. Joriot, V. des Portes, N. Philip, D. Broglin, A. Roubertie, G. Pitelet, M.L. Moutard, J.M. Pinard, C. Cances, A. Kaminska, J. Chelly, C. Beldjord, N. Bahi-Buisson, LIS1-related isolated lissencephaly: spectrum of mutations and relationships with malformation severity, Arch. Neurol. 66 (2009) 1007-1015. doi:10.1001/archneurol.2009.149.

[63] M. Philbert, C. Maillard, M. Cavallin, A. Goldenberg, C. Masson, N. Boddaert, A. El Morjani, J. Steffann, J. Chelly, X. Gerard, N Bahi-Buisson, A novel recurrent LIS1 splice site mutation in classic lissencephaly, Am. J. Med. Genet. A. 173 (2017) 561-564. doi:10.1002/ajmg.a.38041. 
[64] S. Hirotsune, M.W. Fleck, M.J. Gambello, G.J. Bix, A. Chen, G.D. Clark, D.H. Ledbetter, C.J. McBain, A. Wynshaw-Boris, Graded reduction of Pafah1b1 (Lis1) activity results in neuronal migration defects and early embryonic lethality, Nat. Genet. 19 (1998) 333-339. doi:10.1038/1221.

[65] A. Cahana, T. Escamez, R.S. Nowakowski, N.L. Hayes, M. Giacobini, A. von Holst, O. Shmueli, T. Sapir, S.K. McConnell, W. Wurst, S. Martinez, O. Reiner, Targeted mutagenesis of Lis1 disrupts cortical development and LIS1 homodimerization, Proc. Natl. Acad. Sci. U. S. A. 98 (2001) 6429-6434. doi:10.1073/pnas.101122598.

[66] J.-W. Tsai, Y. Chen, A.R. Kriegstein, R.B. Vallee, LIS1 RNA interference blocks neural stem cell division, morphogenesis, and motility at multiple stages, J. Cell Biol. 170 (2005) 935-945. doi:10.1083/jcb.200505166.

[67] M.J. Gambello, D.L. Darling, J. Yingling, T. Tanaka, J.G. Gleeson, A. Wynshaw-Boris, Multiple dose-dependent effects of Lis1 on cerebral cortical development, J. Neurosci. Off. J. Soc. Neurosci. 23 (2003) 1719-1729.

[68] H.M. Moon, Y.H. Youn, H. Pemble, J. Yingling, T. Wittmann, A. Wynshaw-Boris, LIS1 controls mitosis and mitotic spindle organization via the LIS1-NDEL1-dynein complex, Hum. Mol. Genet. 23 (2014) 449-466. doi:10.1093/hmg/ddt436.

[69] M.H. Kim, D.R. Cooper, A. Oleksy, Y. Devedjiev, U. Derewenda, O. Reiner, J. Otlewski, Z.S. Derewenda, The structure of the Nterminal domain of the product of the lissencephaly gene Lis1 and its functional implications, Struct. Lond. Engl. 1993. 12 (2004) 987-998. doi:10.1016/j.str.2004.03.024.

[70] N.E. Faulkner, D.L. Dujardin, C.Y. Tai, K.T. Vaughan, C.B. O’Connell, Y. Wang, R.B. Vallee, A role for the lissencephaly gene LIS1 in mitosis and cytoplasmic dynein function, Nat. Cell Biol. 2 (2000) 784-791. doi:10.1038/35041020.

[71] S. Sasaki, A. Shionoya, M. Ishida, M.J. Gambello, J. Yingling, A. Wynshaw-Boris, S. Hirotsune, A LIS1/NUDEL/cytoplasmic dynein heavy chain complex in the developing and adult nervous system, Neuron. 28 (2000) 681-696.

[72] R.J. McKenney, M. Vershinin, A. Kunwar, R.B. Vallee, S.P. Gross, LIS1 and NudE induce a persistent dynein force-producing state, Cell. 141 (2010) 304-314. doi:10.1016/j.cell.2010.02.035.

[73] K. Toropova, S. Zou, A.J. Roberts, W.B. Redwine, B.S. Goodman, S.L. Reck-Peterson, A.E. Leschziner, Lis1 regulates dynein by sterically blocking its mechanochemical cycle, eLife. 3 (2014). doi:10.7554/eLife.03372.

[74] J.-W. Tsai, K.H. Bremner, R.B. Vallee, Dual subcellular roles for LIS1 and dynein in radial neuronal migration in live brain tissue, Nat. Neurosci. 10 (2007) 970-979. doi:10.1038/nn1934.

[75] V.P. Efimov, N.R. Morris, The LIS1-related NUDF protein of Aspergillus nidulans interacts with the coiled-coil domain of the NUDE/RO11 protein, J. Cell Biol. 150 (2000) 681-688.

[76] M. Niethammer, D.S. Smith, R. Ayala, J. Peng, J. Ko, M.S. Lee, M. Morabito, L.H. Tsai, NUDEL is a novel Cdk5 substrate that associates with LIS1 and cytoplasmic dynein, Neuron. 28 (2000) 697-711.

[77] Y. Feng, C.A. Walsh, Mitotic spindle regulation by Nde1 controls cerebral cortical size, Neuron. 44 (2004) 279-293. doi:10.1016/j.neuron.2004.09.023.

[78] F.S. Alkuraya, X. Cai, C. Emery, G.H. Mochida, M.S. Al-Dosari, J.M. Felie, R.S. Hill, B.J. Barry, J.N. Partlow, G.G. Gascon, A Kentab, M. Jan, R. Shaheen, Y. Feng, C.A. Walsh, Human mutations in NDE1 cause extreme microcephaly with lissencephaly [corrected], Am. J. Hum. Genet. 88 (2011) 536-547. doi:10.1016/j.ajhg.2011.04.003.

[79] A. Guven, A. Gunduz, T.M. Bozoglu, C. Yalcinkaya, A. Tolun, Novel NDE1 homozygous mutation resulting in microhydranencephaly and not microlyssencephaly, Neurogenetics. 13 (2012) 189-194. doi:10.1007/s10048-012-0326-9.

[80] A.S. Pawlisz, C. Mutch, A. Wynshaw-Boris, A. Chenn, C.A. Walsh, Y. Feng, Lis1-Nde1-dependent neuronal fate control determines cerebral cortical size and lamination, Hum. Mol. Genet. 17 (2008) 2441-2455. doi:10.1093/hmg/ddn144.

[81] T. Shu, R. Ayala, M.-D. Nguyen, Z. Xie, J.G. Gleeson, L.-H. Tsai, Ndel1 operates in a common pathway with LIS1 and cytoplasmic dynein to regulate cortical neuronal positioning, Neuron. 44 (2004) 263-277. doi:10.1016/j.neuron.2004.09.030.

[82] A. Wynshaw-Boris, Lissencephaly and LIS1: insights into the molecular mechanisms of neuronal migration and development, Clin Genet. 72 (2007) 296-304. doi:10.1111/j.1399-0004.2007.00888.x.

[83] M. Yamada, S. Toba, Y. Yoshida, K. Haratani, D. Mori, Y. Yano, Y. Mimori-Kiyosue, T. Nakamura, K. Itoh, S. Fushiki, M. Setou, A. Wynshaw-Boris, T. Torisawa, Y.Y. Toyoshima, S. Hirotsune, LIS1 and NDEL1 coordinate the plus-end-directed transport of cytoplasmic dynein, EMBO J. 27 (2008) 2471-2483. doi:10.1038/emboj.2008.182.

[84] J. Li, W.-L. Lee, J.A. Cooper, NudEL targets dynein to microtubule ends through LIS1, Nat. Cell Biol. 7 (2005) 686-690. doi:10.1038/ncb1273.

[85] B. Sheeman, P. Carvalho, I. Sagot, J. Geiser, D. Kho, M.A. Hoyt, D. Pellman, Determinants of S. cerevisiae dynein localization and activation: implications for the mechanism of spindle positioning, Curr. Biol. CB. 13 (2003) 364-372.

[86] M.J. Egan, K. Tan, S.L. Reck-Peterson, Lis1 is an initiation factor for dynein-driven organelle transport, J. Cell Biol. 197 (2012) 971-982. doi:10.1083/jcb.201112101.

[87] V. des Portes, J.M. Pinard, P. Billuart, M.C. Vinet, A. Koulakoff, A. Carrié, A. Gelot, E. Dupuis, J. Motte, Y. Berwald-Netter, M. Catala, A. Kahn, C. Beldjord, J. Chelly, A novel CNS gene required for neuronal migration and involved in X-linked subcortical laminar heterotopia and lissencephaly syndrome, Cell. 92 (1998) 51-61.

[88] J.G. Gleeson, K.M. Allen, J.W. Fox, E.D. Lamperti, S. Berkovic, I. Scheffer, E.C. Cooper, W.B. Dobyns, S.R. Minnerath, M.E. Ross, C.A. Walsh, Doublecortin, a brain-specific gene mutated in human X-linked lissencephaly and double cortex syndrome, encodes a putative signaling protein, Cell. 92 (1998) 63-72.

[89] F. Francis, A. Koulakoff, D. Boucher, P. Chafey, B. Schaar, M.C. Vinet, G. Friocourt, N. McDonnell, O. Reiner, A. Kahn, S.K. McConnell, Y. Berwald-Netter, P. Denoulet, J. Chelly, Doublecortin is a developmentally regulated, microtubule-associated protein expressed in migrating and differentiating neurons, Neuron. 23 (1999) 247-256.

[90] J.G. Gleeson, P.T. Lin, L.A. Flanagan, C.A. Walsh, Doublecortin is a microtubule-associated protein and is expressed widely by migrating neurons, Neuron. 23 (1999) 257-271.

[91] T. Sapir, D. Horesh, M. Caspi, R. Atlas, H.A. Burgess, S.G. Wolf, F. Francis, J. Chelly, M. Elbaum, S. Pietrokovski, O. Reiner, Doublecortin mutations cluster in evolutionarily conserved functional domains, Hum. Mol. Genet. 9 (2000) 703-712.

[92] C. Kappeler, Y. Saillour, J.-P. Baudoin, F.P.D. Tuy, C. Alvarez, C. Houbron, P. Gaspar, G. Hamard, J. Chelly, C. Métin, F. Francis, Branching and nucleokinesis defects in migrating interneurons derived from doublecortin knockout mice, Hum. Mol. Genet. 15 (2006) 1387-1400. doi:10.1093/hmg/dd1062.

[93] H. Koizumi, T. Tanaka, J.G. Gleeson, Doublecortin-like kinase functions with doublecortin to mediate fiber tract decussation and neuronal migration, Neuron. 49 (2006) 55-66. doi:10.1016/j.neuron.2005.10.040.

[94] H. Koizumi, H. Higginbotham, T. Poon, T. Tanaka, B.C. Brinkman, J.G. Gleeson, Doublecortin maintains bipolar shape and nuclear translocation during migration in the adult forebrain, Nat. Neurosci. 9 (2006) 779-786. doi:10.1038/nn1704.

[95] A.E. Fry, T.D. Cushion, D.T. Pilz, The genetics of lissencephaly, Am. J. Med. Genet. C Semin. Med. Genet. 166C (2014) 198-210. doi:10.1002/ajmg.c.31402.

[96] P. Marcorelles, A. Laquerrière, C. Adde-Michel, S. Marret, P. Saugier-Veber, C. Beldjord, G. Friocourt, Evidence for tangential migration disturbances in human lissencephaly resulting from a defect in LIS1, DCX and ARX genes, Acta Neuropathol. (Berl.). 120 (2010) 503-515. doi:10.1007/s00401-010-0692-z. 
[97] K.R. Taylor, A.K. Holzer, J.F. Bazan, C.A. Walsh, J.G. Gleeson, Patient mutations in doublecortin define a repeated tubulinbinding domain, J. Biol. Chem. 275 (2000) 34442-34450. doi:10.1074/jbc.M007078200.

[98] N. Bahi-Buisson, I. Souville, F.J. Fourniol, A. Toussaint, C.A. Moores, A. Houdusse, J.Y. Lemaitre, K. Poirier, R. Khalaf-Nazzal, M. Hully, P.L. Leger, C. Elie, N. Boddaert, C. Beldjord, J. Chelly, F. Francis, SBH-LIS European Consortium, New insights into genotype-phenotype correlations for the doublecortin-related lissencephaly spectrum, Brain J. Neurol. 136 (2013) $223-244$. doi:10.1093/brain/aws323.

[99] N. Matsumoto, R.J. Leventer, J.A. Kuc, S.K. Mewborn, L.L. Dudlicek, M.B. Ramocki, D.T. Pilz, P.L. Mills, S. Das, M.E. Ross, D.H. Ledbetter, W.B. Dobyns, Mutation analysis of the DCX gene and genotype/phenotype correlation in subcortical band heterotopia, Eur. J. Hum. Genet. EJHG. 9 (2001) 5-12. doi:10.1038/sj.ejhg.5200548.

[100] J.G. Gleeson, S. Minnerath, R.I. Kuzniecky, W.B. Dobyns, I.D. Young, M.E. Ross, C.A. Walsh, Somatic and germline mosaic mutations in the doublecortin gene are associated with variable phenotypes, Am. J. Hum. Genet. 67 (2000) 574-581. doi:10.1086/303043.

[101] N. Bahi-Buisson, K. Poirier, N. Boddaert, Y. Saillour, L. Castelnau, N. Philip, G. Buyse, L. Villard, S. Joriot, S. Marret, M. Bourgeois, H. Van Esch, L. Lagae, J. Amiel, L. Hertz-Pannier, A. Roubertie, F. Rivier, J.M. Pinard, C. Beldjord, J. Chelly, Refinement of cortical dysgeneses spectrum associated with TUBA1A mutations, J. Med. Genet. 45 (2008) $647-653$. doi:10.1136/jmg.2008.058073.

[102] E.V. Haverfield, A.J. Whited, K.S. Petras, W.B. Dobyns, S. Das, Intragenic deletions and duplications of the LIS1 and DCX genes: a major disease-causing mechanism in lissencephaly and subcortical band heterotopia, Eur. J. Hum. Genet. EJHG. 17 (2009) $911-$ 918. doi:10.1038/ejhg.2008.213.

[103] G. Friocourt, A. Koulakoff, P. Chafey, D. Boucher, F. Fauchereau, J. Chelly, F. Francis, Doublecortin functions at the extremities of growing neuronal processes, Cereb. Cortex N. Y. N 1991. 13 (2003) 620-626.

[104] J.C. Corbo, T.A. Deuel, J.M. Long, P. LaPorte, E. Tsai, A. Wynshaw-Boris, C.A. Walsh, Doublecortin is required in mice for lamination of the hippocampus but not the neocortex, J. Neurosci. Off. J. Soc. Neurosci. 22 (2002) 7548-7557.

[105] C. Kappeler, M. Dhenain, F. Phan Dinh Tuy, Y. Saillour, S. Marty, C. Fallet-Bianco, I. Souville, E. Souil, J.-M. Pinard, G. Meyer, F. Encha-Razavi, A. Volk, C. Beldjord, J. Chelly, F. Francis, Magnetic resonance imaging and histological studies of corpus callosal and hippocampal abnormalities linked to doublecortin deficiency, J. Comp. Neurol. 500 (2007) $239-254$. doi:10.1002/cne.21170.

[106] M. Bazelot, J. Simonnet, C. Dinocourt, E. Bruel-Jungerman, R. Miles, D. Fricker, F. Francis, Cellular anatomy, physiology and epileptiform activity in the CA3 region of Dcx knockout mice: a neuronal lamination defect and its consequences, Eur. J. Neurosci. 35 (2012) 244-256. doi:10.1111/j.1460-9568.2011.07962.x.

[107] M. Nosten-Bertrand, C. Kappeler, C. Dinocourt, C. Denis, J. Germain, F. Phan Dinh Tuy, S. Verstraeten, C. Alvarez, C. Métin, J. Chelly, B. Giros, R. Miles, A. Depaulis, F. Francis, Epilepsy in Dcx knockout mice associated with discrete lamination defects and enhanced excitability in the hippocampus, PloS One. 3 (2008) e2473. doi:10.1371/journal.pone.0002473.

[108] T.A.S. Deuel, J.S. Liu, J.C. Corbo, S.-Y. Yoo, L.B. Rorke-Adams, C.A. Walsh, Genetic interactions between doublecortin and doublecortin-like kinase in neuronal migration and axon outgrowth, Neuron. 49 (2006) 41-53. doi:10.1016/j.neuron.2005.10.038.

[109] J. Bai, R.L. Ramos, J.B. Ackman, A.M. Thomas, R.V. Lee, J.J. LoTurco, RNAi reveals doublecortin is required for radial migration in rat neocortex, Nat. Neurosci. 6 (2003) 1277-1283. doi:10.1038/nn1153.

[110] T. Pramparo, Y.H. Youn, J. Yingling, S. Hirotsune, A. Wynshaw-Boris, Novel embryonic neuronal migration and proliferation defects in Dcx mutant mice are exacerbated by Lis1 reduction, J. Neurosci. Off. J. Soc. Neurosci. 30 (2010) 3002-3012. doi:10.1523/JNEUROSCI.4851-09.2010.

[111] T. Ohshima, J.M. Ward, C.G. Huh, G. Longenecker, null Veeranna, H.C. Pant, R.O. Brady, L.J. Martin, A.B. Kulkarni, Targeted disruption of the cyclin-dependent kinase 5 gene results in abnormal corticogenesis, neuronal pathology and perinatal death, Proc. Natl. Acad. Sci. U. S. A. 93 (1996) 11173-11178.

[112] G. Kerjan, H. Koizumi, E.B. Han, C.M. Dubé, S.N. Djakovic, G.N. Patrick, T.Z. Baram, S.F. Heinemann, J.G. Gleeson, Mice lacking doublecortin and doublecortin-like kinase 2 display altered hippocampal neuronal maturation and spontaneous seizures, Proc. Natl. Acad. Sci. U. S. A. 106 (2009) 6766-6771. doi:10.1073/pnas.0812687106.

[113] G. Friocourt, J.S. Liu, M. Antypa, S. Rakic, C.A. Walsh, J.G. Parnavelas, Both doublecortin and doublecortin-like kinase play a role in cortical interneuron migration, J. Neurosci. Off. J. Soc. Neurosci. 27 (2007) 3875-3883. doi:10.1523/JNEUROSCI.453006.2007.

[114] D.E. Lysko, M. Putt, J.A. Golden, SDF1 regulates leading process branching and speed of migrating interneurons, J. Neurosci. Off J. Soc. Neurosci. 31 (2011) 1739-1745. doi:10.1523/JNEUROSCI.3118-10.2011

[115] D.E. Lysko, M. Putt, J.A. Golden, SDF1 reduces interneuron leading process branching through dual regulation of actin and microtubules, J. Neurosci. Off. J. Soc. Neurosci. 34 (2014) 4941-4962. doi:10.1523/JNEUROSCI.4351-12.2014.

[116] T. Tanaka, F.F. Serneo, C. Higgins, M.J. Gambello, A. Wynshaw-Boris, J.G. Gleeson, Lis1 and doublecortin function with dynein to mediate coupling of the nucleus to the centrosome in neuronal migration, J. Cell Biol. 165 (2004) 709-721. doi:10.1083/jcb.200309025.

[117] R. Khalaf-Nazzal, M.A. Stouffer, R. Olaso, L. Muresan, A. Roumegous, V. Lavilla, W. Carpentier, I. Moutkine, S. Dumont, B Albaud, N. Cagnard, H. Roest Crollius, F. Francis, Early born neurons are abnormally positioned in the doublecortin knockout hippocampus, Hum. Mol. Genet. 26 (2017) 90-108. doi:10.1093/hmg/ddw370.

[118] C.C. Yap, L. Digilio, L. McMahon, M. Roszkowska, C.J. Bott, K. Kruczek, B. Winckler, Different Doublecortin (DCX) Patient Alleles Show Distinct Phenotypes in Cultured Neurons: EVIDENCE FOR DIVERGENT LOSS-OF-FUNCTION AND "OFFPATHWAY" CELLULAR MECHANISMS, J. Biol. Chem. 291 (2016) 26613-26626. doi:10.1074/jbc.M116.760777.

[119] T. Bienvenu, K. Poirier, G. Friocourt, N. Bahi, D. Beaumont, F. Fauchereau, L. Ben Jeema, R. Zemni, M.-C. Vinet, F. Francis, P. Couvert, M. Gomot, C. Moraine, H. van Bokhoven, V. Kalscheuer, S. Frints, J. Gecz, K. Ohzaki, H. Chaabouni, J.-P. Fryns, V. Desportes, C. Beldjord, J. Chelly, ARX, a novel Prd-class-homeobox gene highly expressed in the telencephalon, is mutated in Xlinked mental retardation, Hum. Mol. Genet. 11 (2002) 981-991.

[120] M. Kato, S. Das, K. Petras, K. Kitamura, K. Morohashi, D.N. Abuelo, M. Barr, D. Bonneau, A.F. Brady, N.J. Carpenter, K.L. Cipero, F. Frisone, T. Fukuda, R. Guerrini, E. Iida, M. Itoh, A.F. Lewanda, Y. Nanba, A. Oka, V.K. Proud, P. Saugier-Veber, S.L Schelley, A. Selicorni, R. Shaner, M. Silengo, F. Stewart, N. Sugiyama, J. Toyama, A. Toutain, A.L. Vargas, M. Yanazawa, E.H. Zackai, W.B. Dobyns, Mutations of ARX are associated with striking pleiotropy and consistent genotype-phenotype correlation, Hum. Mutat. 23 (2004) 147-159. doi:10.1002/humu.10310.

[121] T. Fullston, M. Finnis, A. Hackett, B. Hodgson, L. Brueton, G. Baynam, A. Norman, O. Reish, C. Shoubridge, J. Gecz, Screening and cell-based assessment of mutations in the Aristaless-related homeobox (ARX) gene, Clin. Genet. 80 (2011) 510-522. doi:10.1111/j.1399-0004.2011.01685.x.

[122] R. Wallerstein, R. Sugalski, L. Cohn, R. Jawetz, M. Friez, Expansion of the ARX spectrum, Clin. Neurol. Neurosurg. 110 (2008) 631-634. doi:10.1016/j.clineuro.2008.03.007. 
[123] R. Oegema, A. Maat-Kievit, M.H. Lequin, R. Schot, V.M.H. Nanninga-van den Neste, M.E. Doornbos, M.C.Y. de Wit, D.J. Halley, G.M.S. Mancini, Asymmetric polymicrogyria and periventricular nodular heterotopia due to mutation in ARX, Am. J. Med. Genet. A. 158A (2012) 1472-1476. doi:10.1002/ajmg.a.35365.

[124] E.H. Sherr, The ARX story (epilepsy, mental retardation, autism, and cerebral malformations): one gene leads to many phenotypes, Curr. Opin. Pediatr. 15 (2003) 567-571.

[125] K. Poirier, M. Eisermann, I. Caubel, A. Kaminska, S. Peudonnier, N. Boddaert, Y. Saillour, O. Dulac, I. Souville, C. Beldjord, K. Lascelles, P. Plouin, J. Chelly, N. Bahi-Buisson, Combination of infantile spasms, non-epileptic seizures and complex movement disorder: a new case of ARX-related epilepsy, Epilepsy Res. 80 (2008) 224-228. doi:10.1016/j.eplepsyres.2008.03.019.

[126] D. Bonneau, A. Toutain, A. Laquerrière, S. Marret, P. Saugier-Veber, M.-A. Barthez, S. Radi, V. Biran-Mucignat, D. Rodriguez A. Gélot, X-linked lissencephaly with absent corpus callosum and ambiguous genitalia (XLAG): clinical, magnetic resonance imaging, and neuropathological findings, Ann. Neurol. 51 (2002) 340-349.

[127] S. Okazaki, M. Ohsawa, I. Kuki, H. Kawawaki, T. Koriyama, S. Ri, H. Ichiba, E. Hai, T. Inoue, H. Nakamura, Y.-I. Goto, K. Tomiwa, T. Yamano, K. Kitamura, M. Itoh, Aristaless-related homeobox gene disruption leads to abnormal distribution of GABAergic interneurons in human neocortex: evidence based on a case of X-linked lissencephaly with abnormal genitalia (XLAG), Acta Neuropathol. (Berl.). 116 (2008) 453-462. doi:10.1007/s00401-008-0382-2.

[128] R. Miyata, M. Hayashi, K. Miyai, T. Akashi, M. Kato, J. Kohyama, Analysis of the hypothalamus in a case of X-linked lissencephaly with abnormal genitalia (XLAG), Brain Dev. 31 (2009) 456-460. doi:10.1016/j.braindev.2008.08.008

[129] C. Moey, S. Topper, M. Karn, A.K. Johnson, S. Das, J. Vidaurre, C. Shoubridge, Reinitiation of mRNA translation in a patient with X-linked infantile spasms with a protein-truncating variant in ARX, Eur. J. Hum. Genet. EJHG. 24 (2016) 681-689. doi:10.1038/ejhg.2015.176

[130] Y.Z. Ekșioğlu, A.W. Pong, M. Takeoka, A novel mutation in the aristaless domain of the ARX gene leads to Ohtahara syndrome, global developmental delay, and ambiguous genitalia in males and neuropsychiatric disorders in females, Epilepsia. 52 (2011) 984992. doi:10.1111/j.1528-1167.2011.02980.x.

[131] I. Marques, M.J. Sá, G. Soares, M. do C. Mota, C. Pinheiro, L. Aguiar, M. Amado, C. Soares, A. Calado, P. Dias, A.B. Sousa, A.M. Fortuna, R. Santos, K.B. Howell, M.M. Ryan, R.J. Leventer, R. Sachdev, R. Catford, K. Friend, T.R. Mattiske, C. Shoubridge, P. Jorge, Unraveling the pathogenesis of ARX polyalanine tract variants using a clinical and molecular interfacing approach, Mol. Genet. Genomic Med. 3 (2015) 203-214. doi:10.1002/mgg3.133.

[132] O. Marín, J.L.R. Rubenstein, Cell migration in the forebrain, Annu. Rev. Neurosci. 26 (2003) 441-483. doi:10.1146/annurev.neuro.26.041002.131058

[133] O. Marín, Interneuron dysfunction in psychiatric disorders, Nat. Rev. Neurosci. 13 (2012) 107-120. doi:10.1038/nrn3155

[134] M. Kato, W.B. Dobyns, X-linked lissencephaly with abnormal genitalia as a tangential migration disorder causing intractable epilepsy: proposal for a new term, “interneuronopathy,” J. Child Neurol. 20 (2005) 392-397. doi:10.1177/08830738050200042001.

[135] M. Pancoast, W. Dobyns, J.A. Golden, Interneuron deficits in patients with the Miller-Dieker syndrome, Acta Neuropathol. (Berl.) 109 (2005) 400-404. doi:10.1007/s00401-004-0979-z.

[136] C. Fallet-Bianco, L. Loeuillet, K. Poirier, P. Loget, F. Chapon, L. Pasquier, Y. Saillour, C. Beldjord, J. Chelly, F. Francis, Neuropathological phenotype of a distinct form of lissencephaly associated with mutations in TUBA1A, Brain J. Neurol. 131 (2008) 2304-2320. doi:10.1093/brain/awn155.

[137] G. Cho, Y. Lim, I.-T. Cho, J.C. Simonet, J.A. Golden, Arx together with FoxA2, regulates Shh floor plate expression, Dev. Biol 393 (2014) 137-148. doi:10.1016/j.ydbio.2014.06.012

[138] C. Shoubridge, M.H. Tan, T. Fullston, D. Cloosterman, D. Coman, G. McGillivray, G.M. Mancini, T. Kleefstra, J. Gécz, Mutations in the nuclear localization sequence of the Aristaless related homeobox; sequestration of mutant ARX with IPO13 disrupts normal subcellular distribution of the transcription factor and retards cell division, PathoGenetics. 3 (2010) 1. doi:10.1186/1755-8417-3-1.

[139] P. Collombat, A. Mansouri, J. Hecksher-Sorensen, P. Serup, J. Krull, G. Gradwohl, P. Gruss, Opposing actions of Arx and Pax4 in endocrine pancreas development, Genes Dev. 17 (2003) 2591-2603. doi:10.1101/gad.269003.

[140] K. Kitamura, M. Yanazawa, N. Sugiyama, H. Miura, A. Iizuka-Kogo, M. Kusaka, K. Omichi, R. Suzuki, Y. Kato-Fukui, K. Kamiirisa, M. Matsuo, S. Kamijo, M. Kasahara, H. Yoshioka, T. Ogata, T. Fukuda, I. Kondo, M. Kato, W.B. Dobyns, M. Yokoyama, K. Morohashi, Mutation of ARX causes abnormal development of forebrain and testes in mice and X-linked lissencephaly with abnormal genitalia in humans, Nat. Genet. 32 (2002) 359-369. doi:10.1038/ng1009.

[141] E. Colombo, P. Collombat, G. Colasante, M. Bianchi, J. Long, A. Mansouri, J.L.R. Rubenstein, V. Broccoli, Inactivation of Arx, the murine ortholog of the X-linked lissencephaly with ambiguous genitalia gene, leads to severe disorganization of the ventral telencephalon with impaired neuronal migration and differentiation, J. Neurosci. Off. J. Soc. Neurosci. 27 (2007) $4786-4798$. doi:10.1523/JNEUROSCI.0417-07.2007.

[142] J.C. Simonet, C.N. Sunnen, J. Wu, J.A. Golden, E.D. Marsh, Conditional Loss of Arx From the Developing Dorsal Telencephalon Results in Behavioral Phenotypes Resembling Mild Human ARX Mutations, Cereb. Cortex N. Y. N 1991. 25 (2015) 2939-2950. doi:10.1093/cercor/bhu090.

[143] G. Colasante, J.C. Simonet, R. Calogero, S. Crispi, A. Sessa, G. Cho, J.A. Golden, V. Broccoli, ARX regulates cortical intermediate progenitor cell expansion and upper layer neuron formation through repression of Cdkn1c, Cereb. Cortex N. Y. N 1991. 25 (2015) 322-335. doi:10.1093/cercor/bht222.

[144] E.D. Marsh, M.P. Nasrallah, C. Walsh, K.A. Murray, C. Nicole Sunnen, A. McCoy, J.A. Golden, Developmental interneuron subtype deficits after targeted loss of Arx, BMC Neurosci. 17 (2016) 35. doi:10.1186/s12868-016-0265-8.

[145] E. Marsh, C. Fulp, E. Gomez, I. Nasrallah, J. Minarcik, J. Sudi, S.L. Christian, G. Mancini, P. Labosky, W. Dobyns, A. BrooksKayal, J.A. Golden, Targeted loss of Arx results in a developmental epilepsy mouse model and recapitulates the human phenotype in heterozygous females, Brain J. Neurol. 132 (2009) 1563-1576. doi:10.1093/brain/awp107.

[146] F. Tissir, A.M. Goffinet, Reelin and brain development, Nat. Rev. Neurosci. 4 (2003) 496-505. doi:10.1038/nrn1113.

[147] A.M. Goffinet, The reeler gene: a clue to brain development and evolution, Int. J. Dev. Biol. 36 (1992) $101-107$.

[148] G. D'Arcangelo, G.G. Miao, S.C. Chen, H.D. Soares, J.I. Morgan, T. Curran, A protein related to extracellular matrix proteins deleted in the mouse mutant reeler, Nature. 374 (1995) 719-723. doi:10.1038/374719a0.

[149] V. Borrell, J.A. Del Río, S. Alcántara, M. Derer, A. Martínez, G. D’Arcangelo, K. Nakajima, K. Mikoshiba, P. Derer, T. Curran, E. Soriano, Reelin regulates the development and synaptogenesis of the layer-specific entorhino-hippocampal connections, J. Neurosci. Off. J. Soc. Neurosci. 19 (1999) 1345-1358.

[150] S.E. Hong, Y.Y. Shugart, D.T. Huang, S.A. Shahwan, P.E. Grant, J.O. Hourihane, N.D. Martin, C.A. Walsh, Autosomal recessive lissencephaly with cerebellar hypoplasia is associated with human RELN mutations, Nat. Genet. 26 (2000) 93-96. doi:10.1038/79246.

[151] M.E. Ross, K. Swanson, W.B. Dobyns, Lissencephaly with cerebellar hypoplasia (LCH): a heterogeneous group of cortical malformations, Neuropediatrics. 32 (2001) 256-263. doi:10.1055/s-2001-19120. 
[152] D.A. Keays, G. Tian, K. Poirier, G.-J. Huang, C. Siebold, J. Cleak, P.L. Oliver, M. Fray, R.J. Harvey, Z. Molnár, M.C. Piñon, N. Dear, W. Valdar, S.D.M. Brown, K.E. Davies, J.N.P. Rawlins, N.J. Cowan, P. Nolan, J. Chelly, J. Flint, Mutations in alpha-tubulin cause abnormal neuronal migration in mice and lissencephaly in humans, Cell. 128 (2007) 45-57. doi:10.1016/j.cell.2006.12.017.

[153] X.H. Jaglin, K. Poirier, Y. Saillour, E. Buhler, G. Tian, N. Bahi-Buisson, C. Fallet-Bianco, F. Phan-Dinh-Tuy, X.P. Kong, P. Bomont, L. Castelnau-Ptakhine, S. Odent, P. Loget, M. Kossorotoff, I. Snoeck, G. Plessis, P. Parent, C. Beldjord, C. Cardoso, A. Represa, J. Flint, D.A. Keays, N.J. Cowan, J. Chelly, Mutations in the beta-tubulin gene TUBB2B result in asymmetrical polymicrogyria, Nat. Genet. 41 (2009) 746-752. doi:10.1038/ng.380.

[154] D. Magen, A. Ofir, L. Berger, D. Goldsher, A. Eran, N. Katib, N. Katib, Y. Nijem, E. Vlodavsky, S. Tzur, S. Zur, D.M. Behar, Y. Fellig, H. Mandel, Autosomal recessive lissencephaly with cerebellar hypoplasia is associated with a loss-of-function mutation in CDK5, Hum. Genet. 134 (2015) 305-314. doi:10.1007/s00439-014-1522-5.

[155] K.M. Boycott, S. Flavelle, A. Bureau, H.C. Glass, T.M. Fujiwara, E. Wirrell, K. Davey, A.E. Chudley, J.N. Scott, D.R. McLeod, J.S. Parboosingh, Homozygous deletion of the very low density lipoprotein receptor gene causes autosomal recessive cerebellar hypoplasia with cerebral gyral simplification, Am. J. Hum. Genet. 77 (2005) 477-483. doi:10.1086/4444400.

[156] S. Valence, C. Garel, M. Barth, A. Toutain, C. Paris, D. Amsallem, M.-A. Barthez, M. Mayer, D. Rodriguez, L. Burglen, RELN and VLDLR mutations underlie two distinguishable clinico-radiological phenotypes, Clin. Genet. 90 (2016) 545-549. doi: $10.1111 /$ cge. 12779

[157] L. Schlotawa, A. Hotz, C. Zeschnigk, B. Hartmann, J. Gärtner, D. Morris-Rosendahl, Cerebellar ataxia, mental retardation and dysequilibrium syndrome 1 (CAMRQ1) caused by an unusual constellation of VLDLR mutation, J. Neurol. 260 (2013) 1678-1680. doi:10.1007/s00415-013-6941-z.

[158] V. de Bergeyck, K. Nakajima, C. Lambert de Rouvroit, B. Naerhuyzen, A.M. Goffinet, T. Miyata, M. Ogawa, K. Mikoshiba, A truncated Reelin protein is produced but not secreted in the "Orleans" reeler mutation (Reln[rl-Orl]), Brain Res. Mol. Brain Res. 50 (1997) 85-90.

[159] S. Ha, P.P. Tripathi, A.B. Mihalas, R.F. Hevner, D.R. Beier, C-Terminal Region Truncation of RELN Disrupts an Interaction with VLDLR, Causing Abnormal Development of the Cerebral Cortex and Hippocampus, J. Neurosci. Off. J. Soc. Neurosci. 37 (2017) 960-971. doi:10.1523/JNEUROSCI.1826-16.2017.

[160] H.H. Bock, P. May, Canonical and Non-canonical Reelin Signaling, Front. Cell. Neurosci. 10 (2016) 166 doi:10.3389/fncel.2016.00166

[161] G.H. Lee, Z. Chhangawala, S. von Daake, J.N. Savas, J.R. Yates, D. Comoletti, G. D’Arcangelo, Reelin induces Erk1/2 signaling in cortical neurons through a non-canonical pathway, J. Biol. Chem. 289 (2014) 20307-20317. doi:10.1074/jbc.M114.576249.

[162] S.J. Franco, I. Martinez-Garay, C. Gil-Sanz, S.R. Harkins-Perry, U. Müller, Reelin regulates cadherin function via Dab1/Rap1 to control neuronal migration and lamination in the neocortex, Neuron. 69 (2011) 482-497. doi:10.1016/j.neuron.2011.01.003.

[163] G. D’Arcangelo, R. Homayouni, L. Keshvara, D.S. Rice, M. Sheldon, T. Curran, Reelin is a ligand for lipoprotein receptors, Neuron. 24 (1999) 471-479.

[164] T. Hiesberger, M. Trommsdorff, B.W. Howell, A. Goffinet, M.C. Mumby, J.A. Cooper, J. Herz, Direct binding of Reelin to VLDL receptor and ApoE receptor 2 induces tyrosine phosphorylation of disabled-1 and modulates tau phosphorylation, Neuron. 24 (1999) 481-489.

[165] A. Sentürk, S. Pfennig, A. Weiss, K. Burk, A. Acker-Palmer, Ephrin Bs are essential components of the Reelin pathway to regulate neuronal migration, Nature. 472 (2011) 356-360. doi:10.1038/nature09874

[166] S. He, Z. Li, S. Ge, Y.-C. Yu, S.-H. Shi, Inside-Out Radial Migration Facilitates Lineage-Dependent Neocortical Microcircuit Assembly, Neuron. 86 (2015) 1159-1166. doi:10.1016/j.neuron.2015.05.002.

[167] A.C. Horton, M.D. Ehlers, Neuronal polarity and trafficking, Neuron. 40 (2003) 277-295

[168] A.B. Jaffe, A. Hall, Rho GTPases: biochemistry and biology, Annu. Rev. Cell Dev. Biol. 21 (2005) 247-269. doi:10.1146/annurev.cellbio.21.020604.150721.

[169] J. Leemhuis, E. Bouché, M. Frotscher, F. Henle, L. Hein, J. Herz, D.K. Meyer, M. Pichler, G. Roth, C. Schwan, H.H. Bock, Reelin signals through apolipoprotein E receptor 2 and $\mathrm{Cdc} 42$ to increase growth cone motility and filopodia formation, J. Neurosci. Off. J. Soc. Neurosci. 30 (2010) 14759-14772. doi:10.1523/JNEUROSCI.4036-10.2010.

[170] G.M. Dillon, W.A. Tyler, K.C. Omuro, J. Kambouris, C. Tyminski, S. Henry, T.F. Haydar, U. Beffert, A. Ho, CLASP2 Links Reelin to the Cytoskeleton during Neocortical Development, Neuron. 93 (2017) 1344-1358.e5. doi:10.1016/j.neuron.2017.02.039.

[171] S.T. Baek, B. Copeland, E.-J. Yun, S.-K. Kwon, A. Guemez-Gamboa, A.E. Schaffer, S. Kim, H.-C. Kang, S. Song, G.W. Mathern, J.G. Gleeson, An AKT3-FOXG1-reelin network underlies defective migration in human focal malformations of cortical development, Nat. Med. 21 (2015) 1445-1454. doi:10.1038/nm.3982.

[172] F. Kortüm, S. Das, M. Flindt, D.J. Morris-Rosendahl, I. Stefanova, A. Goldstein, D. Horn, E. Klopocki, G. Kluger, P. Martin, A. Rauch, A. Roumer, S. Saitta, L.E. Walsh, D. Wieczorek, G. Uyanik, K. Kutsche, W.B. Dobyns, The core FOXG1 syndrome phenotype consists of postnatal microcephaly, severe mental retardation, absent language, dyskinesia, and corpus callosum hypogenesis, J. Med. Genet. 48 (2011) 396-406. doi:10.1136/jmg.2010.087528.

[173] X.H. Jaglin, J. Chelly, Tubulin-related cortical dysgeneses: microtubule dysfunction underlying neuronal migration defects, Trends Genet. TIG. 25 (2009) 555-566. doi:10.1016/j.tig.2009.10.003.

[174] T.D. Cushion, A.R. Paciorkowski, D.T. Pilz, J.G.L. Mullins, L.E. Seltzer, R.W. Marion, E. Tuttle, D. Ghoneim, S.L. Christian, S.K. Chung, M.I. Rees, W.B. Dobyns, De novo mutations in the beta-tubulin gene TUBB2A cause simplified gyral patterning and infantile-onset epilepsy, Am. J. Hum. Genet. 94 (2014) 634-641. doi:10.1016/j.ajhg.2014.03.009.

[175] N. Bahi-Buisson, M. Cavallin, Tubulinopathies Overview, in: R.A. Pagon, M.P. Adam, H.H. Ardinger, S.E. Wallace, A. Amemiya, L.J. Bean, T.D. Bird, N. Ledbetter, H.C. Mefford, R.J. Smith, K. Stephens (Eds.), GeneReviews(®), University of Washington, Seattle, Seattle (WA), 1993. http://www.ncbi.nlm.nih.gov/books/NBK350554/ (accessed May 13, 2017).

[176] T.D. Cushion, W.B. Dobyns, J.G.L. Mullins, N. Stoodley, S.-K. Chung, A.E. Fry, U. Hehr, R. Gunny, A.S. Aylsworth, P. Prabhakar, G. Uyanik, J. Rankin, M.I. Rees, D.T. Pilz, Overlapping cortical malformations and mutations in TUBB2B and TUBA1A, Brain J. Neurol. 136 (2013) 536-548. doi:10.1093/brain/aws338.

[177] K. Poirier, D.A. Keays, F. Francis, Y. Saillour, N. Bahi, S. Manouvrier, C. Fallet-Bianco, L. Pasquier, A. Toutain, F.P.D. Tuy, T Bienvenu, S. Joriot, S. Odent, D. Ville, I. Desguerre, A. Goldenberg, M.-L. Moutard, J.-P. Fryns, H. van Esch, R.J. Harvey, C. Siebold, J. Flint, C. Beldjord, J. Chelly, Large spectrum of lissencephaly and pachygyria phenotypes resulting from de novo missense mutations in tubulin alpha 1A (TUBA1A), Hum. Mutat. 28 (2007) 1055-1064. doi:10.1002/humu.20572.

[178] D.J. Morris-Rosendahl, J. Najm, A.M.A. Lachmeijer, L. Sztriha, M. Martins, A. Kuechler, V. Haug, C. Zeschnigk, P. Martin, M. Santos, C. Vasconcelos, H. Omran, U. Kraus, M.S. Van der Knaap, G. Schuierer, K. Kutsche, G. Uyanik, Refining the phenotype of alpha-1a Tubulin (TUBA1A) mutation in patients with classical lissencephaly, Clin. Genet. 74 (2008) 425-433. doi:10.1111/j.1399-0004.2008.01093.x. 
[179] R.A. Kumar, D.T. Pilz, T.D. Babatz, T.D. Cushion, K. Harvey, M. Topf, L. Yates, S. Robb, G. Uyanik, G.M.S. Mancini, M.I. Rees, R.J. Harvey, W.B. Dobyns, TUBA1A mutations cause wide spectrum lissencephaly (smooth brain) and suggest that multiple neuronal migration pathways converge on alpha tubulins, Hum. Mol. Genet. 19 (2010) 2817-2827. doi:10.1093/hmg/ddq182.

[180] R. Guerrini, D. Mei, D.M. Cordelli, D. Pucatti, E. Franzoni, E. Parrini, Symmetric polymicrogyria and pachygyria associated with TUBB2B gene mutations, Eur. J. Hum. Genet. EJHG. 20 (2012) 995-998. doi:10.1038/ejhg.2012.21.

[181] A. Laquerriere, M. Gonzales, Y. Saillour, M. Cavallin, N. Joyē, C. Quēlin, L. Bidat, M. Dommergues, G. Plessis, F. Encha-Razavi, J. Chelly, N. Bahi-Buisson, K. Poirier, De novo TUBB2B mutation causes fetal akinesia deformation sequence with microlissencephaly: An unusual presentation of tubulinopathy, Eur. J. Med. Genet. 59 (2016) 249-256. doi:10.1016/j.ejmg.2015.12.007.

[182] K. Poirier, Y. Saillour, N. Bahi-Buisson, X.H. Jaglin, C. Fallet-Bianco, R. Nabbout, L. Castelnau-Ptakhine, A. Roubertie, T. AttieBitach, I. Desguerre, D. Genevieve, C. Barnerias, B. Keren, N. Lebrun, N. Boddaert, F. Encha-Razavi, J. Chelly, Mutations in the neuronal $\beta$-tubulin subunit TUBB3 result in malformation of cortical development and neuronal migration defects, Hum. Mol. Genet. 19 (2010) 4462-4473. doi:10.1093/hmg/ddq377.

[183] Y. Saillour, L. Broix, E. Bruel-Jungerman, N. Lebrun, G. Muraca, J. Rucci, K. Poirier, R. Belvindrah, F. Francis, J. Chelly, Beta tubulin isoforms are not interchangeable for rescuing impaired radial migration due to Tubb3 knockdown, Hum. Mol. Genet. 23 (2014) 1516-1526. doi:10.1093/hmg/ddt538.

[184] M. Breuss, J.I.-T. Heng, K. Poirier, G. Tian, X.H. Jaglin, Z. Qu, A. Braun, T. Gstrein, L. Ngo, M. Haas, N. Bahi-Buisson, M.-L. Moutard, S. Passemard, A. Verloes, P. Gressens, Y. Xie, K.J.H. Robson, D.S. Rani, K. Thangaraj, T. Clausen, J. Chelly, N.J. Cowan, D.A. Keays, Mutations in the $\beta$-tubulin gene TUBB5 cause microcephaly with structural brain abnormalities, Cell Rep. 2 (2012) 1554-1562. doi:10.1016/j.celrep.2012.11.017.

[185] R.W. Stottmann, M. Donlin, A. Hafner, A. Bernard, D.A. Sinclair, D.R. Beier, A mutation in Tubb2b, a human polymicrogyria gene, leads to lethality and abnormal cortical development in the mouse, Hum. Mol. Genet. 22 (2013) 4053-4063. doi: $10.1093 / \mathrm{hmg} / \mathrm{ddt} 255$.

[186] M. Breuss, T. Fritz, T. Gstrein, K. Chan, L. Ushakova, N. Yu, F.W. Vonberg, B. Werner, U. Elling, D.A. Keays, Mutations in the murine homologue of TUBB5 cause microcephaly by perturbing cell cycle progression and inducing p53-associated apoptosis, Dev. Camb. Engl. 143 (2016) 1126-1133. doi:10.1242/dev.131516.

[187] A. Yuba-Kubo, A. Kubo, M. Hata, S. Tsukita, Gene knockout analysis of two gamma-tubulin isoforms in mice, Dev. Biol. 282 (2005) 361-373. doi:10.1016/j.ydbio.2005.03.031.

[188] V.L. Sheen, Filamin A mediated Big2 dependent endocytosis: From apical abscission to periventricular heterotopia, Tissue Barriers. 2 (2014) e29431. doi:10.4161/tisb.29431

[189] L. Broix, H. Jagline, E. L Ivanova, S. Schmucker, N. Drouot, J. Clayton-Smith, A.T. Pagnamenta, K.A. Metcalfe, B. Isidor, U.W. Louvier, A. Poduri, J.C. Taylor, P. Tilly, K. Poirier, Y. Saillour, N. Lebrun, T. Stemmelen, G. Rudolf, G. Muraca, B. Saintpierre, A. Elmorjani, Deciphering Developmental Disorders study, M. Moïse, N.B. Weirauch, R. Guerrini, A. Boland, R. Olaso, C. Masson, R. Tripathy, D. Keays, C. Beldjord, L. Nguyen, J. Godin, U. Kini, P. Nischké, J.-F. Deleuze, N. Bahi-Buisson, I. Sumara, M.-V. Hinckelmann, J. Chelly, Mutations in the HECT domain of NEDD4L lead to AKT-mTOR pathway deregulation and cause periventricular nodular heterotopia, Nat. Genet. 48 (2016) 1349-1358. doi:10.1038/ng.3676.

[190] E. Parrini, A. Ramazzotti, W.B. Dobyns, D. Mei, F. Moro, P. Veggiotti, C. Marini, E.H. Brilstra, B. Dalla Bernardina, L. Goodwin, A. Bodell, M.C. Jones, M. Nangeroni, S. Palmeri, E. Said, J.W. Sander, P. Striano, Y. Takahashi, L. Van Maldergem, G. Leonardi, M. Wright, C.A. Walsh, R. Guerrini, Periventricular heterotopia: phenotypic heterogeneity and correlation with Filamin A mutations, Brain J. Neurol. 129 (2006) 1892-1906. doi:10.1093/brain/awl125.

[191] V.L. Sheen, M. Topçu, S. Berkovic, D. Yalnizoglu, I. Blatt, A. Bodell, R.S. Hill, V.S. Ganesh, T.J. Cherry, Y.Y. Shugart, C.A. Walsh, Autosomal recessive form of periventricular heterotopia, Neurology. 60 (2003) 1108-1112.

[192] J.W. Fox, E.D. Lamperti, Y.Z. Ekşioğlu, S.E. Hong, Y. Feng, D.A. Graham, I.E. Scheffer, W.B. Dobyns, B.A. Hirsch, R.A. Radtke, S.F. Berkovic, P.R. Huttenlocher, C.A. Walsh, Mutations in filamin 1 prevent migration of cerebral cortical neurons in human periventricular heterotopia, Neuron. 21 (1998) 1315-1325.

[193] V.L. Sheen, V.S. Ganesh, M. Topcu, G. Sebire, A. Bodell, R.S. Hill, P.E. Grant, Y.Y. Shugart, J. Imitola, S.J. Khoury, R. Guerrini, C.A. Walsh, Mutations in ARFGEF2 implicate vesicle trafficking in neural progenitor proliferation and migration in the human cerebral cortex, Nat. Genet. 36 (2004) 69-76. doi:10.1038/ng1276.

[194] R.J. Ferland, L.F. Batiz, J. Neal, G. Lian, E. Bundock, J. Lu, Y.-C. Hsiao, R. Diamond, D. Mei, A.H. Banham, P.J. Brown, C.R. Vanderburg, J. Joseph, J.L. Hecht, R. Folkerth, R. Guerrini, C.A. Walsh, E.M. Rodriguez, V.L. Sheen, Disruption of neural progenitors along the ventricular and subventricular zones in periventricular heterotopia, Hum. Mol. Genet. 18 (2009) 497-516. doi: $10.1093 / \mathrm{hmg} / \mathrm{ddn} 377$

[195] S. Cappello, M.J. Gray, C. Badouel, S. Lange, M. Einsiedler, M. Srour, D. Chitayat, F.F. Hamdan, Z.A. Jenkins, T. Morgan, N. Preitner, T. Uster, J. Thomas, P. Shannon, V. Morrison, N. Di Donato, L. Van Maldergem, T. Neuhann, R. Newbury-Ecob, M. Swinkells, P. Terhal, L.C. Wilson, P.J.G. Zwijnenburg, A.J. Sutherland-Smith, M.A. Black, D. Markie, J.L. Michaud, M.A. Simpson, S. Mansour, H. McNeill, M. Götz, S.P. Robertson, Mutations in genes encoding the cadherin receptor-ligand pair DCHS1 and FAT4 disrupt cerebral cortical development, Nat. Genet. 45 (2013) 1300-1308. doi:10.1038/ng.2765.

[196] N. Hamada, Y. Negishi, M. Mizuno, F. Miya, A. Hattori, N. Okamoto, M. Kato, T. Tsunoda, M. Yamasaki, Y. Kanemura, K. Kosaki, H. Tabata, S. Saitoh, K.-I. Nagata, Role of a heterotrimeric G-protein, Gi2, in the corticogenesis: possible involvement in periventricular nodular heterotopia and intellectual disability, J. Neurochem. 140 (2017) 82-95. doi:10.1111/jnc.13878.

[197] V. Conti, A. Carabalona, E. Pallesi-Pocachard, E. Parrini, R.J. Leventer, E. Buhler, G. McGillivray, F.J. Michel, P. Striano, D. Mei, F. Watrin, S. Lise, A.T. Pagnamenta, J.C. Taylor, U. Kini, J. Clayton-Smith, F. Novara, O. Zuffardi, W.B. Dobyns, I.E. Scheffer, S.P. Robertson, S.F. Berkovic, A. Represa, D.A. Keays, C. Cardoso, R. Guerrini, Periventricular heterotopia in 6q terminal deletion syndrome: role of the C6orf70 gene, Brain J. Neurol. 136 (2013) 3378-3394. doi:10.1093/brain/awt249.

[198] Y. Feng, M.H. Chen, I.P. Moskowitz, A.M. Mendonza, L. Vidali, F. Nakamura, D.J. Kwiatkowski, C.A. Walsh, Filamin A (FLNA) is required for cell-cell contact in vascular development and cardiac morphogenesis, Proc. Natl. Acad. Sci. U. S. A. 103 (2006) 19836-19841. doi:10.1073/pnas.0609628104.

[199] S. Bizzotto, F. Francis, Morphological and functional aspects of progenitors perturbed in cortical malformations, Front. Cell. Neurosci. 9 (2015) 30. doi:10.3389/fncel.2015.00030.

[200] S.L. Houlihan, A.A. Lanctot, Y. Guo, Y. Feng, Upregulation of neurovascular communication through filamin abrogation promotes ectopic periventricular neurogenesis, eLife. 5 (2016). doi:10.7554/eLife.17823.

[201] M.R. Sarkisian, C.M. Bartley, H. Chi, F. Nakamura, K. Hashimoto-Torii, M. Torii, R.A. Flavell, P. Rakic, MEKK4 signaling regulates filamin expression and neuronal migration, Neuron. 52 (2006) 789-801. doi:10.1016/j.neuron.2006.10.024.

[202] M. Adams, R.J. Simms, Z. Abdelhamed, H.R. Dawe, K. Szymanska, C.V. Logan, G. Wheway, E. Pitt, K. Gull, M.A. Knowles, E. Blair, S.H. Cross, J.A. Sayer, C.A. Johnson, A meckelin-filamin A interaction mediates ciliogenesis, Hum. Mol. Genet. 21 (2012) 1272-1286. doi:10.1093/hmg/ddr557. 
[203] A.W. Hart, J.E. Morgan, J. Schneider, K. West, L. McKie, S. Bhattacharya, I.J. Jackson, S.H. Cross, Cardiac malformations and midline skeletal defects in mice lacking filamin A, Hum. Mol. Genet. 15 (2006) 2457-2467. doi:10.1093/hmg/ddl168.

[204] J.M. Gerdes, Y. Liu, N.A. Zaghloul, C.C. Leitch, S.S. Lawson, M. Kato, P.A. Beachy, P.L. Beales, G.N. DeMartino, S. Fisher, J.L. Badano, N. Katsanis, Disruption of the basal body compromises proteasomal function and perturbs intracellular Wnt response, Nat. Genet. 39 (2007) 1350-1360. doi:10.1038/ng.2007.12.

[205] P. Grzmil, Z. Enkhbaatar, B. Gundsambuu, O. Oidovsambuu, S. Yalcin, S. Wolf, W. Engel, J. Neesen, Early embryonic lethality in gene trap mice with disruption of the Arfgef2 gene, Int. J. Dev. Biol. 54 (2010) 1259-1266. doi:10.1387/ijdb.092959pg.

[206] M.S. van der Knaap, L.M. Smit, P.G. Barth, C.E. Catsman-Berrevoets, O.F. Brouwer, J.H. Begeer, I.F. de Coo, J. Valk, Magnetic resonance imaging in classification of congenital muscular dystrophies with brain abnormalities, Ann. Neurol. 42 (1997) 50-59. doi:10.1002/ana.410420110

[207] E.C. Olson, C.A. Walsh, Smooth, rough and upside-down neocortical development, Curr. Opin. Genet. Dev. 12 (2002) 320-327.

[208] T. Geis, K. Marquard, T. Rödl, C. Reihle, S. Schirmer, T. von Kalle, A. Bornemann, U. Hehr, M. Blankenburg, Homozygous dystroglycan mutation associated with a novel muscle-eye-brain disease-like phenotype with multicystic leucodystrophy, Neurogenetics. 14 (2013) 205-213. doi:10.1007/s10048-013-0374-9.

[209] Y. Hara, B. Balci-Hayta, T. Yoshida-Moriguchi, M. Kanagawa, D. Beltrán-Valero de Bernabé, H. Gündeşli, T. Willer, J.S. Satz, R.W. Crawford, S.J. Burden, S. Kunz, M.B.A. Oldstone, A. Accardi, B. Talim, F. Muntoni, H. Topaloğlu, P. Dinçer, K.P. Campbell, A dystroglycan mutation associated with limb-girdle muscular dystrophy, N. Engl. J. Med. 364 (2011) 939-946. doi:10.1056/NEJMoa1006939.

[210] H.S. Booler, J.L. Williams, M. Hopkinson, S.C. Brown, Degree of Cajal-Retzius Cell Mislocalization Correlates with the Severity of Structural Brain Defects in Mouse Models of Dystroglycanopathy, Brain Pathol. Zurich Switz. 26 (2016) 465-478. doi:10.1111/bpa.12306.

[211] M.D. Henry, K.P. Campbell, A role for dystroglycan in basement membrane assembly, Cell. 95 (1998) 859-870

[212] K. Kobayashi, Y. Nakahori, M. Miyake, K. Matsumura, E. Kondo-lida, Y. Nomura, M. Segawa, M. Yoshioka, K. Saito, M. Osawa, K. Hamano, Y. Sakakihara, I. Nonaka, Y. Nakagome, I. Kanazawa, Y. Nakamura, K. Tokunaga, T. Toda, An ancient retrotransposal insertion causes Fukuyama-type congenital muscular dystrophy, Nature. 394 (1998) 388-392. doi:10.1038/28653.

[213] A. Yoshida, K. Kobayashi, H. Manya, K. Taniguchi, H. Kano, M. Mizuno, T. Inazu, H. Mitsuhashi, S. Takahashi, M. Takeuchi, R. Herrmann, V. Straub, B. Talim, T. Voit, H. Topaloglu, T. Toda, T. Endo, Muscular dystrophy and neuronal migration disorder caused by mutations in a glycosyltransferase, POMGnT1, Dev. Cell. 1 (2001) 717-724.

[214] D.E. Michele, R. Barresi, M. Kanagawa, F. Saito, R.D. Cohn, J.S. Satz, J. Dollar, I. Nishino, R.I. Kelley, H. Somer, V. Straub, K.D. Mathews, S.A. Moore, K.P. Campbell, Post-translational disruption of dystroglycan-ligand interactions in congenital muscular dystrophies, Nature. 418 (2002) 417-422. doi:10.1038/nature00837.

[215] J. Jerber, M.S. Zaki, J.Y. Al-Aama, R.O. Rosti, T. Ben-Omran, E. Dikoglu, J.L. Silhavy, C. Caglar, D. Musaev, B. Albrecht, K.P. Campbell, T. Willer, M. Almuriekhi, A.O. Çağlayan, J. Vajsar, K. Bilgüvar, G. Ogur, R. Abou Jamra, M. Günel, J.G. Gleeson, Biallelic Mutations in TMTC3, Encoding a Transmembrane and TPR-Containing Protein, Lead to Cobblestone Lissencephaly, Am. J. Hum. Genet. 99 (2016) 1181-1189. doi:10.1016/j.ajhg.2016.09.007.

[216] D. Beltrán-Valero de Bernabé, S. Currier, A. Steinbrecher, J. Celli, E. van Beusekom, B. van der Zwaag, H. Kayserili, L. Merlini, D. Chitayat, W.B. Dobyns, B. Cormand, A.-E. Lehesjoki, J. Cruces, T. Voit, C.A. Walsh, H. van Bokhoven, H.G. Brunner, Mutations in the O-mannosyltransferase gene POMT1 give rise to the severe neuronal migration disorder Walker-Warburg syndrome, Am. J. Hum. Genet. 71 (2002) 1033-1043. doi:10.1086/342975.

[217] T. Willer, H. Lee, M. Lommel, T. Yoshida-Moriguchi, D.B.V. de Bernabe, D. Venzke, S. Cirak, H. Schachter, J. Vajsar, T. Voit, F. Muntoni, A.S. Loder, W.B. Dobyns, T.L. Winder, S. Strahl, K.D. Mathews, S.F. Nelson, S.A. Moore, K.P. Campbell, ISPD lossof-function mutations disrupt dystroglycan O-mannosylation and cause Walker-Warburg syndrome, Nat. Genet. 44 (2012) $575-$ 580. doi:10.1038/ng.2252.

[218] S. Vuillaumier-Barrot, C. Bouchet-Séraphin, M. Chelbi, L. Devisme, S. Quentin, S. Gazal, A. Laquerrière, C. Fallet-Bianco, P. Loget, S. Odent, D. Carles, A. Bazin, J. Aziza, A. Clemenson, F. Guimiot, M. Bonnière, S. Monnot, C. Bole-Feysot, J.-P. Bernard, L. Loeuillet, M. Gonzales, K. Socha, B. Grandchamp, T. Attié-Bitach, F. Encha-Razavi, N. Seta, Identification of mutations in TMEM5 and ISPD as a cause of severe cobblestone lissencephaly, Am. J. Hum. Genet. 91 (2012) 1135-1143. doi:10.1016/j.ajhg.2012.10.009

[219] J. van Reeuwijk, M. Janssen, C. van den Elzen, D. Beltran-Valero de Bernabé, P. Sabatelli, L. Merlini, M. Boon, H. Scheffer, M. Brockington, F. Muntoni, M.A. Huynen, A. Verrips, C.A. Walsh, P.G. Barth, H.G. Brunner, H. van Bokhoven, POMT2 mutations cause alpha-dystroglycan hypoglycosylation and Walker-Warburg syndrome, J. Med. Genet. 42 (2005) 907-912. doi:10.1136/jmg.2005.031963

[220] J. van Reeuwijk, P.K. Grewal, M.A.M. Salih, D. Beltrán-Valero de Bernabé, J.M. McLaughlan, C.B. Michielse, R. Herrmann, J.E. Hewitt, A. Steinbrecher, M.Z. Seidahmed, M.M. Shaheed, A. Abomelha, H.G. Brunner, H. van Bokhoven, T. Voit, Intragenic deletion in the LARGE gene causes Walker-Warburg syndrome, Hum. Genet. 121 (2007) 685-690. doi:10.1007/s00439-007-0362y.

[221] E. Stevens, K.J. Carss, S. Cirak, A.R. Foley, S. Torelli, T. Willer, D.E. Tambunan, S. Yau, L. Brodd, C.A. Sewry, L. Feng, G. Haliloglu, D. Orhan, W.B. Dobyns, G.M. Enns, M. Manning, A. Krause, M.A. Salih, C.A. Walsh, M. Hurles, K.P. Campbell, M.C. Manzini, UK10K Consortium, D. Stemple, Y.-Y. Lin, F. Muntoni, Mutations in B3GALNT2 cause congenital muscular dystrophy and hypoglycosylation of $\alpha$-dystroglycan, Am. J. Hum. Genet. 92 (2013) 354-365. doi:10.1016/j.ajhg.2013.01.016.

[222] A. von Renesse, M.V. Petkova, S. Lützkendorf, J. Heinemeyer, E. Gill, C. Hübner, A. von Moers, W. Stenzel, M. Schuelke, POMK mutation in a family with congenital muscular dystrophy with merosin deficiency, hypomyelination, mild hearing deficit and intellectual disability, J. Med. Genet. 51 (2014) 275-282. doi:10.1136/jmedgenet-2013-102236.

[223] N. Nakagawa, H. Yagi, K. Kato, H. Takematsu, S. Oka, Ectopic clustering of Cajal-Retzius and subplate cells is an initial pathological feature in Pomgnt2-knockout mice, a model of dystroglycanopathy, Sci. Rep. 5 (2015) 11163. doi:10.1038/srep11163. K. Buysse, M. Riemersma, G. Powell, J. van Reeuwijk, D. Chitayat, T. Roscioli, E.-J. Kamsteeg, C. van den Elzen, E. van Beusekom, S. Blaser, R. Babul-Hirji, W. Halliday, G.J. Wright, D.L. Stemple, Y.-Y. Lin, D.J. Lefeber, H. van Bokhoven, Missense mutations in $\beta-1,3-\mathrm{N}$-acetylglucosaminyltransferase 1 (B3GNT1) cause Walker-Warburg syndrome, Hum. Mol. Genet. 22 (2013) 1746-1754. doi:10.1093/hmg/ddt021.

[225] T. Roscioli, E.-J. Kamsteeg, K. Buysse, I. Maystadt, J. van Reeuwijk, C. van den Elzen, E. van Beusekom, M. Riemersma, R. Pfundt, L.E.L.M. Vissers, M. Schraders, U. Altunoglu, M.F. Buckley, H.G. Brunner, B. Grisart, H. Zhou, J.A. Veltman, C. Gilissen, G.M.S. Mancini, P. Delrée, M.A. Willemsen, D.P. Ramadža, D. Chitayat, C. Bennett, E. Sheridan, E.A.J. Peeters, G.M.B. Tan-Sindhunata, C.E. de Die-Smulders, K. Devriendt, H. Kayserili, O.A.E.-F. El-Hashash, D.L. Stemple, D.J. Lefeber, Y.-Y. Lin, H. van Bokhoven, Mutations in ISPD cause Walker-Warburg syndrome and defective glycosylation of $\alpha$-dystroglycan, Nat. Genet. 44 (2012) 581-585. doi:10.1038/ng.2253. 
[226] C. Labelle-Dumais, D.J. Dilworth, E.P. Harrington, M. de Leau, D. Lyons, Z. Kabaeva, M.C. Manzini, W.B. Dobyns, C.A. Walsh, D.E. Michele, D.B. Gould, COL4A1 mutations cause ocular dysgenesis, neuronal localization defects, and myopathy in mice and Walker-Warburg syndrome in humans, PLoS Genet. 7 (2011) e1002062. doi:10.1371/journal.pgen.1002062.

[227] N. Bahi-Buisson, K. Poirier, N. Boddaert, C. Fallet-Bianco, N. Specchio, E. Bertini, O. Caglayan, K. Lascelles, C. Elie, J. Rambaud, M. Baulac, I. An, P. Dias, V. des Portes, M.L. Moutard, C. Soufflet, M. El Maleh, C. Beldjord, L. Villard, J. Chelly, GPR56-related bilateral frontoparietal polymicrogyria: further evidence for an overlap with the cobblestone complex, Brain J. Neurol. 133 (2010) 3194-3209. doi:10.1093/brain/awq259.

[228] L. Vandervore, K. Stouffs, I. Tanyalçin, T. Vanderhasselt, F. Roelens, M. Holder-Espinasse, A. Jørgensen, M.G. Pepin, F. Petit, P. Khau Van Kien, N. Bahi-Buisson, W. Lissens, A. Gheldof, P.H. Byers, A.C. Jansen, Bi-allelic variants in COL3A1 encoding the ligand to GPR56 are associated with cobblestone-like cortical malformation, white matter changes and cerebellar cysts, J. Med. Genet. (2017). doi:10.1136/jmedgenet-2016-104421.

[229] P.K. Grewal, J.E. Hewitt, Mutation of Large, which encodes a putative glycosyltransferase, in an animal model of muscular dystrophy, Biochim. Biophys. Acta. 1573 (2002) 216-224.

[230] S.A. Moore, F. Saito, J. Chen, D.E. Michele, M.D. Henry, A. Messing, R.D. Cohn, S.E. Ross-Barta, S. Westra, R.A. Williamson, T. Hoshi, K.P. Campbell, Deletion of brain dystroglycan recapitulates aspects of congenital muscular dystrophy, Nature. 418 (2002) 422-425. doi:10.1038/nature00838.

[231] J. Liu, S.L. Ball, Y. Yang, P. Mei, L. Zhang, H. Shi, H.J. Kaminski, V.P. Lemmon, H. Hu, A genetic model for muscle-eye-brain disease in mice lacking protein O-mannose 1,2-N-acetylglucosaminyltransferase (POMGnT1), Mech. Dev. 123 (2006) 228-240. doi:10.1016/j.mod.2005.12.003.

[232] M.R. Ackroyd, L. Skordis, M. Kaluarachchi, J. Godwin, S. Prior, M. Fidanboylu, R.J. Piercy, F. Muntoni, S.C. Brown, Reduced expression of fukutin related protein in mice results in a model for fukutin related protein associated muscular dystrophies, Brain $\mathrm{J}$ Neurol. 132 (2009) 439-451. doi:10.1093/brain/awn335.

[233] H.E. Beggs, D. Schahin-Reed, K. Zang, S. Goebbels, K.A. Nave, J. Gorski, K.R. Jones, D. Sretavan, L.F. Reichardt, FAK deficiency in cells contributing to the basal lamina results in cortical abnormalities resembling congenital muscular dystrophies, Neuron. 40 (2003) 501-514.

[234] A. Niewmierzycka, J. Mills, R. St-Arnaud, S. Dedhar, L.F. Reichardt, Integrin-linked kinase deletion from mouse cortex results in cortical lamination defects resembling cobblestone lissencephaly, J. Neurosci. Off. J. Soc. Neurosci. 25 (2005) $7022-7031$. doi:10.1523/JNEUROSCI.1695-05.2005.

[235] M.C. Manzini, D.E. Tambunan, R.S. Hill, T.W. Yu, T.M. Maynard, E.L. Heinzen, K.V. Shianna, C.R. Stevens, J.N. Partlow, B.J. Barry, J. Rodriguez, V.A. Gupta, A.-K. Al-Qudah, W.M. Eyaid, J.M. Friedman, M.A. Salih, R. Clark, I. Moroni, M. Mora, A.H. Beggs, S.B. Gabriel, C.A. Walsh, Exome sequencing and functional validation in zebrafish identify GTDC2 mutations as a cause of Walker-Warburg syndrome, Am. J. Hum. Genet. 91 (2012) 541-547. doi:10.1016/j.ajhg.2012.07.009.

[236] S. Di Costanzo, A. Balasubramanian, H.L. Pond, A. Rozkalne, C. Pantaleoni, S. Saredi, V.A. Gupta, C.M. Sunu, T.W. Yu, P.B. Kang, M.A. Salih, M. Mora, E. Gussoni, C.A. Walsh, M.C. Manzini, POMK mutations disrupt muscle development leading to a spectrum of neuromuscular presentations, Hum. Mol. Genet. 23 (2014) 5781-5792. doi:10.1093/hmg/ddu296.

[237] A.J. Barkovich, Current concepts of polymicrogyria, Neuroradiology. 52 (2010) 479-487. doi:10.1007/s00234-009-0644-2

[238] S. Kheradmand Kia, E. Verbeek, E. Engelen, R. Schot, R.A. Poot, I.F.M. de Coo, M.H. Lequin, C.J. Poulton, F. Pourfarzad, F.G. Grosveld, A. Brehm, M.C.Y. de Wit, R. Oegema, W.B. Dobyns, F.W. Verheijen, G.M.S. Mancini, RTTN mutations link primary cilia function to organization of the human cerebral cortex, Am. J. Hum. Genet. 91 (2012) 533-540. oi:10.1016/j.ajhg.2012.07.008.

[239] A.G. Bassuk, E.H. Sherr, A de novo mutation in PRICKLE1 in fetal agenesis of the corpus callosum and polymicrogyria, J. Neurogenet. 29 (2015) 174-177. doi:10.3109/01677063.2015.1088847.

[240] M.T. Handley, D.J. Morris-Rosendahl, S. Brown, F. Macdonald, C. Hardy, D. Bem, S.M. Carpanini, G. Borck, L. Martorell, C. Izzi, F. Faravelli, P. Accorsi, L. Pinelli, L. Basel-Vanagaite, G. Peretz, G.M.H. Abdel-Salam, M.S. Zaki, A. Jansen, D. Mowat, I Glass, H. Stewart, G. Mancini, D. Lederer, T. Roscioli, F. Giuliano, A.S. Plomp, A. Rolfs, J.M. Graham, E. Seemanova, P. Poo, A García-Cazorla, P. Edery, I.J. Jackson, E.R. Maher, I.A. Aligianis, Mutation spectrum in RAB3GAP1, RAB3GAP2, and RAB18 and genotype-phenotype correlations in warburg micro syndrome and Martsolf syndrome, Hum. Mutat. 34 (2013) $686-696$. doi:10.1002/humu.22296.

[241] H. Shamseldin, A.M. Alazami, M. Manning, A. Hashem, O. Caluseiu, B. Tabarki, E. Esplin, S. Schelley, A.M. Innes, J.S. Parboosingh, R. Lamont, Care4Rare Canada Consortium, J. Majewski, F.P. Bernier, F.S. Alkuraya, RTTN Mutations Cause Primary Microcephaly and Primordial Dwarfism in Humans, Am. J. Hum. Genet. 97 (2015) 862-868. doi:10.1016/j.ajhg.2015.10.012.

[242] A. Grandone, A. Torella, C. Santoro, T. Giugliano, F. Del Vecchio Blanco, M. Mutarelli, M. Cirillo, G. Cirillo, G. Piluso, C. Capristo, A. Festa, P. Marzuillo, E. Miraglia Del Giudice, L. Perrone, V. Nigro, Expanding the phenotype of RTTN variations: a new family with primary microcephaly, severe growth failure, brain malformations and dermatitis, Clin. Genet. 90 (2016) 445-450. doi:10.1111/cge.12771.

[243] J.H. Lee, M. Huynh, J.L. Silhavy, S. Kim, T. Dixon-Salazar, A. Heiberg, E. Scott, V. Bafna, K.J. Hill, A. Collazo, V. Funari, C. Russ, S.B. Gabriel, G.W. Mathern, J.G. Gleeson, De novo somatic mutations in components of the PI3K-AKT3-mTOR pathway cause hemimegalencephaly, Nat. Genet. 44 (2012) 941-945. doi:10.1038/ng.2329.

[244] J.-B. Rivière, G.M. Mirzaa, B.J. O’Roak, M. Beddaoui, D. Alcantara, R.L. Conway, J. St-Onge, J.A. Schwartzentruber, K.W. Gripp, S.M. Nikkel, T. Worthylake, C.T. Sullivan, T.R. Ward, H.E. Butler, N.A. Kramer, B. Albrecht, C.M. Armour, L. Armstrong, O. Caluseriu, C. Cytrynbaum, B.A. Drolet, A.M. Innes, J.L. Lauzon, A.E. Lin, G.M.S. Mancini, W.S. Meschino, J.D. Reggin, A.K. Saggar, T. Lerman-Sagie, G. Uyanik, R. Weksberg, B. Zirn, C.L. Beaulieu, Finding of Rare Disease Genes (FORGE) Canada Consortium, J. Majewski, D.E. Bulman, M. O’Driscoll, J. Shendure, J.M. Graham, K.M. Boycott, W.B. Dobyns, De novo germline and postzygotic mutations in AKT3, PIK3R2 and PIK3CA cause a spectrum of related megalencephaly syndromes, Nat. Genet. 44 (2012) 934-940. doi:10.1038/ng.2331.

[245] G.M. Mirzaa, C.D. Campbell, N. Solovieff, C.P. Goold, L.A. Jansen, S. Menon, A.E. Timms, V. Conti, J.D. Biag, C. Olds, E.A. Boyle, S. Collins, G. Ishak, S.L. Poliachik, K.M. Girisha, K.-S. Yeung, B.H.Y. Chung, E. Rahikkala, S.A. Gunter, S.S. McDaniel, C.F. Macmurdo, J.A. Bernstein, B. Martin, R.J. Leary, S. Mahan, S. Liu, M. Weaver, M.O. Dorschner, S. Jhangiani, D.M. Muzny, E. Boerwinkle, R.A. Gibbs, J.R. Lupski, J. Shendure, R.P. Saneto, E.J. Novotny, C.J. Wilson, W.R. Sellers, M.P. Morrissey, R.F. Hevner, J.G. Ojemann, R. Guerrini, L.O. Murphy, W. Winckler, W.B. Dobyns, Association of MTOR Mutations With Developmental Brain Disorders, Including Megalencephaly, Focal Cortical Dysplasia, and Pigmentary Mosaicism, JAMA Neurol. 73 (2016) 836-845. doi:10.1001/jamaneurol.2016.0363.

[246] G.M. Mirzaa, D.A. Parry, A.E. Fry, K.A. Giamanco, J. Schwartzentruber, M. Vanstone, C.V. Logan, N. Roberts, C.A. Johnson, S. Singh, S.S. Kholmanskikh, C. Adams, R.D. Hodge, R.F. Hevner, D.T. Bonthron, K.P.J. Braun, L. Faivre, J.-B. Rivière, J. St-Onge, K.W. Gripp, G.M.S. Mancini, K. Pang, E. Sweeney, H. van Esch, N. Verbeek, D. Wieczorek, M. Steinraths, J. Majewski, FORGE Canada Consortium, K.M. Boycott, D.T. Pilz, M.E. Ross, W.B. Dobyns, E.G. Sheridan, De novo CCND2 mutations leading to 
stabilization of cyclin D2 cause megalencephaly-polymicrogyria-polydactyly-hydrocephalus syndrome, Nat. Genet. 46 (2014) 510515. doi:10.1038/ng.2948

[247] G.M. Mirzaa, V. Conti, A.E. Timms, C.D. Smyser, S. Ahmed, M. Carter, S. Barnett, R.B. Hufnagel, A. Goldstein, Y. NarumiKishimoto, C. Olds, S. Collins, K. Johnston, J.-F. Deleuze, P. Nitschké, K. Friend, C. Harris, A. Goetsch, B. Martin, E.A. Boyle, E. Parrini, D. Mei, L. Tattini, A. Slavotinek, E. Blair, C. Barnett, J. Shendure, J. Chelly, W.B. Dobyns, R. Guerrini, Characterisation of mutations of the phosphoinositide-3-kinase regulatory subunit, PIK3R2, in perisylvian polymicrogyria: a next-generation sequencing study, Lancet Neurol. 14 (2015) 1182-1195. doi:10.1016/S1474-4422(15)00278-1.

[248] A. Garthe, Z. Huang, L. Kaczmarek, R.K. Filipkowski, G. Kempermann, Not all water mazes are created equal: cyclin D2 knockout mice with constitutively suppressed adult hippocampal neurogenesis do show specific spatial learning deficits, Genes Brain Behav. 13 (2014) 357-364. doi:10.1111/gbb.12130.

[249] R.S. Møller, S. Weckhuysen, M. Chipaux, E. Marsan, V. Taly, E.M. Bebin, S.M. Hiatt, J.W. Prokop, K.M. Bowling, D. Mei, V. Conti, P. de la Grange, S. Ferrand-Sorbets, G. Dorfmüller, V. Lambrecq, L.H.G. Larsen, E. Leguern, R. Guerrini, G. Rubboli, G.M. Cooper, S. Baulac, Germline and somatic mutations in the MTOR gene in focal cortical dysplasia and epilepsy, Neurol. Genet. 2 (2016) e118. doi:10.1212/NXG.0000000000000118.

[250] L. Flores-Sarnat, H.B. Sarnat, G. Dávila-Gutiérrez, A. Alvarez, Hemimegalencephaly: part 2. Neuropathology suggests a disorder of cellular lineage, J. Child Neurol. 18 (2003) 776-785. doi:10.1177/08830738030180111101.

[251] T. Glaser, L. Jepeal, J.G. Edwards, S.R. Young, J. Favor, R.L. Maas, PAX6 gene dosage effect in a family with congenital cataracts, aniridia, anophthalmia and central nervous system defects, Nat. Genet. 7 (1994) 463-471. doi:10.1038/ng0894-463.

[252] X. Piao, R.S. Hill, A. Bodell, B.S. Chang, L. Basel-Vanagaite, R. Straussberg, W.B. Dobyns, B. Qasrawi, R.M. Winter, A.M. Innes, T. Voit, M.E. Ross, J.L. Michaud, J.-C. Déscarie, A.J. Barkovich, C.A. Walsh, G protein-coupled receptor-dependent development of human frontal cortex, Science. 303 (2004) 2033-2036. doi:10.1126/science.1092780.

[253] S. Li, Z. Jin, S. Koirala, L. Bu, L. Xu, R.O. Hynes, C.A. Walsh, G. Corfas, X. Piao, GPR56 regulates pial basement membrane integrity and cortical lamination, J. Neurosci. Off. J. Soc. Neurosci. 28 (2008) 5817-5826. doi:10.1523/JNEUROSCI.085308.2008 .

[254] B.-I. Bae, I. Tietjen, K.D. Atabay, G.D. Evrony, M.B. Johnson, E. Asare, P.P. Wang, A.Y. Murayama, K. Im, S.N. Lisgo, L. Overman, N. Šestan, B.S. Chang, A.J. Barkovich, P.E. Grant, M. Topçu, J. Politsky, H. Okano, X. Piao, C.A. Walsh, Evolutionarily dynamic alternative splicing of GPR56 regulates regional cerebral cortical patterning, Science. 343 (2014) 764-768. doi:10.1126/science. 1244392.

[255] R. Luo, S.-J. Jeong, Z. Jin, N. Strokes, S. Li, X. Piao, G protein-coupled receptor 56 and collagen III, a receptor-ligand pair, regulates cortical development and lamination, Proc. Natl. Acad. Sci. U. S. A. 108 (2011) 12925-12930. doi:10.1073/pnas.1104821108.

[256] M.C. Manzini, C.A. Walsh, What disorders of cortical development tell us about the cortex: one plus one does not always make two, Curr. Opin. Genet. Dev. 21 (2011) 333-339. doi:10.1016/j.gde.2011.01.006

[257] D. Jayaraman, A. Kodani, D.M. Gonzalez, J.D. Mancias, G.H. Mochida, C. Vagnoni, J. Johnson, N. Krogan, J.W. Harper, J.F. Reiter, T.W. Yu, B.-I. Bae, C.A. Walsh, Microcephaly Proteins Wdr62 and Aspm Define a Mother Centriole Complex Regulating Centriole Biogenesis, Apical Complex, and Cell Fate, Neuron. 92 (2016) 813-828. doi:10.1016/j.neuron.2016.09.056.

[258] K. Bilgüvar, A.K. Oztürk, A. Louvi, K.Y. Kwan, M. Choi, B. Tatli, D. Yalnizoğlu, B. Tüysüz, A.O. Cağlayan, S. Gökben, H. Kaymakçalan, T. Barak, M. Bakircioğlu, K. Yasuno, W. Ho, S. Sanders, Y. Zhu, S. Yilmaz, A. Dinçer, M.H. Johnson, R.A. Bronen, N. Koçer, H. Per, S. Mane, M.N. Pamir, C. Yalçinkaya, S. Kumandaş, M. Topçu, M. Ozmen, N. Sestan, R.P. Lifton, M.W. State, M. Günel, Whole-exome sequencing identifies recessive WDR62 mutations in severe brain malformations, Nature. 467 (2010) 207-210. doi:10.1038/nature09327.

[259] T.W. Yu, G.H. Mochida, D.J. Tischfield, S.K. Sgaier, L. Flores-Sarnat, C.M. Sergi, M. Topçu, M.T. McDonald, B.J. Barry, J.M. Felie, C. Sunu, W.B. Dobyns, R.D. Folkerth, A.J. Barkovich, C.A. Walsh, Mutations in WDR62, encoding a centrosome-associated protein, cause microcephaly with simplified gyri and abnormal cortical architecture, Nat. Genet. 42 (2010) 1015-1020. doi:10.1038/ng.683.

[260] D.R. Murdock, G.D. Clark, M.N. Bainbridge, I. Newsham, Y.-Q. Wu, D.M. Muzny, S.W. Cheung, R.A. Gibbs, M.B. Ramocki, Whole-exome sequencing identifies compound heterozygous mutations in WDR62 in siblings with recurrent polymicrogyria, Am. J. Med. Genet. A. 155A (2011) 2071-2077. doi:10.1002/ajmg.a.34165.

[261] K. Nakamura, T. Inui, F. Miya, Y. Kanemura, N. Okamoto, S. Saitoh, M. Yamasaki, T. Tsunoda, K. Kosaki, S. Tanaka, M. Kato, Primary microcephaly with anterior predominant pachygyria caused by novel compound heterozygous mutations in ASPM, Pediatr. Neurol. 52 (2015) e7-8. doi:10.1016/j.pediatrneurol.2015.01.019.

[262] D. Germanaud, J. Lefèvre, C. Fischer, M. Bintner, A. Curie, V. des Portes, S. Eliez, M. Elmaleh-Bergès, D. Lamblin, S. Passemard, G. Operto, M. Schaer, A. Verloes, R. Toro, J.F. Mangin, L. Hertz-Pannier, Simplified gyral pattern in severe developmental microcephalies? New insights from allometric modeling for spatial and spectral analysis of gyrification, NeuroImage. 102 Pt 2 (2014) 317-331. doi:10.1016/j.neuroimage.2014.07.057.

[263] D. Xu, F. Zhang, Y. Wang, Y. Sun, Z. Xu, Microcephaly-associated protein WDR62 regulates neurogenesis through JNK1 in the developing neocortex, Cell Rep. 6 (2014) 104-116. doi:10.1016/j.celrep.2013.12.016.

[264] N.J. Bradshaw, M.A.F. Hayashi, NDE1 and NDEL1 from genes to (mal)functions: parallel but distinct roles impacting on neurodevelopmental disorders and psychiatric illness, Cell. Mol. Life Sci. CMLS. 74 (2017) 1191-1210. doi:10.1007/s00018-0162395-7.

[265] S. Hippenmeyer, Y.H. Youn, H.M. Moon, K. Miyamichi, H. Zong, A. Wynshaw-Boris, L. Luo, Genetic mosaic dissection of Lis1 and Ndel1 in neuronal migration, Neuron. 68 (2010) 695-709. doi:10.1016/j.neuron.2010.09.027.

[266] R. Gelineau-Morel, M. Lukacs, K.N. Weaver, R.B. Hufnagel, D.L. Gilbert, R.W. Stottmann, Congenital Cataracts and Gut Dysmotility in a DYNC1H1 Dyneinopathy Patient, Genes. 7 (2016). doi:10.3390/genes7100085.

[267] M. Kielar, F.P.D. Tuy, S. Bizzotto, C. Lebrand, C. de Juan Romero, K. Poirier, R. Oegema, G.M. Mancini, N. Bahi-Buisson, R. Olaso, A.-G. Le Moing, K. Boutourlinsky, D. Boucher, W. Carpentier, P. Berquin, J.-F. Deleuze, R. Belvindrah, V. Borrell, E. Welker, J. Chelly, A. Croquelois, F. Francis, Mutations in Eml1 lead to ectopic progenitors and neuronal heterotopia in mouse and human, Nat. Neurosci. 17 (2014) 923-933. doi:10.1038/nn.3729.

[268] N. Di Donato, Y.Y. Jean, A.M. Maga, B.D. Krewson, A.B. Shupp, M.I. Avrutsky, A. Roy, S. Collins, C. Olds, R.A. Willert, A.M. Czaja, R. Johnson, J.A. Stover, S. Gottlieb, D. Bartholdi, A. Rauch, A. Goldstein, V. Boyd-Kyle, K.A. Aldinger, G.M. Mirzaa, A. Nissen, K.W. Brigatti, E.G. Puffenberger, K.J. Millen, K.A. Strauss, W.B. Dobyns, C.M. Troy, R.N. Jinks, Mutations in CRADD Result in Reduced Caspase-2-Mediated Neuronal Apoptosis and Cause Megalencephaly with a Rare Lissencephaly Variant, Am. J. Hum. Genet. 99 (2016) 1117-1129. doi:10.1016/j.ajhg.2016.09.010.

[269] I.A. Belyantseva, B.J. Perrin, K.J. Sonnemann, M. Zhu, R. Stepanyan, J. McGee, G.I. Frolenkov, E.J. Walsh, K.H. Friderici, T.B. Friedman, J.M. Ervasti, Gamma-actin is required for cytoskeletal maintenance but not development, Proc. Natl. Acad. Sci. U. S. A. 106 (2009) 9703-9708. doi:10.1073/pnas.0900221106. 
[270] K. Poirier, J. Martinovic, A. Laquerrière, M. Cavallin, C. Fallet-Bianco, I. Desguerre, S. Valence, J. Grande-Goburghun, C. Francannet, J.-F. Deleuze, A. Boland, J. Chelly, N. Bahi-Buisson, Rare ACTG1 variants in fetal microlissencephaly, Eur. J. Med. Genet. 58 (2015) 416-418. doi:10.1016/j.ejmg.2015.06.006.

[271] K. Mishra-Gorur, A.O. Çağlayan, A.E. Schaffer, C. Chabu, O. Henegariu, F. Vonhoff, G.T. Akgümüş, S. Nishimura, W. Han, S. Tu, B. Baran, H. Gümüş, C. Dilber, M.S. Zaki, H.A.A. Hossni, J.-B. Rivière, H. Kayserili, E.G. Spencer, R.Ö. Rosti, J. Schroth, H. Per, C. Cağlar, C. Cağlar, D. Dölen, J.F. Baranoski, S. Kumandas, F.J. Minja, E.Z. Erson-Omay, S.M. Mane, R.P. Lifton, T. Xu, H. Keshishian, W.B. Dobyns, N.C. Chi, N. Šestan, A. Louvi, K. Bilgüvar, K. Yasuno, J.G. Gleeson, M. Günel, Mutations in KATNB1 cause complex cerebral malformations by disrupting asymmetrically dividing neural progenitors, Neuron. 84 (2014) 1226-1239. doi:10.1016/j.neuron.2014.12.014.

[272] M.-T. Schmid, F. Weinandy, M. Wilsch-Bräuninger, W.B. Huttner, S. Cappello, M. Götz, The role of $\alpha$-E-catenin in cerebral cortex development: radial glia specific effect on neuronal migration, Front. Cell. Neurosci. 8 (2014) 215. doi:10.3389/fncel.2014.00215.

[273] S. Cappello, C.R.J. Böhringer, M. Bergami, K.-K. Conzelmann, A. Ghanem, G.S. Tomassy, P. Arlotta, M. Mainardi, M. Allegra, M. Caleo, J. van Hengel, C. Brakebusch, M. Götz, A radial glia-specific role of RhoA in double cortex formation, Neuron. 73 (2012) 911-924. doi:10.1016/j.neuron.2011.12.030.

[274] N. Mori, M. Kuwamura, N. Tanaka, R. Hirano, M. Nabe, M. Ibuki, J. Yamate, Ccdc85c encoding a protein at apical junctions of radial glia is disrupted in hemorrhagic hydrocephalus (hhy) mice, Am. J. Pathol. 180 (2012) 314-327. doi:10.1016/j.ajpath.2011.09.014.

[275] H. Yamamoto, T. Maruo, T. Majima, H. Ishizaki, M. Tanaka-Okamoto, J. Miyoshi, K. Mandai, Y. Takai, Genetic deletion of afadin causes hydrocephalus by destruction of adherens junctions in radial glial and ependymal cells in the midbrain, PloS One. 8 (2013) e80356. doi:10.1371/journal.pone.0080356.

[276] K. Maeta, H. Edamatsu, K. Nishihara, J. Ikutomo, S.E. Bilasy, T. Kataoka, Crucial Role of Rapgef2 and Rapgef6, a Family of Guanine Nucleotide Exchange Factors for Rap1 Small GTPase, in Formation of Apical Surface Adherens Junctions and Neural Progenitor Development in the Mouse Cerebral Cortex, eNeuro. 3 (2016). doi:10.1523/ENEURO.0142-16.2016.

[277] W.F. Hu, O. Pomp, T. Ben-Omran, A. Kodani, K. Henke, G.H. Mochida, T.W. Yu, M.B. Woodworth, C. Bonnard, G.S. Raj, T.T. Tan, H. Hamamy, A. Masri, M. Shboul, M. Al Saffar, J.N. Partlow, M. Al-Dosari, A. Alazami, M. Alowain, F.S. Alkuraya, J.F. Reiter, M.P. Harris, B. Reversade, C.A. Walsh, Katanin p80 regulates human cortical development by limiting centriole and cilia number, Neuron. 84 (2014) 1240-1257. doi:10.1016/j.neuron.2014.12.017.

[278] M. Jin, O. Pomp, T. Shinoda, S. Toba, T. Torisawa, K. 'ya Furuta, K. Oiwa, T. Yasunaga, D. Kitagawa, S. Matsumura, T. Miyata, T.T. Tan, B. Reversade, S. Hirotsune, Katanin p80, NuMA and cytoplasmic dynein cooperate to control microtubule dynamics, Sci. Rep. 7 (2017) 39902. doi:10.1038/srep39902.

[279] M. Salmi, N. Bruneau, J. Cillario, N. Lozovaya, A. Massacrier, E. Buhler, R. Cloarec, T. Tsintsadze, F. Watrin, V. Tsintsadze, C. Zimmer, C. Villard, D. Lafitte, C. Cardoso, L. Bao, G. Lesca, G. Rudolf, F. Muscatelli, V. Pauly, I. Khalilov, P. Durbec, Y. BenAri, N. Burnashev, A. Represa, P. Szepetowski, Tubacin prevents neuronal migration defects and epileptic activity caused by rat Srpx2 silencing in utero, Brain J. Neurol. 136 (2013) 2457-2473. doi:10.1093/brain/awt161.

[280] H. Oda, T. Sato, S. Kunishima, K. Nakagawa, K. Izawa, E. Hiejima, T. Kawai, T. Yasumi, H. Doi, K. Katamura, H. Numabe, S. Okamoto, H. Nakase, A. Hijikata, O. Ohara, H. Suzuki, H. Morisaki, T. Morisaki, H. Nunoi, S. Hattori, R. Nishikomori, T. Heike, Exon skipping causes atypical phenotypes associated with a loss-of-function mutation in FLNA by restoring its protein function, Eur. J. Hum. Genet. EJHG. 24 (2016) 408-414. doi:10.1038/ejhg.2015.119.

[281] X. Zhang, M.H. Chen, X. Wu, A. Kodani, J. Fan, R. Doan, M. Ozawa, J. Ma, N. Yoshida, J.F. Reiter, D.L. Black, P.V. Kharchenko, P.A. Sharp, C.A. Walsh, Cell-Type-Specific Alternative Splicing Governs Cell Fate in the Developing Cerebral Cortex, Cell. 166 (2016) 1147-1162.e15. doi:10.1016/j.cell.2016.07.025.

[282] I.L. Weissman, Stem cells: units of development, units of regeneration, and units in evolution, Cell. 100 (2000) 157-168.

[283] K. Takahashi, K. Okita, M. Nakagawa, S. Yamanaka, Induction of pluripotent stem cells from fibroblast cultures, Nat. Protoc. 2 (2007) 3081-3089. doi:10.1038/nprot.2007.418.

[284] J. Yu, M.A. Vodyanik, K. Smuga-Otto, J. Antosiewicz-Bourget, J.L. Frane, S. Tian, J. Nie, G.A. Jonsdottir, V. Ruotti, R. Stewart, I.I. Slukvin, J.A. Thomson, Induced pluripotent stem cell lines derived from human somatic cells, Science. 318 (2007) 1917-1920. doi:10.1126/science. 1151526

[285] Y. Elkabetz, G. Panagiotakos, G. Al Shamy, N.D. Socci, V. Tabar, L. Studer, Human ES cell-derived neural rosettes reveal a functionally distinct early neural stem cell stage, Genes Dev. 22 (2008) 152-165. doi:10.1101/gad.1616208.

[286] S.C. Zhang, M. Wernig, I.D. Duncan, O. Brüstle, J.A. Thomson, In vitro differentiation of transplantable neural precursors from human embryonic stem cells, Nat. Biotechnol. 19 (2001) 1129-1133. doi:10.1038/nbt1201-1129.

[287] M.A. Lancaster, J.A. Knoblich, Organogenesis in a dish: modeling development and disease using organoid technologies, Science 345 (2014) 1247125. doi:10.1126/science.1247125.

[288] M.A. Lancaster, M. Renner, C.-A. Martin, D. Wenzel, L.S. Bicknell, M.E. Hurles, T. Homfray, J.M. Penninger, A.P. Jackson, J.A. Knoblich, Cerebral organoids model human brain development and microcephaly, Nature. 501 (2013) 373-379. doi:10.1038/nature12517.

[289] J.G. Camp, F. Badsha, M. Florio, S. Kanton, T. Gerber, M. Wilsch-Bräuninger, E. Lewitus, A. Sykes, W. Hevers, M. Lancaster, J.A. Knoblich, R. Lachmann, S. Pääbo, W.B. Huttner, B. Treutlein, Human cerebral organoids recapitulate gene expression programs of fetal neocortex development, Proc. Natl. Acad. Sci. U. S. A. 112 (2015) 15672-15677. doi:10.1073/pnas.1520760112

[290] Y. Shi, P. Kirwan, J. Smith, H.P.C. Robinson, F.J. Livesey, Human cerebral cortex development from pluripotent stem cells to functional excitatory synapses, Nat. Neurosci. 15 (2012) 477-486, S1. doi:10.1038/nn.3041.

[291] T. Kadoshima, H. Sakaguchi, T. Nakano, M. Soen, S. Ando, M. Eiraku, Y. Sasai, Self-organization of axial polarity, inside-out layer pattern, and species-specific progenitor dynamics in human ES cell-derived neocortex, Proc. Natl. Acad. Sci. U. S. A. 110 (2013) 20284-20289. doi:10.1073/pnas.1315710110.

[292] X. Qian, H.N. Nguyen, M.M. Song, C. Hadiono, S.C. Ogden, C. Hammack, B. Yao, G.R. Hamersky, F. Jacob, C. Zhong, K.-J Yoon, W. Jeang, L. Lin, Y. Li, J. Thakor, D.A. Berg, C. Zhang, E. Kang, M. Chickering, D. Nauen, C.-Y. Ho, Z. Wen, K.M. Christian, P.-Y. Shi, B.J. Maher, H. Wu, P. Jin, H. Tang, H. Song, G.-L. Ming, Brain-Region-Specific Organoids Using Minibioreactors for Modeling ZIKV Exposure, Cell. 165 (2016) 1238-1254. doi:10.1016/j.cell.2016.04.032.

[293] S. Yamanaka, Induced pluripotent stem cells: past, present, and future, Cell Stem Cell. 10 (2012) 678-684. doi:10.1016/j.stem.2012.05.005.

[294] J. Dang, S.K. Tiwari, G. Lichinchi, Y. Qin, V.S. Patil, A.M. Eroshkin, T.M. Rana, Zika Virus Depletes Neural Progenitors in Human Cerebral Organoids through Activation of the Innate Immune Receptor TLR3, Cell Stem Cell. 19 (2016) 258-265. doi:10.1016/j.stem.2016.04.014. 
[295] P.P. Garcez, E.C. Loiola, R. Madeiro da Costa, L.M. Higa, P. Trindade, R. Delvecchio, J.M. Nascimento, R. Brindeiro, A. Tanuri, S.K. Rehen, Zika virus impairs growth in human neurospheres and brain organoids, Science. 352 (2016) 816-818. doi:10.1126/science.aaf6116.

[296] T.J. Nowakowski, A.A. Pollen, E. Di Lullo, C. Sandoval-Espinosa, M. Bershteyn, A.R. Kriegstein, Expression Analysis Highlights AXL as a Candidate Zika Virus Entry Receptor in Neural Stem Cells, Cell Stem Cell. 18 (2016) 591-596. doi:10.1016/j.stem.2016.03.012.

[297] H. Tang, C. Hammack, S.C. Ogden, Z. Wen, X. Qian, Y. Li, B. Yao, J. Shin, F. Zhang, E.M. Lee, K.M. Christian, R.A. Didier, P. Jin, H. Song, G.-L. Ming, Zika Virus Infects Human Cortical Neural Progenitors and Attenuates Their Growth, Cell Stem Cell. 18 (2016) 587-590. doi:10.1016/j.stem.2016.02.016.

[298] M. Bershteyn, T.J. Nowakowski, A.A. Pollen, E. Di Lullo, A. Nene, A. Wynshaw-Boris, A.R. Kriegstein, Human iPSC-Derived Cerebral Organoids Model Cellular Features of Lissencephaly and Reveal Prolonged Mitosis of Outer Radial Glia, Cell Stem Cell. 20 (2017) 435-449.e4. doi:10.1016/j.stem.2016.12.007.

[299] V. Iefremova, G. Manikakis, O. Krefft, A. Jabali, K. Weynans, R. Wilkens, F. Marsoner, B. Brändl, F.-J. Müller, P. Koch, J. Ladewig, An Organoid-Based Model of Cortical Development Identifies Non-Cell-Autonomous Defects in Wnt Signaling Contributing to Miller-Dieker Syndrome, Cell Rep. 19 (2017) 50-59. doi:10.1016/j.celrep.2017.03.047.

[300] N. Neu, J. Duchon, P. Zachariah, TORCH infections, Clin. Perinatol. 42 (2015) 77-103, viii. doi:10.1016/j.clp.2014.11.001.

[301] D. Abuelo, Microcephaly syndromes, Semin. Pediatr. Neurol. 14 (2007) 118-127. doi:10.1016/j.spen.2007.07.003

[302] C.B. Coyne, H.M. Lazear, Zika virus - reigniting the TORCH, Nat. Rev. Microbiol. 14 (2016) 707-715. doi:10.1038/nrmicro.2016.125.

[303] J.D. Sanchez, PAHO WHO |Regional Zika Epidemiological Update (Americas) April 27, 2017, Pan Am. Health Organ. World Health Organ. (2017). http://www.paho.org/hq/index.php?option=com_content\&view=article\&id=11599:regional-zikaepidemiological-update-americas\&catid=8424: contents\&Itemid=41691\&lang=en (accessed May 13, 2017).

[304] E. Petersen, M.E. Wilson, S. Touch, B. McCloskey, P. Mwaba, M. Bates, O. Dar, F. Mattes, M. Kidd, G. Ippolito, E.I. Azhar, A. Zumla, Rapid Spread of Zika Virus in The Americas--Implications for Public Health Preparedness for Mass Gatherings at the 2016 Brazil Olympic Games, Int. J. Infect. Dis. IJID Off. Publ. Int. Soc. Infect. Dis. 44 (2016) 11-15. doi:10.1016/j.ijid.2016.02.001.

[305] G. Calvet, R.S. Aguiar, A.S.O. Melo, S.A. Sampaio, I. de Filippis, A. Fabri, E.S.M. Araujo, P.C. de Sequeira, M.C.L. de Mendonça, L. de Oliveira, D.A. Tschoeke, C.G. Schrago, F.L. Thompson, P. Brasil, F.B. Dos Santos, R.M.R. Nogueira, A. Tanuri, A.M.B. de Filippis, Detection and sequencing of Zika virus from amniotic fluid of fetuses with microcephaly in Brazil: a case study, Lancet Infect. Dis. 16 (2016) 653-660. doi:10.1016/S1473-3099(16)00095-5.

[306] J. Mlakar, M. Korva, N. Tul, M. Popović, M. Poljšak-Prijatelj, J. Mraz, M. Kolenc, K. Resman Rus, T. Vesnaver Vipotnik, V. Fabjan Vodušek, A. Vizjak, J. Pižem, M. Petrovec, T. Avšič Županc, Zika Virus Associated with Microcephaly, N. Engl. J. Med. 374 (2016) 951-958. doi:10.1056/NEJMoa1600651.

[307] F.S. Ramalho, A.Y. Yamamoto, L.L. da Silva, L.T. Figueiredo, L.B. Rocha, L. Neder, S.R. Teixeira, L.A. Apolinário, L.N. Ramalho, D.M. Silva, C.M. Coutinho, P.P. Melli, M.J. Augusto, L.B. Santoro, G. Duarte, M.M. Mussi-Pinhata, Congenital Zika virus infection induces severe spinal cord injury, Clin. Infect. Dis. Off. Publ. Infect. Dis. Soc. Am. (2017). doi:10.1093/cid/cix374

[308] A.Q. Sousa, D.I.M. Cavalcante, L.M. Franco, F.M.C. Araújo, E.T. Sousa, J.T. Valença-Junior, D.B. Rolim, M.E.L. Melo, P.D.T. Sindeaux, M.T.F. Araújo, R.D. Pearson, M.E. Wilson, M.M.L. Pompeu, Postmortem Findings for 7 Neonates with Congenital Zika Virus Infection, Emerg. Infect. Dis. 23 (2017). doi:10.3201/eid2307.162019.

[309] C. Li, D. Xu, Q. Ye, S. Hong, Y. Jiang, X. Liu, N. Zhang, L. Shi, C.-F. Qin, Z. Xu, Zika Virus Disrupts Neural Progenitor Development and Leads to Microcephaly in Mice, Cell Stem Cell. 19 (2016) 672. doi:10.1016/j.stem.2016.10.017.

[310] M. Onorati, Z. Li, F. Liu, A.M.M. Sousa, N. Nakagawa, M. Li, M.T. Dell'Anno, F.O. Gulden, S. Pochareddy, A.T.N. Tebbenkamp, W. Han, M. Pletikos, T. Gao, Y. Zhu, C. Bichsel, L. Varela, K. Szigeti-Buck, S. Lisgo, Y. Zhang, A. Testen, X.-B. Gao, J. Mlakar, M. Popovic, M. Flamand, S.M. Strittmatter, L.K. Kaczmarek, E.S. Anton, T.L. Horvath, B.D. Lindenbach, N. Sestan, Zika Virus Disrupts Phospho-TBK1 Localization and Mitosis in Human Neuroepithelial Stem Cells and Radial Glia, Cell Rep. 16 (2016) 25762592. doi:10.1016/j.celrep.2016.08.038.

[311] E. Gabriel, A. Ramani, U. Karow, M. Gottardo, K. Natarajan, L.M. Gooi, G. Goranci-Buzhala, O. Krut, F. Peters, M. Nikolic, S. Kuivanen, E. Korhonen, T. Smura, O. Vapalahti, A. Papantonis, J. Schmidt-Chanasit, M. Riparbelli, G. Callaini, M. Krönke, O. Utermöhlen, J. Gopalakrishnan, Recent Zika Virus Isolates Induce Premature Differentiation of Neural Progenitors in Human Brain Organoids, Cell Stem Cell. 20 (2017) 397-406.e5. doi:10.1016/j.stem.2016.12.005

[312] Y. Yang, D.M. Muzny, F. Xia, Z. Niu, R. Person, Y. Ding, P. Ward, A. Braxton, M. Wang, C. Buhay, N. Veeraraghavan, A Hawes, T. Chiang, M. Leduc, J. Beuten, J. Zhang, W. He, J. Scull, A. Willis, M. Landsverk, W.J. Craigen, M.R. Bekheirnia, A Stray-Pedersen, P. Liu, S. Wen, W. Alcaraz, H. Cui, M. Walkiewicz, J. Reid, M. Bainbridge, A. Patel, E. Boerwinkle, A.L. Beaudet, J.R. Lupski, S.E. Plon, R.A. Gibbs, C.M. Eng, Molecular findings among patients referred for clinical whole-exome sequencing, JAMA. 312 (2014) 1870-1879. doi:10.1001/jama.2014.14601

[313] X. Wang, J.-W. Tsai, B. LaMonica, A.R. Kriegstein, A new subtype of progenitor cell in the mouse embryonic neocortex, Nat. Neurosci. 14 (2011) 555-561. doi:10.1038/nn.2807.

[314] V. Borrell, M. Götz, Role of radial glial cells in cerebral cortex folding, Curr. Opin. Neurobiol. 27 (2014) 39-46. doi:10.1016/j.conb.2014.02.007

[315] M. Florio, M. Albert, E. Taverna, T. Namba, H. Brandl, E. Lewitus, C. Haffner, A. Sykes, F.K. Wong, J. Peters, E. Guhr, S. Klemroth, K. Prüfer, J. Kelso, R. Naumann, I. Nüsslein, A. Dahl, R. Lachmann, S. Pääbo, W.B. Huttner, Human-specific gene ARHGAP11B promotes basal progenitor amplification and neocortex expansion, Science. 347 (2015) 1465-1470. doi:10.1126/science.aaa1975.

[316] A.E. Ayoub, S. Oh, Y. Xie, J. Leng, J. Cotney, M.H. Dominguez, J.P. Noonan, P. Rakic, Transcriptional programs in transient embryonic zones of the cerebral cortex defined by high-resolution mRNA sequencing, Proc. Natl. Acad. Sci. U. S. A. 108 (2011) 14950-14955. doi:10.1073/pnas.1112213108.

[317] S.A. Fietz, R. Lachmann, H. Brandl, M. Kircher, N. Samusik, R. Schröder, N. Lakshmanaperumal, I. Henry, J. Vogt, A. Riehn, W. Distler, R. Nitsch, W. Enard, S. Pääbo, W.B. Huttner, Transcriptomes of germinal zones of human and mouse fetal neocortex suggest a role of extracellular matrix in progenitor self-renewal, Proc. Natl. Acad. Sci. U. S. A. 109 (2012) 11836-11841. doi:10.1073/pnas.1209647109.

[318] C. de Juan Romero, C. Bruder, U. Tomasello, J.M. Sanz-Anquela, V. Borrell, Discrete domains of gene expression in germinal layers distinguish the development of gyrencephaly, EMBO J. 34 (2015) 1859-1874. doi:10.15252/embj.201591176.

[319] M.B. Johnson, P.P. Wang, K.D. Atabay, E.A. Murphy, R.N. Doan, J.L. Hecht, C.A. Walsh, Single-cell analysis reveals transcriptional heterogeneity of neural progenitors in human cortex, Nat. Neurosci. 18 (2015) 637-646. doi:10.1038/nn.3980. 
[320] A.A. Pollen, T.J. Nowakowski, J. Chen, H. Retallack, C. Sandoval-Espinosa, C.R. Nicholas, J. Shuga, S.J. Liu, M.C. Oldham, A Diaz, D.A. Lim, A.A. Leyrat, J.A. West, A.R. Kriegstein, Molecular identity of human outer radial glia during cortical development, Cell. 163 (2015) 55-67. doi:10.1016/j.cell.2015.09.004.

[321] K.A. Meyer, T. Marques-Bonet, N. Sestan, Differential Gene Expression in the Human Brain Is Associated with Conserved, but Not Accelerated, Noncoding Sequences, Mol. Biol. Evol. 34 (2017) 1217-1229. doi:10.1093/molbev/msx076.

[322] J.L. Boyd, S.L. Skove, J.P. Rouanet, L.-J. Pilaz, T. Bepler, R. Gordân, G.A. Wray, D.L. Silver, Human-chimpanzee differences in a FZD8 enhancer alter cell-cycle dynamics in the developing neocortex, Curr. Biol. CB. 25 (2015) 772-779. doi:10.1016/j.cub.2015.01.041.

[323] M. Shibata, F.O. Gulden, N. Sestan, From trans to cis: transcriptional regulatory networks in neocortical development, Trends Genet. TIG. 31 (2015) 77-87. doi:10.1016/j.tig.2014.12.004

[324] K. Toyo-oka, A. Shionoya, M.J. Gambello, C. Cardoso, R. Leventer, H.L. Ward, R. Ayala, L.-H. Tsai, W. Dobyns, D. Ledbetter, S Hirotsune, A. Wynshaw-Boris, 14-3-3epsilon is important for neuronal migration by binding to NUDEL: a molecular explanation for Miller-Dieker syndrome, Nat. Genet. 34 (2003) 274-285. doi:10.1038/ng1169.

[325] L.F. Petit, M. Jalabert, E. Buhler, A. Malvache, A. Peret, Y. Chauvin, F. Watrin, A. Represa, J.-B. Manent, Normotopic cortex is the major contributor to epilepsy in experimental double cortex, Ann. Neurol. 76 (2014) 428-442. doi:10.1002/ana.24237.

[326] C. Lambert de Rouvroit, A.M. Goffinet, The reeler mouse as a model of brain development, Adv. Anat. Embryol. Cell Biol. 150 (1998) $1-106$

[327] T. Ohshima, J.M. Ward, C.G. Huh, G. Longenecker, null Veeranna, H.C. Pant, R.O. Brady, L.J. Martin, A.B. Kulkarni, Targeted disruption of the cyclin-dependent kinase 5 gene results in abnormal corticogenesis, neuronal pathology and perinatal death, Proc. Natl. Acad. Sci. U. S. A. 93 (1996) 11173-11178.

[328] N. Homma, Y. Takei, Y. Tanaka, T. Nakata, S. Terada, M. Kikkawa, Y. Noda, N. Hirokawa, Kinesin superfamily protein 2A (KIF2A) functions in suppression of collateral branch extension, Cell. 114 (2003) 229-239.

[329] A.L. Manning, N.J. Ganem, S.F. Bakhoum, M. Wagenbach, L. Wordeman, D.A. Compton, The kinesin-13 proteins Kif2a, Kif2b, and Kif2c/MCAK have distinct roles during mitosis in human cells, Mol. Biol. Cell. 18 (2007) 2970-2979. doi:10.1091/mbc.E0702-0110.

[330] C. Li, Z. Huang, R. Kingsley, X. Zhou, F. Li, D.W. Parke, W. Cao, Biochemical alterations in the retinas of very low-density lipoprotein receptor knockout mice: an animal model of retinal angiomatous proliferation, Arch. Ophthalmol. Chic. Ill 1960. 125 (2007) 795-803. doi:10.1001/archopht.125.6.795.

[331] W. Shawlot, J.M. Deng, L.E. Fohn, R.R. Behringer, Restricted beta-galactosidase expression of a hygromycin-lacZ gene targeted to the beta-actin locus and embryonic lethality of beta-actin mutant mice, Transgenic Res. 7 (1998) 95-103.

[332] A. Verloes, N. Di Donato, J. Masliah-Planchon, M. Jongmans, O.A. Abdul-Raman, B. Albrecht, J. Allanson, H. Brunner, D. Bertola, N. Chassaing, A. David, K. Devriendt, P. Eftekhari, V. Drouin-Garraud, F. Faravelli, L. Faivre, F. Giuliano, L. Guion Almeida, J. Juncos, M. Kempers, H.K. Eker, D. Lacombe, A. Lin, G. Mancini, D. Melis, C.M. Lourenço, V.M. Siu, G. Morin, M. Nezarati, M.J.M. Nowaczyk, J.C. Ramer, S. Osimani, N. Philip, M.E. Pierpont, V. Procaccio, Z.-S. Roseli, M. Rossi, C. Rusu, Y. Sznajer, L. Templin, V. Uliana, M. Klaus, B. Van Bon, C. Van Ravenswaaij, B. Wainer, A.E. Fry, A. Rump, A. Hoischen, S Drunat, J.-B. Rivière, W.B. Dobyns, D.T. Pilz, Baraitser-Winter cerebrofrontofacial syndrome: delineation of the spectrum in 42 cases, Eur. J. Hum. Genet. EJHG. 23 (2015) 292-301. doi:10.1038/ejhg.2014.95.

[333] N. Di Donato, A. Rump, R. Koenig, V.M. Der Kaloustian, F. Halal, K. Sonntag, C. Krause, K. Hackmann, G. Hahn, E. Schrock, A. Verloes, Severe forms of Baraitser-Winter syndrome are caused by ACTB mutations rather than ACTG1 mutations, Eur. J. Hum. Genet. EJHG. 22 (2014) 179-183. doi:10.1038/ejhg.2013.130.

[334] T.M. Bunnell, B.J. Burbach, Y. Shimizu, J.M. Ervasti, $\beta$-Actin specifically controls cell growth, migration, and the G-actin pool, Mol. Biol. Cell. 22 (2011) 4047-4058, doi:10.1091/mbc.E11-06-0582.

[335] M.H. Willemsen, L.E.L. Vissers, M.A.A.P. Willemsen, B.W.M. van Bon, T. Kroes, J. de Ligt, B.B. de Vries, J. Schoots, D. Lugtenberg, B.C.J. Hamel, H. van Bokhoven, H.G. Brunner, J.A. Veltman, T. Kleefstra, Mutations in DYNC1H1 cause severe intellectual disability with neuronal migration defects, J. Med. Genet. 49 (2012) 179-183. doi:10.1136/jmedgenet-2011-100542.

[336] S. Yokoi, N. Ishihara, F. Miya, M. Tsutsumi, I. Yanagihara, N. Fujita, H. Yamamoto, M. Kato, N. Okamoto, T. Tsunoda, M. Yamasaki, Y. Kanemura, K. Kosaki, S. Kojima, S. Saitoh, H. Kurahashi, J. Natsume, TUBA1A mutation can cause a hydranencephaly-like severe form of cortical dysgenesis, Sci. Rep. 5 (2015) 15165. doi:10.1038/srep15165.

[337] L.H. Rodan, C.M. El Achkar, G.T. Berry, A. Poduri, S.P. Prabhu, E. Yang, I. Anselm, De Novo TUBB2A Variant Presenting With Anterior Temporal Pachygyria, J. Child Neurol. 32 (2017) 127-131. doi:10.1177/0883073816672998.

[338] M.A. Tischfield, H.N. Baris, C. Wu, G. Rudolph, L. Van Maldergem, W. He, W.-M. Chan, C. Andrews, J.L. Demer, R.L. Robertson, D.A. Mackey, J.B. Ruddle, T.D. Bird, I. Gottlob, C. Pieh, E.I. Traboulsi, S.L. Pomeroy, D.G. Hunter, J.S. Soul, A. Newlin, L.J. Sabol, E.J. Doherty, C.E. de Uzcátegui, N. de Uzcátegui, M.L.Z. Collins, E.C. Sener, B. Wabbels, H. Hellebrand, T. Meitinger, T. de Berardinis, A. Magli, C. Schiavi, M. Pastore-Trossello, F. Koc, A.M. Wong, A.V. Levin, M.T. Geraghty, M. Descartes, M. Flaherty, R.V. Jamieson, H.U. Møller, I. Meuthen, D.F. Callen, J. Kerwin, S. Lindsay, A. Meindl, M.L. Gupta, D. Pellman, E.C. Engle, Human TUBB3 mutations perturb microtubule dynamics, kinesin interactions, and axon guidance, Cell. 140 (2010) 74-87. doi:10.1016/j.cell.2009.12.011

[339] E. Banne, O. Atawneh, M. Henneke, K. Brockmann, J. Gärtner, O. Elpeleg, S. Edvardson, West syndrome, microcephaly, grey matter heterotopia and hypoplasia of corpus callosum due to a novel ARFGEF2 mutation, J. Med. Genet. 50 (2013) $772-775$. doi:10.1136/jmedgenet-2013-101752.

[340] M. Alders, L. Al-Gazali, I. Cordeiro, B. Dallapiccola, L. Garavelli, B. Tuysuz, F. Salehi, M.A. Haagmans, O.R. Mook, C.B. Majoie, M.M. Mannens, R.C. Hennekam, Hennekam syndrome can be caused by FAT4 mutations and be allelic to Van Maldergem syndrome, Hum. Genet. 133 (2014) 1161-1167. doi:10.1007/s00439-014-1456-y.

[341] S. Peddibhotla, S.C.S. Nagamani, A. Erez, J.V. Hunter, J.L. Holder, M.E. Carlin, P.I. Bader, H.M.F. Perras, J.E. Allanson, L. Newman, G. Simpson, L. Immken, E. Powell, A. Mohanty, S.-H.L. Kang, P. Stankiewicz, C.A. Bacino, W. Bi, A. Patel, S.W. Cheung, Delineation of candidate genes responsible for structural brain abnormalities in patients with terminal deletions of chromosome 6q27, Eur. J. Hum. Genet. EJHG. 23 (2015) 54-60. doi:10.1038/ejhg.2014.51.

[342] S. Yanpallewar, T. Wang, D.C.I. Koh, E. Quarta, G. Fulgenzi, L. Tessarollo, Nedd4-2 haploinsufficiency causes hyperactivity and increased sensitivity to inflammatory stimuli, Sci. Rep. 6 (2016) 32957. doi:10.1038/srep32957.

[343] M. Riemersma, H. Mandel, E. van Beusekom, I. Gazzoli, T. Roscioli, A. Eran, R. Gershoni-Baruch, M. Gershoni, S. Pietrokovski, L.E. Vissers, D.J. Lefeber, M.A. Willemsen, R.A. Wevers, H. van Bokhoven, Absence of $\alpha$ - and $\beta$-dystroglycan is associated with Walker-Warburg syndrome, Neurology. 84 (2015) 2177-2182. doi:10.1212/WNL.0000000000001615. 
[344] T. Willer, B. Prados, J.M. Falcón-Pérez, I. Renner-Müller, G.K.H. Przemeck, M. Lommel, A. Coloma, M.C. Valero, M.H. de Angelis, W. Tanner, E. Wolf, S. Strahl, J. Cruces, Targeted disruption of the Walker-Warburg syndrome gene Pomt 1 in mouse results in embryonic lethality, Proc. Natl. Acad. Sci. U. S. A. 101 (2004) 14126-14131. doi:10.1073/pnas.0405899101.

[345] A. Blaeser, E. Keramaris, Y.M. Chan, S. Sparks, D. Cowley, X. Xiao, Q.L. Lu, Mouse models of fukutin-related protein mutations show a wide range of disease phenotypes, Hum. Genet. 132 (2013) 923-934. doi:10.1007/s00439-013-1302-7.

[346] Y. Endo, M. Dong, S. Noguchi, M. Ogawa, Y.K. Hayashi, S. Kuru, K. Sugiyama, S. Nagai, S. Ozasa, I. Nonaka, I. Nishino, Milder forms of muscular dystrophy associated with POMGNT2 mutations, Neurol. Genet. 1 (2015) e33. doi:10.1212/NXG.0000000000000033.

[347] P.J. Holzfeind, P.K. Grewal, H.A. Reitsamer, J. Kechvar, H. Lassmann, H. Hoeger, J.E. Hewitt, R.E. Bittner, Skeletal, cardiac and tongue muscle pathology, defective retinal transmission, and neuronal migration defects in the Large(myd) mouse defines a natural model for glycosylation-deficient muscle - eye - brain disorders, Hum. Mol. Genet. 11 (2002) 2673-2687.

[348] E.J. Yun, T.H. Vu, mSmile is necessary for bronchial smooth muscle and alveolar myofibroblast development, Anat. Rec. Hoboken NJ 2007. 295 (2012) 167-176. doi:10.1002/ar.21475.

[349] K.M. Wright, K.A. Lyon, H. Leung, D.J. Leahy, L. Ma, D.D. Ginty, Dystroglycan organizes axon guidance cue localization and axonal pathfinding, Neuron. 76 (2012) 931-944. doi:10.1016/j.neuron.2012.10.009.

[350] G. Astrea, I. Pezzini, E. Picillo, R. Pasquariello, F. Moro, M. Ergoli, P. D’Ambrosio, A. D’Amico, L. Politano, F.M. Santorelli, TMEM5-associated dystroglycanopathy presenting with CMD and mild limb-girdle muscle involvement, Neuromuscul. Disord. NMD. 26 (2016) 459-461. doi:10.1016/j.nmd.2016.05.003.

[351] P. Vogel, R.W. Read, G.M. Hansen, B.J. Payne, D. Small, A.T. Sands, B.P. Zambrowicz, Congenital hydrocephalus in genetically engineered mice, Vet. Pathol. 49 (2012) 166-181. doi:10.1177/0300985811415708.

[352] R. Shaheen, E. Faqeih, S. Ansari, F.S. Alkuraya, A truncating mutation in B3GNT1 causes severe Walker-Warburg syndrome, Neurogenetics. 14 (2013) 243-245. doi:10.1007/s10048-013-0367-8.

[353] Y. Fujii, N. Ishikawa, Y. Kobayashi, M. Kobayashi, M. Kato, Compound heterozygosity in GPR56 with bilateral frontoparietal polymicrogyria, Brain Dev. 36 (2014) 528-531. doi:10.1016/j.braindev.2013.07.015.

[354] K. Ueki, C.M. Yballe, S.M. Brachmann, D. Vicent, J.M. Watt, C.R. Kahn, L.C. Cantley, Increased insulin sensitivity in mice lacking p85beta subunit of phosphoinositide 3-kinase, Proc. Natl. Acad. Sci. U. S. A. 99 (2002) 419-424. doi:10.1073/pnas.012581799.

[355] S. Tokuda, C.L. Mahaffey, B. Monks, C.R. Faulkner, M.J. Birnbaum, S.C. Danzer, W.N. Frankel, A novel Akt3 mutation associated with enhanced kinase activity and seizure susceptibility in mice, Hum. Mol. Genet. 20 (2011) 988-999. doi:10.1093/hmg/ddq544.

[356] A. Poduri, G.D. Evrony, X. Cai, P.C. Elhosary, R. Beroukhim, M.K. Lehtinen, L.B. Hills, E.L. Heinzen, A. Hill, R.S. Hill, B.J. Barry, B.F.D. Bourgeois, J.J. Riviello, A.J. Barkovich, P.M. Black, K.L. Ligon, C.A. Walsh, Somatic activation of AKT3 causes hemispheric developmental brain malformations, Neuron. 74 (2012) 41-48. doi:10.1016/j.neuron.2012.03.010.

[357] M. Nellist, R. Schot, M. Hoogeveen-Westerveld, R.F. Neuteboom, E.J.T.M. van der Louw, M.H. Lequin, K. Bindels-de Heus, B.J. Sibbles, R. de Coo, A. Brooks, G.M.S. Mancini, Germline activating AKT3 mutation associated with megalencephaly, polymicrogyria, epilepsy and hypoglycemia, Mol. Genet. Metab. 114 (2015) 467-473. doi:10.1016/j.ymgme.2014.11.018.

[358] M. Murakami, T. Ichisaka, M. Maeda, N. Oshiro, K. Hara, F. Edenhofer, H. Kiyama, K. Yonezawa, S. Yamanaka, mTOR is essential for growth and proliferation in early mouse embryos and embryonic stem cells, Mol. Cell. Biol. 24 (2004) 6710-6718. doi:10.1128/MCB.24.15.6710-6718.2004

[359] P. Jaholkowski, A. Kiryk, P. Jedynak, N.M. Ben Abdallah, E. Knapska, A. Kowalczyk, A. Piechal, K. Blecharz-Klin, I. Figiel, V. Lioudyno, E. Widy-Tyszkiewicz, G.M. Wilczynski, H.-P. Lipp, L. Kaczmarek, R.K. Filipkowski, New hippocampal neurons are not obligatory for memory formation; cyclin D2 knockout mice with no adult brain neurogenesis show learning, Learn. Mem. Cold Spring Harb. N. 16 (2009) 439-451. doi:10.1101/lm.1459709.

[360] W. Schmahl, M. Knoedlseder, J. Favor, D. Davidson, Defects of neuronal migration and the pathogenesis of cortical malformations are associated with Small eye (Sey) in the mouse, a point mutation at the Pax-6-locus, Acta Neuropathol. (Berl.). 86 (1993) 126135.

[361] D. Carić, D. Gooday, R.E. Hill, S.K. McConnell, D.J. Price, Determination of the migratory capacity of embryonic cortical cells lacking the transcription factor Pax-6, Dev. Camb. Engl. 124 (1997) 5087-5096.

[362] H. Kawano, T. Fukuda, K. Kubo, M. Horie, K. Uyemura, K. Takeuchi, N. Osumi, K. Eto, K. Kawamura, Pax-6 is required for thalamocortical pathway formation in fetal rats, J. Comp. Neurol. 408 (1999) 147-160.

[363] D.-E. Bamiou, S.L. Free, S.M. Sisodiya, W.K. Chong, F. Musiek, K.A. Williamson, V. van Heyningen, A.T. Moore, D. Gadian, L.M. Luxon, Auditory interhemispheric transfer deficits, hearing difficulties, and brain magnetic resonance imaging abnormalities in children with congenital aniridia due to PAX6 mutations, Arch. Pediatr. Adolesc. Med. 161 (2007) 463-469. doi:10.1001/archpedi.161.5.463.

[364] T. Nakayama, M. Fisher, K. Nakajima, A.O. Odeleye, K.B. Zimmerman, M.B. Fish, Y. Yaoita, J.L. Chojnowski, J.D. Lauderdale, P.A. Netland, R.M. Grainger, Xenopus pax6 mutants affect eye development and other organ systems, and have phenotypic similarities to human aniridia patients, Dev. Biol. 408 (2015) 328-344. doi:10.1016/j.ydbio.2015.02.012.

[365] I.A. Aligianis, C.A. Johnson, P. Gissen, D. Chen, D. Hampshire, K. Hoffmann, E.N. Maina, N.V. Morgan, L. Tee, J. Morton, J.R. Ainsworth, D. Horn, E. Rosser, T.R.P. Cole, I. Stolte-Dijkstra, K. Fieggen, J. Clayton-Smith, A. Mégarbané, J.P. Shield, R. Newbury-Ecob, W.B. Dobyns, J.M. Graham, K.W. Kjaer, M. Warburg, J. Bond, R.C. Trembath, L.W. Harris, Y. Takai, S. Mundlos, D. Tannahill, C.G. Woods, E.R. Maher, Mutations of the catalytic subunit of RAB3GAP cause Warburg Micro syndrome, Nat. Genet. 37 (2005) 221-223. doi:10.1038/ng1517.

[366] A. Sakane, S. Manabe, H. Ishizaki, M. Tanaka-Okamoto, E. Kiyokage, K. Toida, T. Yoshida, J. Miyoshi, H. Kamiya, Y. Takai, T. Sasaki, Rab3 GTPase-activating protein regulates synaptic transmission and plasticity through the inactivation of Rab3, Proc. Natl Acad. Sci. U. S. A. 103 (2006) 10029-10034 doi:10.1073/pnas.0600304103.

[367] D.J. Morris-Rosendahl, R. Segel, A.P. Born, C. Conrad, B. Loeys, S.S. Brooks, L. Müller, C. Zeschnigk, C. Botti, R. Rabinowitz, G. Uyanik, M.-A. Crocq, U. Kraus, I. Degen, F. Faes, New RAB3GAP1 mutations in patients with Warburg Micro Syndrome from different ethnic backgrounds and a possible founder effect in the Danish, Eur. J. Hum. Genet. EJHG. 18 (2010) $1100-1106$. doi:10.1038/ejhg.2010.79

[368] M. Müller, E.C.G. Pym, A. Tong, G.W. Davis, Rab3-GAP controls the progression of synaptic homeostasis at a late stage of vesicle release, Neuron. 69 (2011) 749-762. doi:10.1016/j.neuron.2011.01.025.

[369] I.A. Aligianis, N.V. Morgan, M. Mione, C.A. Johnson, E. Rosser, R.C. Hennekam, G. Adams, R.C. Trembath, D.T. Pilz, N. Stoodley, A.T. Moore, S. Wilson, E.R. Maher, Mutation in Rab3 GTPase-activating protein (RAB3GAP) noncatalytic subunit in a kindred with Martsolf syndrome, Am. J. Hum. Genet. 78 (2006) 702-707. doi:10.1086/502681.

[370] D. Bem, S.-I. Yoshimura, R. Nunes-Bastos, F.C. Bond, F.F. Bond, M.A. Kurian, F. Rahman, M.T.W. Handley, Y. Hadzhiev, I. Masood, A.A. Straatman-Iwanowska, A.R. Cullinane, A. McNeill, S.S. Pasha, G.A. Kirby, K. Foster, Z. Ahmed, J.E. Morton, D. 
Williams, J.M. Graham, W.B. Dobyns, L. Burglen, J.R. Ainsworth, P. Gissen, F. Müller, E.R. Maher, F.A. Barr, I.A. Aligianis, Loss-of-function mutations in RAB18 cause Warburg micro syndrome, Am. J. Hum. Genet. 88 (2011) $499-507$. doi:10.1016/j.ajhg.2011.03.012.

[371] S.M. Carpanini, L. McKie, D. Thomson, A.K. Wright, S.L. Gordon, S.L. Roche, M.T. Handley, H. Morrison, D. Brownstein, T.M Wishart, M.A. Cousin, T.H. Gillingwater, I.A. Aligianis, I.J. Jackson, A novel mouse model of Warburg Micro syndrome reveals roles for RAB18 in eye development and organisation of the neuronal cytoskeleton, Dis. Model. Mech. 7 (2014) 711-722. doi: $10.1242 / \mathrm{dmm} .015222$.

[372] A.K. Nicholas, M. Khurshid, J. Désir, O.P. Carvalho, J.J. Cox, G. Thornton, R. Kausar, M. Ansar, W. Ahmad, A. Verloes, S. Passemard, J.-P. Misson, S. Lindsay, F. Gergely, W.B. Dobyns, E. Roberts, M. Abramowicz, C.G. Woods, WDR62 is associated with the spindle pole and is mutated in human microcephaly, Nat. Genet. 42 (2010) 1010-1014. doi:10.1038/ng.682.

[373] C. Novorol, J. Burkhardt, K.J. Wood, A. Iqbal, C. Roque, N. Coutts, A.D. Almeida, J. He, C.J. Wilkinson, W.A. Harris, Microcephaly models in the developing zebrafish retinal neuroepithelium point to an underlying defect in metaphase progression, Open Biol. 3 (2013) 130065. doi:10.1098/rsob.130065.

[374] J.-F. Chen, Y. Zhang, J. Wilde, K.C. Hansen, F. Lai, L. Niswander, Microcephaly disease gene Wdr62 regulates mitotic progression of embryonic neural stem cells and brain size, Nat. Commun. 5 (2014) 3885. doi:10.1038/ncomms4885.

[375] P. Sgourdou, K. Mishra-Gorur, I. Saotome, O. Henagariu, B. Tuysuz, C. Campos, K. Ishigame, K. Giannikou, J.L. Quon, N. Sestan, A.O. Caglayan, M. Gunel, A. Louvi, Disruptions in asymmetric centrosome inheritance and WDR62-Aurora kinase B interactions in primary microcephaly, Sci. Rep. 7 (2017) 43708. doi:10.1038/srep43708.

[376] M. Bakircioglu, O.P. Carvalho, M. Khurshid, J.J. Cox, B. Tuysuz, T. Barak, S. Yilmaz, O. Caglayan, A. Dincer, A.K. Nicholas, O. Quarrell, K. Springell, G. Karbani, S. Malik, C. Gannon, E. Sheridan, M. Crosier, S.N. Lisgo, S. Lindsay, K. Bilguvar, F. Gergely, M. Gunel, C.G. Woods, The essential role of centrosomal NDE1 in human cerebral cortex neurogenesis, Am. J. Hum. Genet. 88 (2011) 523-535. doi:10.1016/j.ajhg.2011.03.019.

[377] L. O’Donnell, D. Rhodes, S.J. Smith, D.J. Merriner, B.J. Clark, C. Borg, B. Whittle, A.E. O’Connor, L.B. Smith, F.J. McNally, D.M. de Kretser, C.C. Goodnow, C.J. Ormandy, D. Jamsai, M.K. O’Bryan, An essential role for katanin p 80 and microtubule severing in male gamete production, PLoS Genet. 8 (2012) e1002698. doi:10.1371/journal.pgen.1002698.

[378] W.F. Hu, O. Pomp, T. Ben-Omran, A. Kodani, K. Henke, G.H. Mochida, T.W. Yu, M.B. Woodworth, C. Bonnard, G.S. Raj, T.T. Tan, H. Hamamy, A. Masri, M. Shboul, M. Al Saffar, J.N. Partlow, M. Al-Dosari, A. Alazami, M. Alowain, F.S. Alkuraya, J.F. Reiter, M.P. Harris, B. Reversade, C.A. Walsh, Katanin p80 regulates human cortical development by limiting centriole and cilia number, Neuron. 84 (2014) 1240-1257. doi:10.1016/j.neuron.2014.12.017.

[379] U. Rudolph, M.J. Finegold, S.S. Rich, G.R. Harriman, Y. Srinivasan, P. Brabet, G. Boulay, A. Bradley, L. Birnbaumer, Ulcerative colitis and adenocarcinoma of the colon in G alpha i2-deficient mice, Nat. Genet. 10 (1995) 143-150. doi:10.1038/ng0695-143.

[380] L. Lange, A.T. Pagnamenta, S. Lise, S. Clasper, H. Stewart, E.S. Akha, G. Quaghebeur, S.J.L. Knight, D.A. Keays, J.C. Taylor, U. Kini, A de novo frameshift in HNRNPK causing a Kabuki-like syndrome with nodular heterotopia, Clin. Genet. 90 (2016) 258262. doi:10.1111/cge. 12773 .

[381] E.K. Ruzzo, J.-M. Capo-Chichi, B. Ben-Zeev, D. Chitayat, H. Mao, A.L. Pappas, Y. Hitomi, Y.-F. Lu, X. Yao, F.F. Hamdan, K. Pelak, H. Reznik-Wolf, I. Bar-Joseph, D. Oz-Levi, D. Lev, T. Lerman-Sagie, E. Leshinsky-Silver, Y. Anikster, E. Ben-Asher, T. Olender, L. Colleaux, J.-C. Décarie, S. Blaser, B. Banwell, R.B. Joshi, X.-P. He, L. Patry, R.J. Silver, S. Dobrzeniecka, M.S. Islam, A. Hasnat, M.E. Samuels, D.K. Aryal, R.M. Rodriguiz, Y.-H. Jiang, W.C. Wetsel, J.O. McNamara, G.A. Rouleau, D.L. Silver, D. Lancet, E. Pras, G.A. Mitchell, J.L. Michaud, D.B. Goldstein, Deficiency of asparagine synthetase causes congenital microcephaly and a progressive form of encephalopathy, Neuron. 80 (2013) 429-441. doi:10.1016/j.neuron.2013.08.013.

[382] M.Z. Seidahmed, M.A. Salih, O.B. Abdulbasit, A. Samadi, K. Al Hussien, A.M. Miqdad, M.S. Biary, A.M. Alazami, I.A. Alorainy, M.M. Kabiraj, R. Shaheen, F.S. Alkuraya, Hyperekplexia, microcephaly and simplified gyral pattern caused by novel ASNS mutations, case report, BMC Neurol. 16 (2016) 105. doi:10.1186/s12883-016-0633-0.

[383] P.M. Campeau, G.M. Lenk, J.T. Lu, Y. Bae, L. Burrage, P. Turnpenny, J. Román Corona-Rivera, L. Morandi, M. Mora, H. Reutter, A.T. Vulto-van Silfhout, L. Faivre, E. Haan, R.A. Gibbs, M.H. Meisler, B.H. Lee, Yunis-Varón syndrome is caused by mutations in FIG4, encoding a phosphoinositide phosphatase, Am. J. Hum. Genet. 92 (2013) 781-791. doi:10.1016/j.ajhg.2013.03.020.

[384] S. Baulac, G.M. Lenk, B. Dufresnois, B. Ouled Amar Bencheikh, P. Couarch, J. Renard, P.A. Larson, C.J. Ferguson, E. Noé, K. Poirier, C. Hubans, S. Ferreira, R. Guerrini, R. Ouazzani, K.H. El Hachimi, M.H. Meisler, E. Leguern, Role of the phosphoinositide phosphatase FIG4 gene in familial epilepsy with polymicrogyria, Neurology. 82 (2014) 1068-1075. doi:10.1212/WNL.0000000000000241.

[385] V. Dénes, P. Witkovsky, M. Koch, D.D. Hunter, G. Pinzón-Duarte, W.J. Brunken, Laminin deficits induce alterations in the development of dopaminergic neurons in the mouse retina, Vis. Neurosci. 24 (2007) 549-562. doi:10.1017/S0952523807070514.

[386] T. Barak, K.Y. Kwan, A. Louvi, V. Demirbilek, S. Saygı, B. Tüysüz, M. Choi, H. Boyacı, K. Doerschner, Y. Zhu, H. Kaymakçalan, S. Yılmaz, M. Bakırcıoğlu, A.O. Cağlayan, A.K. Oztürk, K. Yasuno, W.J. Brunken, E. Atalar, C. Yalçınkaya, A. Dinçer, R.A. Bronen, S. Mane, T. Ozçelik, R.P. Lifton, N. Sestan, K. Bilgüvar, M. Günel, Recessive LAMC3 mutations cause malformations of occipital cortical development, Nat. Genet. 43 (2011) 590-594. doi:10.1038/ng.836.

[387] A.M. Waters, R. Asfahani, P. Carroll, L. Bicknell, F. Lescai, A. Bright, E. Chanudet, A. Brooks, S. Christou-Savina, G. Osman, P. Walsh, C. Bacchelli, A. Chapgier, B. Vernay, D.M. Bader, C. Deshpande, M. O’ Sullivan, L. Ocaka, H. Stanescu, H.S. Stewart, F. Hildebrandt, E. Otto, C.A. Johnson, K. Szymanska, N. Katsanis, E. Davis, R. Kleta, M. Hubank, S. Doxsey, A. Jackson, E. Stupka M. Winey, P.L. Beales, The kinetochore protein, CENPF, is mutated in human ciliopathy and microcephaly phenotypes, J. Med. Genet. 52 (2015) 147-156. doi:10.1136/jmedgenet-2014-102691.

[388] I. Filges, E. Bruder, K. Brandal, S. Meier, D.E. Undlien, T.R. Waage, I. Hoesli, M. Schubach, T. de Beer, Y. Sheng, S. Hoeller, S. Schulzke, O. Røsby, P. Miny, S. Tercanli, T. Oppedal, P. Meyer, K.K. Selmer, P. Strømme, Strømme Syndrome Is a Ciliary Disorder Caused by Mutations in CENPF, Hum. Mutat. 37 (2016) 711. doi:10.1002/humu.22997.

[389] C.J. Poulton, R. Schot, S.K. Kia, M. Jones, F.W. Verheijen, H. Venselaar, M.-C.Y. de Wit, E. de Graaff, A.M. Bertoli-Avella, G.M.S. Mancini, Microcephaly with simplified gyration, epilepsy, and infantile diabetes linked to inappropriate apoptosis of neural progenitors, Am. J. Hum. Genet. 89 (2011) 265-276. doi:10.1016/j.ajhg.2011.07.006

[390] G.M.H. Abdel-Salam, A.E. Schaffer, M.S. Zaki, T. Dixon-Salazar, I.S. Mostafa, H.H. Afifi, J.G. Gleeson, A homozygous IER3IP1 mutation causes microcephaly with simplified gyral pattern, epilepsy, and permanent neonatal diabetes syndrome (MEDS), Am. J. Med. Genet. A. 158A (2012) 2788-2796. doi:10.1002/ajmg.a.35583.

[391] A.G. Bassuk, R.H. Wallace, A. Buhr, A.R. Buller, Z. Afawi, M. Shimojo, S. Miyata, S. Chen, P. Gonzalez-Alegre, H.L. Griesbach, S. Wu, M. Nashelsky, E.K. Vladar, D. Antic, P.J. Ferguson, S. Cirak, T. Voit, M.P. Scott, J.D. Axelrod, C. Gurnett, A.S. Daoud, S Kivity, M.Y. Neufeld, A. Mazarib, R. Straussberg, S. Walid, A.D. Korczyn, D.C. Slusarski, S.F. Berkovic, H.I. El-Shanti, A homozygous mutation in human PRICKLE1 causes an autosomal-recessive progressive myoclonus epilepsy-ataxia syndrome, Am. J. Hum. Genet. 83 (2008) 572-581. doi:10.1016/j.ajhg.2008.10.003. 
[392] H. Tao, J.R. Manak, L. Sowers, X. Mei, H. Kiyonari, T. Abe, N.S. Dahdaleh, T. Yang, S. Wu, S. Chen, M.H. Fox, C. Gurnett, T. Montine, T. Bird, L.G. Shaffer, J.A. Rosenfeld, J. McConnell, S. Madan-Khetarpal, E. Berry-Kravis, H. Griesbach, R.P. Saneto, M.P. Scott, D. Antic, J. Reed, R. Boland, S.N. Ehaideb, H. El-Shanti, V.B. Mahajan, P.J. Ferguson, J.D. Axelrod, A.-E. Lehesjoki, B. Fritzsch, D.C. Slusarski, J. Wemmie, N. Ueno, A.G. Bassuk, Mutations in prickle orthologs cause seizures in flies, mice, and humans, Am. J. Hum. Genet. 88 (2011) 138-149. doi:10.1016/j.ajhg.2010.12.012.

[393] P. Roll, G. Rudolf, S. Pereira, B. Royer, I.E. Scheffer, A. Massacrier, M.-P. Valenti, N. Roeckel-Trevisiol, S. Jamali, C. Beclin, C Seegmuller, M.-N. Metz-Lutz, A. Lemainque, M. Delepine, C. Caloustian, A. de Saint Martin, N. Bruneau, D. Depétris, M.-G. Mattéi, E. Flori, A. Robaglia-Schlupp, N. Lévy, B.A. Neubauer, R. Ravid, C. Marescaux, S.F. Berkovic, E. Hirsch, M. Lathrop, P. Cau, P. Szepetowski, SRPX2 mutations in disorders of language cortex and cognition, Hum. Mol. Genet. 15 (2006) 1195-1207. doi: $10.1093 / \mathrm{hmg} / \mathrm{ddl} 035$.

[394] B. Royer-Zemmour, M. Ponsole-Lenfant, H. Gara, P. Roll, C. Lévêque, A. Massacrier, G. Ferracci, J. Cillario, A. RobagliaSchlupp, R. Vincentelli, P. Cau, P. Szepetowski, Epileptic and developmental disorders of the speech cortex: ligand/receptor interaction of wild-type and mutant SRPX2 with the plasminogen activator receptor uPAR, Hum. Mol. Genet. 17 (2008) 36173630. doi: $10.1093 / \mathrm{hmg} / \mathrm{ddn} 256$.

[395] A.P. Russ, S. Wattler, W.H. Colledge, S.A. Aparicio, M.B. Carlton, J.J. Pearce, S.C. Barton, M.A. Surani, K. Ryan, M.C. Nehls, V. Wilson, M.J. Evans, Eomesodermin is required for mouse trophoblast development and mesoderm formation, Nature. 404 (2000) 95-99. doi:10.1038/35003601.

[396] L. Baala, S. Briault, H.C. Etchevers, F. Laumonnier, A. Natiq, J. Amiel, N. Boddaert, C. Picard, A. Sbiti, A. Asermouh, T. AttiéBitach, F. Encha-Razavi, A. Munnich, A. Sefiani, S. Lyonnet, Homozygous silencing of T-box transcription factor EOMES leads to microcephaly with polymicrogyria and corpus callosum agenesis, Nat. Genet. 39 (2007) 454-456. doi:10.1038/ng1993.

[397] S.J. Arnold, G.-J. Huang, A.F.P. Cheung, T. Era, S.-I. Nishikawa, E.K. Bikoff, Z. Molnár, E.J. Robertson, M. Groszer, The T-box transcription factor Eomes/Tbr2 regulates neurogenesis in the cortical subventricular zone, Genes Dev. 22 (2008) 2479-2484. doi:10.1101/gad.475408.

[398] S. Kantarci, L. Al-Gazali, R.S. Hill, D. Donnai, G.C.M. Black, E. Bieth, N. Chassaing, D. Lacombe, K. Devriendt, A. Teebi, M. Loscertales, C. Robson, T. Liu, D.T. MacLaughlin, K.M. Noonan, M.K. Russell, C.A. Walsh, P.K. Donahoe, B.R. Pober, Mutations in LRP2, which encodes the multiligand receptor megalin, cause Donnai-Barrow and facio-oculo-acoustico-renal syndromes, Nat. Genet. 39 (2007) 957-959. doi:10.1038/ng2063.

[399] O. Khalifa, Z. Al-Sahlawi, F. Imtiaz, K. Ramzan, R. Allam, A. Al-Mostafa, M. Abdel-Fattah, G. Abuharb, M. Nester, A. Verloes, H. Al-Zaidan, Variable expression pattern in Donnai-Barrow syndrome: Report of two novel LRP2 mutations and review of the literature, Eur. J. Med. Genet. 58 (2015) 293-299. doi:10.1016/j.ejmg.2014.12.008.

[400] J.N. Pulvers, J. Bryk, J.L. Fish, M. Wilsch-Bräuninger, Y. Arai, D. Schreier, R. Naumann, J. Helppi, B. Habermann, J. Vogt, R. Nitsch, A. Tóth, W. Enard, S. Pääbo, W.B. Huttner, Mutations in mouse Aspm (abnormal spindle-like microcephaly associated) cause not only microcephaly but also major defects in the germline, Proc. Natl. Acad. Sci. U. S. A. 107 (2010) 16595-16600. doi:10.1073/pnas.1010494107.

[401] A. Fujimori, K. Itoh, S. Goto, H. Hirakawa, B. Wang, T. Kokubo, S. Kito, S. Tsukamoto, S. Fushiki, Disruption of Aspm causes microcephaly with abnormal neuronal differentiation, Brain Dev. 36 (2014) 661-669. doi:10.1016/j.braindev.2013.10.006.

[402] W.-H. Lien, O. Klezovitch, T.E. Fernandez, J. Delrow, V. Vasioukhin, alphaE-catenin controls cerebral cortical size by regulating the hedgehog signaling pathway, Science. 311 (2006) 1609-1612. doi:10.1126/science.1121449.

[403] D. Mori, M. Yamada, Y. Mimori-Kiyosue, Y. Shirai, A. Suzuki, S. Ohno, H. Saya, A. Wynshaw-Boris, S. Hirotsune, An essential role of the aPKC-Aurora A-NDEL1 pathway in neurite elongation by modulation of microtubule dynamics, Nat. Cell Biol. 11 (2009) 1057-1068. doi:10.1038/ncb1919.

[404] Y.H. Youn, T. Pramparo, S. Hirotsune, A. Wynshaw-Boris, Distinct dose-dependent cortical neuronal migration and neurite extension defects in Lis1 and Ndel1 mutant mice, J. Neurosci. Off. J. Soc. Neurosci. 29 (2009) 15520-15530. doi:10.1523/JNEUROSCI.4630-09.2009.

[405] D.J. Doobin, S. Kemal, T.J. Dantas, R.B. Vallee, Severe NDE1-mediated microcephaly results from neural progenitor cell cycle arrests at multiple specific stages, Nat. Commun. 7 (2016) 12551. doi:10.1038/ncomms12551.

[406] W. Ikeda, H. Nakanishi, J. Miyoshi, K. Mandai, H. Ishizaki, M. Tanaka, A. Togawa, K. Takahashi, H. Nishioka, H. Yoshida, A. Mizoguchi, S. Nishikawa, Y. Takai, Afadin: A key molecule essential for structural organization of cell-cell junctions of polarized epithelia during embryogenesis, J. Cell Biol. 146 (1999) 1117-1132.

[407] C. Gil-Sanz, B. Landeira, C. Ramos, M.R. Costa, U. Müller, Proliferative defects and formation of a double cortex in mice lacking Mltt4 and Cdh2 in the dorsal telencephalon, J. Neurosci. Off. J. Soc. Neurosci. 34 (2014) 10475-10487. doi:10.1523/JNEUROSCI.1793-14.2014.

[408] A. Satyanarayana, K.O. Gudmundsson, X. Chen, V. Coppola, L. Tessarollo, J.R. Keller, S.X. Hou, RapGEF2 is essential for embryonic hematopoiesis but dispensable for adult hematopoiesis, Blood. 116 (2010) 2921-2931. doi:10.1182/blood-2010-01262964. 


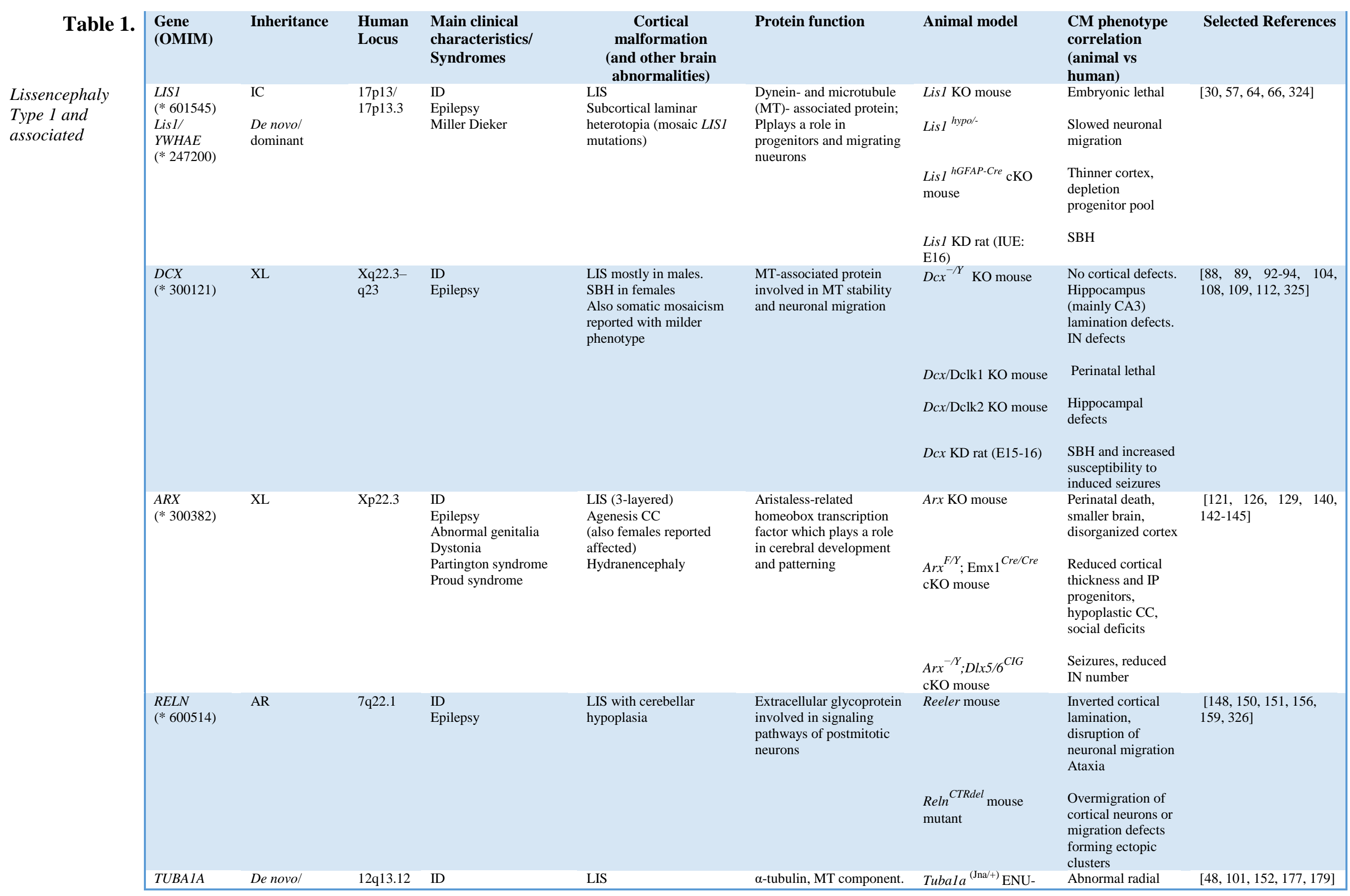




\begin{tabular}{|c|c|c|c|c|c|c|c|c|}
\hline$(* 602529)$ & dominant & & $\begin{array}{l}\text { Epilepsy } \\
\text { Motor delay }\end{array}$ & $\begin{array}{l}\text { SBH } \\
\text { Microcephaly } \\
\text { Dysmorphic basal ganglia } \\
\text { CC dysgenesis, } \\
\text { Brainstem and Cerebellar } \\
\text { hypoplasia }\end{array}$ & & $\begin{array}{l}\text { induced mouse } \\
\text { mutant }\end{array}$ & $\begin{array}{l}\text { migration in } \\
\text { hippocampus }\end{array}$ & \\
\hline $\begin{array}{l}\text { TUBG1 } \\
(* 191135)\end{array}$ & $\begin{array}{l}\text { De novol } \\
\text { dominant }\end{array}$ & $17 \mathrm{q} 21.2$ & $\begin{array}{l}\text { ID } \\
\text { Epilepsy }\end{array}$ & $\begin{array}{l}\text { LIS } \\
\text { SBH, } \\
\text { Microcephaly; } \\
\text { CC dysgenesis }\end{array}$ & $\begin{array}{l}\text { Gamma-tubulin, MT } \\
\text { nucleation }\end{array}$ & $\begin{array}{l}\text { Tubg1 KO mouse } \\
\text { Tubg1 KD mouse } \\
\text { (IUE: E14.5) }\end{array}$ & $\begin{array}{l}\text { Embryonic lethal } \\
\text { Arrest of migrating } \\
\text { cells }\end{array}$ & {$[49,187]$} \\
\hline $\begin{array}{l}\text { CDK5 } \\
(* 123831)\end{array}$ & AR & $7 q 36.1$ & $\begin{array}{l}\text { Patients died from } 2 \\
\text { days after birth to } 3 \\
\text { months of age of } \\
\text { respiratory failure }\end{array}$ & $\begin{array}{l}\text { LIS with cerebellar } \\
\text { hypoplasia } \\
\text { CC Agenesis } \\
\text { Microcephaly }\end{array}$ & $\begin{array}{l}\text { Cyclin-dependent kinase } \\
\text { (post-mitotic) }\end{array}$ & Cdk5 KO mouse & $\begin{array}{l}\text { Pre/Perinatal lethal. } \\
\text { Lack of cortical } \\
\text { lamination and } \\
\text { cerebellar foliation }\end{array}$ & {$[154,327]$} \\
\hline $\begin{array}{l}\text { KIF2A } \\
(* 602591)\end{array}$ & $\begin{array}{l}\text { De novol } \\
\text { dominant }\end{array}$ & $5 q 12.1$ & $\begin{array}{l}\text { ID/ DD } \\
\text { Epilepsy } \\
\text { Hypotonia }\end{array}$ & $\begin{array}{l}\text { LIS } \\
\text { SBH } \\
\text { CC dysgenesis, } \\
\text { Microcephaly }\end{array}$ & $\begin{array}{l}\text { MT motor protein; } \\
\text { induces MT } \\
\text { depolymerization } \\
\text { essential for both bipolar } \\
\text { spindle assembly and } \\
\text { chromosome movement }\end{array}$ & Kif2a KO mouse & $\begin{array}{l}\text { Perinatal lethal } \\
\text { Hippocampal } \\
\text { abnormalities }\end{array}$ & {$[49,328,329]$} \\
\hline $\begin{array}{l}\text { KIF5C } \\
(* 604593)\end{array}$ & $\begin{array}{l}\text { De novol } \\
\text { dominant }\end{array}$ & $\begin{array}{l}2 \mathrm{q} 23.1- \\
\mathrm{q} 23.2\end{array}$ & $\begin{array}{l}\text { ID/ DD } \\
\text { Seizures }\end{array}$ & $\begin{array}{l}\text { Pachygyria } \\
\text { CC dysgenesis, } \\
\text { Microcephaly }\end{array}$ & $\begin{array}{l}\text { Kinesin superfamily } \\
\text { Centrosome/spindle } \\
\text { integrity; cell cycle }\end{array}$ & & & {$[30,49]$} \\
\hline $\begin{array}{l}\text { VLDLR } \\
(* 192977)\end{array}$ & AR & $9 \mathrm{p} 24.2$ & $\begin{array}{l}\text { ID } \\
\text { Epilepsy } \\
\text { Ataxia }\end{array}$ & $\begin{array}{l}\text { LIS with cerebellar } \\
\text { hypoplasia (LCH) } \\
\text { Pontocerebellar } \\
\text { hypoplasia (PCH) }\end{array}$ & $\begin{array}{l}\text { Very Low Density } \\
\text { Lipoprotein Receptor } \\
\text { (RELN receptor) which } \\
\text { plays a role in neuronal } \\
\text { migration }\end{array}$ & Vldlr KO mouse & $\begin{array}{l}\text { Cortical neuron } \\
\text { overmigration }\end{array}$ & {$[155,157,159,330]$} \\
\hline $\begin{array}{l}\text { ACTG1 } \\
(* 102560)\end{array}$ & $\begin{array}{l}\text { De novol } \\
\text { dominant }\end{array}$ & $17 \mathrm{q} 25.3$ & $\begin{array}{l}\text { Baraitser-Winter } \\
\text { syndrome }\end{array}$ & $\begin{array}{l}\text { Pachygyria } \\
\text { Heterotopia } \\
\text { Microcephaly } \\
\text { CC dysgenesis }\end{array}$ & $\begin{array}{l}\text { Gamma actin, cytoskeletal } \\
\text { protein, functional actin- } \\
\text { based structures involve } \\
\text { in cell shape, motility, cell } \\
\text { division, endocytosis } \\
\text { generates contractile force }\end{array}$ & Actg1 KO mouse & $\begin{array}{l}\text { Some embryonic } \\
\text { lethality (born one } \\
\text { third of Mendelian } \\
\text { ratio). Lower body } \\
\text { weight. Hearing } \\
\text { loss in adulthood } \\
\text { and increasing } \\
\text { mortality }\end{array}$ & $\begin{array}{l}{[244,268,269,} \\
333]\end{array}$ \\
\hline $\begin{array}{l}A C T B \\
(* 102630)\end{array}$ & $\begin{array}{l}\text { De novol } \\
\text { dominant }\end{array}$ & $7 \mathrm{p} 22.1$ & $\begin{array}{l}\text { Baraitser-Winter } \\
\text { syndrome }\end{array}$ & $\begin{array}{l}\text { Pachygyria } \\
\text { Microcephaly } \\
\text { CC dysgenesis }\end{array}$ & $\begin{array}{l}\text { Beta actin, involved in } \\
\text { cell proliferation, } \\
\text { migration, vesicle } \\
\text { trafficking, G-actin pool, } \\
\text { and secretion }\end{array}$ & Actb KO mouse & Embryonic lethal & {$[244,268,332-334]$} \\
\hline $\begin{array}{l}N D E 1 \\
(* 609449)\end{array}$ & $\mathrm{AR}$ & $16 \mathrm{p} 13.11$ & $\begin{array}{l}\text { ID/ DD } \\
\text { Epilepsy }\end{array}$ & $\begin{array}{l}\text { LIS with microcephaly } \\
\text { Microhydranencephaly } \\
\text { CC agenesis }\end{array}$ & $\begin{array}{l}\text { Nuclear migration } \\
\text { Centrosome duplication } \\
\text { Mitotic spindle assembly } \\
\text { Reduced progenitor cell } \\
\text { division and altered } \\
\text { neuronal cell fate } \\
\text { Cilium dynamics and cell } \\
\text { cycle progression }\end{array}$ & Nde1KO mouse & $\begin{array}{l}\text { Smaller brain than } \\
-/+ \text { or Wt mice, } \\
\text { fewer neurons and } \\
\text { thin superficial } \\
\text { cortical layers II to } \\
\text { IV }\end{array}$ & [77-79] \\
\hline $\begin{array}{l}\text { DYNC1H1 } \\
(* 600112)\end{array}$ & $\begin{array}{l}\text { De novol } \\
\text { dominant }\end{array}$ & $14 q 32.31$ & $\begin{array}{l}\text { ID } \\
\text { Epilepsy } \\
\text { Motor neuron disease }\end{array}$ & $\begin{array}{l}\text { LIS } \\
\text { PMG } \\
\text { Microcephaly } \\
\text { CC dysgenesis. }\end{array}$ & $\begin{array}{l}\text { Dynein Cytoplasmic } 1 \\
\text { Heavy Chain } 1 \mathrm{MT}- \\
\text { activated ATPases that } \\
\text { function as molecular }\end{array}$ & $\begin{array}{l}\text { Legs at odd angles } \\
(\text { Loa/+), Cramping I } \\
(\text { Cra/+) and } \\
\text { Sprawling (Swl/+) }\end{array}$ & $\begin{array}{l}\text { Abnormal neuronal } \\
\text { migration and axon } \\
\text { growth, as well as } \\
\text { neurodegeneration }\end{array}$ & {$[30,49,335]$} \\
\hline
\end{tabular}


Dysmorphic basal gangli

Brainstem and cerebell
hypoplasia.

Nodular heterotopias intracellular motors

including retrograde

axonal transport, prote

sorting, organelle

movement, and spindle

dynamics mouse models

missense Dynclhl

mutations

Loa and Cra

(missense Dynclhl

Neonatal lethal

mutation)

Dync1h1 KO mouse

Embryonic lethal 


\begin{tabular}{|c|c|c|c|c|c|c|c|c|c|}
\hline Table 2. & $\begin{array}{l}\text { Gene } \\
\text { (OMIM) }\end{array}$ & $\begin{array}{l}\text { Inherita } \\
\text { nce }\end{array}$ & $\begin{array}{l}\text { Human } \\
\text { Locus }\end{array}$ & $\begin{array}{l}\text { Main clinical } \\
\text { characteristics/ } \\
\text { Syndromes }\end{array}$ & $\begin{array}{c}\text { Cortical } \\
\text { malformation } \\
\text { (and other brain } \\
\text { abnormalities) }\end{array}$ & Protein function & Animal model & $\begin{array}{l}\text { CM phenotype } \\
\text { correlation } \\
\text { (animal vs } \\
\text { human) }\end{array}$ & Selected References \\
\hline \multirow[t]{6}{*}{ Tubulinopathies } & $\begin{array}{l}\text { TUBA1A } \\
(* 602529)\end{array}$ & $\begin{array}{l}\text { De novol } \\
\text { dominant }\end{array}$ & $12 \mathrm{q} 13.12$ & $\begin{array}{l}\text { ID } \\
\text { Epilepsy } \\
\text { Ataxia } \\
\text { Motor delay } \\
\text { Tetraplegia }\end{array}$ & $\begin{array}{l}\text { Multiple: } \\
\text { LIS / Microlissencephaly/ } \\
\text { PMG-like cortical } \\
\text { dysplasia } \\
\text { Can include: } \\
\text { CC dysgenesis, } \\
\text { Cerebellar and brainstem } \\
\text { hypoplasia / dysplasia } \\
\text { Dysmorphic basal ganglia }\end{array}$ & $\begin{array}{l}\alpha \text {-tubulin, MT component. } \\
\text { Heterodimer with } \beta \text { - } \\
\text { tubulin. }\end{array}$ & $\begin{array}{l}\text { Tubala }{ }^{(\mathrm{Jna} /+)} \text { ENU- } \\
\text { induced mutant } \\
\text { mouse }\end{array}$ & $\begin{array}{l}\text { Abnormal radial } \\
\text { migration (mainly } \\
\text { hippocampus) } \\
\text { Hippocampal } \\
\text { disorganization }\end{array}$ & $\begin{array}{l}{[47,48,152,176,177,} \\
179,336]\end{array}$ \\
\hline & $\begin{array}{l}\text { TUBB2A } \\
(* 615101)\end{array}$ & $\begin{array}{l}\text { De novol } \\
\text { dominant }\end{array}$ & $6 \mathrm{p} 25.2$ & $\begin{array}{l}\text { Epilepsy } \\
\text { Global developmental } \\
\text { delay } \\
\text { Hypotonia }\end{array}$ & $\begin{array}{l}\text { Pachygyria / Simplified } \\
\text { gyral pattern } \\
\text { Can include: } \\
\text { CC dysgenesis, } \\
\text { Cerebellar and brainstem } \\
\text { hypoplasia / dysplasia } \\
\text { Dysmorphic basal ganglia }\end{array}$ & $\begin{array}{l}\beta \text {-tubulin subunit. } \beta \text { - } \\
\text { tubuline heterodimerize } \\
\text { with } \alpha \text {-tubulin. }\end{array}$ & & & {$[176,337]$} \\
\hline & $\begin{array}{l}\text { TUBB2B } \\
(* 612850)\end{array}$ & $\begin{array}{l}\text { De novol } \\
\text { dominant }\end{array}$ & $6 \mathrm{p} 25.2$ & $\begin{array}{l}\text { ID/ DD } \\
\text { Epilepsy } \\
\text { Mild hypotonia } \\
\text { Optic tract defects } \\
\text { Congenital fibrosis of } \\
\text { the extraocular muscles } \\
\text { (CFEOM) }\end{array}$ & $\begin{array}{l}\text { Cortical malformations } \\
\text { including } \\
\text { LIS / Microlissencephaly/ } \\
\text { PMG-like cortical } \\
\text { dysplasia symmetric or } \\
\text { asymmetric } \\
\text { Can include: } \\
\text { CC dysgenesis, } \\
\text { Cerebellar and brainstem } \\
\text { hypoplasia / dysplasia } \\
\text { Dysmorphic basal ganglia }\end{array}$ & $\begin{array}{l}\beta \text {-tubulin subunit, binds } \\
\text { to } \alpha \text {-tubulin. }\end{array}$ & $\begin{array}{l}\text { Tubb2b KO mouse } \\
\text { Tubb2 } 2^{b b r d p /+} \\
\text { heterozygous mutant } \\
\text { mouse } \\
\text { Tubb2b KD (IUE: } \\
\text { E15.5) rat }\end{array}$ & $\begin{array}{l}\text { Perinatal lethal } \\
\text { Abnormal } \\
\text { hippocampal } \\
\text { structure } \\
\text { Migration defects }\end{array}$ & $\begin{array}{l}{[30,47,173,176,180,} \\
181,185]\end{array}$ \\
\hline & $\begin{array}{l}\text { TUBB5 } \\
(\text { TUBB }) \\
(* 191130)\end{array}$ & $\begin{array}{l}\text { De novol } \\
\text { dominant }\end{array}$ & $6 \mathrm{p} 21.33$ & $\begin{array}{l}\text { ID/ DD } \\
\text { Microcephaly } \\
\text { Non neurological } \\
\text { phenotype congenital } \\
\text { symmetric } \\
\text { circumferential skin } \\
\text { creases (MIM 156610) }\end{array}$ & $\begin{array}{l}\text { Microcephaly } \\
\text { Multifocal PMG like } \\
\text { Cortical dysplasia / } \\
\text { Simplified gyral pattern } \\
\text { Can include: } \\
\text { CC dysgenesis, } \\
\text { Cerebellar and brainstem } \\
\text { hypoplasia / dysplasia } \\
\text { Dysmorphic basal ganglia }\end{array}$ & $\begin{array}{l}\beta \text { - tubulin subunit, binds } \\
\text { to } \alpha \text {-tubulin. }\end{array}$ & $\begin{array}{l}\text { Tubb5 KO mouse } \\
\text { Tubb5 KI mouse }\end{array}$ & $\begin{array}{l}\text { Microcephaly } \\
\text { due to massive } \\
\text { apoptosis. } \\
\text { Mitotic progression } \\
\text { defects }\end{array}$ & {$[184,186]$} \\
\hline & $\begin{array}{l}\text { TUBB3 } \\
(* 602661)\end{array}$ & $\begin{array}{l}\text { De novol } \\
\text { dominant }\end{array}$ & $16 \mathrm{q} 24.3$ & $\begin{array}{l}\text { Epilepsy } \\
\text { DD/ (ID) } \\
\\
\text { Non neurological } \\
\text { phenotype: Congenital } \\
\text { Fibrosis of Extraocular } \\
\text { Muscles 3A } \\
\text { (Nystagmus, non } \\
\text { paralytic strabismus, or } \\
\text { oculomotor apraxia) }\end{array}$ & $\begin{array}{l}\text { Cortical malformations } \\
\text { including } \\
\text { LIS / Microlissencephaly/ } \\
\text { PMG-like cortical } \\
\text { dysplasia } \\
\text { Can include: } \\
\text { CC dysgenesis, } \\
\text { Cerebellar and brainstem } \\
\text { hypoplasia / dysplasia } \\
\text { Dysmorphic basal ganglia }\end{array}$ & $\begin{array}{l}\beta \text { - tubulin subunit, binds } \\
\text { to } \alpha \text {-tubulin. }\end{array}$ & $\begin{array}{l}\text { Tubb3 }{ }^{\mathrm{R} 262 \mathrm{C} /+} \text { mouse } \\
\text { mutant } \\
\text { Tubb3 }{ }^{\mathrm{R} 262 \mathrm{C} / \mathrm{R} 262 \mathrm{C}} \\
\text { mouse mutant }\end{array}$ & $\begin{array}{l}\text { No eye phenotype. } \\
\text { Thin anterior } \\
\text { commissures } \\
\text { Perinatal lethal. } \\
\text { Defects in the } \\
\text { guidance of } \\
\text { commissural axons } \\
\text { and cranial nerves. } \\
\text { Agenesis/ thin CC. }\end{array}$ & {$[47,182,183,338]$} \\
\hline & & & & & & & $\begin{array}{l}\text { Tubb3 KD (IUE: } \\
\text { E14.5) mouse }\end{array}$ & Migration defects & \\
\hline
\end{tabular}




\begin{tabular}{|c|c|c|c|c|c|c|c|c|c|}
\hline Table 3. & $\begin{array}{l}\text { Gene } \\
\text { (OMIM) }\end{array}$ & Inheritance & $\begin{array}{l}\text { Human } \\
\text { Locus }\end{array}$ & $\begin{array}{l}\text { Main clinical } \\
\text { characteristics/ } \\
\text { Syndromes }\end{array}$ & $\begin{array}{c}\text { Cortical } \\
\text { malformation } \\
\text { (and other brain } \\
\text { abnormalities) }\end{array}$ & Protein function & Animal model & $\begin{array}{l}\text { CM phenotype } \\
\text { correlation (animal } \\
\text { vs human) }\end{array}$ & Selected References \\
\hline \multirow[t]{5}{*}{$\begin{array}{l}\text { Periventricular } \\
\text { nodular } \\
\text { heterotopia }\end{array}$} & $\begin{array}{l}F L N A \\
(* 300017)\end{array}$ & $\begin{array}{l}\text { Dominant X- } \\
\text { linked }\end{array}$ & $\mathrm{Xq} 28$ & $\begin{array}{l}\text { ID / DD } \\
\text { Epilepsy } \\
\text { Can include: } \\
\text { cardiac valvular } \\
\text { dysplasia } \\
\text { coagulopathy } \\
\text { Ehlers-Danlos } \\
\text { syndrome } \\
\text { Chronic idiopathic } \\
\text { intestinal } \\
\text { pseudoobstruction } \\
\text { (CIIP) }\end{array}$ & $\mathrm{PVH}$ in females & $\begin{array}{l}\text { Actin-binding protein, } \\
\text { regulates } \\
\text { reorganization of the } \\
\text { actin cytoskeleton. } \\
\text { Affects RGCs and IPs } \\
\text { Interacts with } \\
\text { meckelin and mediates } \\
\text { ciliogenesis }\end{array}$ & $\begin{array}{l}\text { Flna cKO mouse } \\
(\text { Flna } \text { flox/y; EmxlCre+ }) \\
\text { Flna cKO; Flnb KO } \\
\text { mouse } \\
\text { (NPCs double mutant } \\
\text { mouse) }\end{array}$ & $\begin{array}{l}\text { Similar to FLNA } \\
\text { mutations in males. } \\
\text { Embryonic lethal, } \\
\text { abnormal vessels, } \\
\text { cardiac defects. } \\
\text { Die at birth } \\
\text { Mild phenotype in } \\
\text { neuroependyma. } \\
\text { PVH, mislocalized of } \\
\text { IPs, increased IP } \\
\text { neurogenesis. Loss of } \\
\text { epithelial-like features } \\
\text { of mutant RG cells. }\end{array}$ & $\begin{array}{l}{[30,190,191,198,200,} \\
202]\end{array}$ \\
\hline & & & & & & & $\begin{array}{l}\text { Flna }{ }^{\text {Dilp2 } 2} \text { hemizygote } \\
\text { mutant mouse (Dilp2: } \\
\text { dilated pupils 2) }\end{array}$ & $\begin{array}{l}\text { Embryonic lethal } \\
\text { (E15.5). Cardiac } \\
\text { defects. At E13.5 PVH } \\
\text { and intraventricular } \\
\text { heterotopia. Broad } \\
\text { midline, fusion of the } \\
\text { fourth ventricle with } \\
\text { the aqueduct and the } \\
\text { presence of severe } \\
\text { oedema. Disruption of } \\
\text { VZ, meckelin } \\
\text { distribution, cilia } \\
\text { formation and basal } \\
\text { body position. }\end{array}$ & \\
\hline & & & & & & & $\begin{array}{l}\text { Flna KD MO } \\
\text { Zebrafish }\end{array}$ & $\begin{array}{l}\text { Increased mortality, } \\
\text { hydrocephalus, eye } \\
\text { defects, cardiac } \\
\text { oedema, body axis } \\
\text { defects, among others. }\end{array}$ & \\
\hline & $\begin{array}{l}A R F G E F 2 \\
(* 605371)\end{array}$ & AR & $20 \mathrm{q} 13.13$ & $\begin{array}{l}\text { ID/DD } \\
\text { Epilepsy } \\
\text { Postnatal } \\
\text { Microcephaly } \\
\text { Dystonia }\end{array}$ & $\begin{array}{l}\text { PVH } \\
\text { Thin CC }\end{array}$ & $\begin{array}{l}\text { ADP Ribosylation } \\
\text { Factor Guanine } \\
\text { Nucleotide Exchange } \\
\text { Factor 2. Regulates } \\
\text { exchange of GDP for } \\
\text { GTP and plays an } \\
\text { important role in } \\
\text { intracellular vesicular } \\
\text { trafficking }\end{array}$ & $\begin{array}{l}\text { Arfgef2 } 2^{G T / G T} \text { (gene } \\
\text { trap insertion) mouse } \\
\begin{array}{l}\text { Arfgef2 } 2^{G T /+} \text { mouse } \\
\text { (het) }\end{array}\end{array}$ & $\begin{array}{l}\text { Embryonic lethal } \\
\text { Fertile and with no } \\
\text { obvious malformation }\end{array}$ & $\begin{array}{l}{[191,193,194,205,} \\
339]\end{array}$ \\
\hline & $\begin{array}{l}\text { FAT4 } \\
(* 612411) \\
\text { DCHS1 }\end{array}$ & AR & $4 \mathrm{q} 28.1$ & $\begin{array}{l}\text { Van Maldergem } \\
\text { syndrome-2 }\end{array}$ & PVH & $\begin{array}{l}\text { Member of the } \\
\text { protocadherin family } \\
\text { which binds and }\end{array}$ & $\begin{array}{l}\text { Fat4 KO mouse } \\
\text { Fat4 KD (IUE: E13- }\end{array}$ & $\begin{array}{l}\text { Perinatal lethal } \\
\text { Increased progenitor }\end{array}$ & {$[194,340]$} \\
\hline
\end{tabular}




\begin{tabular}{|c|c|c|c|c|c|c|c|c|}
\hline & & & $\begin{array}{l}\text { Hennekam } \\
\text { lymphangiectasia- } \\
\text { lymphedema } \\
\text { syndrome-(without } \\
\mathrm{PVH} \text { ) }\end{array}$ & & $\begin{array}{l}\text { another protocadherin } \\
\text { called DCHS1. FAT4 } \\
\text { and DCHS1 form an } \\
\text { apically located } \\
\text { adhesive complex in } \\
\text { the developing brain. } \\
\text { Cell polarity }\end{array}$ & E14) mouse & $\begin{array}{l}\text { number in VZ and } \\
\text { SVZ. Decreased } \\
\text { neurogenesis. } \\
\text { Ectopic accumulation } \\
\text { at VL. } \\
\text { Differentiation defects } \\
\text { between the Pax6+ } \\
\text { and Tbr2+ states }\end{array}$ & \\
\hline $\begin{array}{l}\text { ERMARD } \\
(\text { C6orf70) } \\
(* 615532)\end{array}$ & $\begin{array}{l}\text { De novol } \\
\text { dominant }\end{array}$ & $6 \mathrm{q} 27$ & $\begin{array}{l}\text { ID } \\
\text { Epilepsy } \\
\text { Developmental delay } \\
\text { Hypotonia } \\
\text { Hydrocephalus } \\
\text { Enlarged ventricles } \\
\text { Macrocephaly } \\
\text { Microcephaly } \\
\text { Micrognathia }\end{array}$ & $\begin{array}{l}\mathrm{PVH} \\
\text { CC dysplastic } \\
\text { Cerebellar abnormalities }\end{array}$ & $\begin{array}{l}\text { Protein with } 2 \\
\text { transmembrane } \\
\text { domains localized in } \\
\text { the endoplasmic } \\
\text { reticulum. }\end{array}$ & $\begin{array}{l}\text { Ermard KD rat (IUE: } \\
\text { E15) }\end{array}$ & $\begin{array}{l}\text { Neuronal migration } \\
\text { defects and PVH }\end{array}$ & {$[197,341]$} \\
\hline $\begin{array}{l}\text { NEDD4L } \\
(* 606384)\end{array}$ & $\begin{array}{l}\text { De novo/ } \\
\text { dominant }\end{array}$ & $18 \mathrm{q} 21.31$ & $\begin{array}{l}\text { ID/DD/ } \\
\text { Seizures } \\
\text { Toe syndactyly } \\
\text { Can include: } \\
\text { Cleft palate } \\
\text { Dysmorphic features }\end{array}$ & $\begin{array}{l}\text { PVH +/- PMG } \\
\text { CC dysmorphic }\end{array}$ & $\begin{array}{l}\text { HECT-type E3 } \\
\text { ubiquitin ligase that } \\
\text { regulates channel } \\
\text { internalization and } \\
\text { turnover }\end{array}$ & $\begin{array}{l}\text { Nedd4l KO mouse } \\
\text { Nedd4l mutant } \\
\text { overexpression mouse } \\
\text { (IUE:E14.5) }\end{array}$ & $\begin{array}{l}\text { Perinatal lethal } \\
\text { Abnormal distribution } \\
\text { of neurons, increased } \\
\text { progenitor number, } \\
\text { migration } \\
\text { abnormalities }\end{array}$ & {$[189,342]$} \\
\hline
\end{tabular}

Van Maldergem syndrome is characterized by dysmorphic facies, tracheomalacia, deafness, renal hypoplasia microtia, ID, and skeletal dysplasia. And periventricular nodular heterotopia 


\begin{tabular}{|c|c|c|c|c|c|c|c|c|c|}
\hline Table 4. & $\begin{array}{l}\text { Gene } \\
\text { (OMIM) }\end{array}$ & Inheritance & $\begin{array}{l}\text { Human } \\
\text { Locus }\end{array}$ & $\begin{array}{l}\text { Main clinical } \\
\text { characteristics/ } \\
\text { Syndromes }\end{array}$ & $\begin{array}{c}\text { Cortical } \\
\text { malformation } \\
\text { (and other brain } \\
\text { abnormalities) }\end{array}$ & Protein function & Animal model & $\begin{array}{l}\text { CM phenotype } \\
\text { correlation } \\
\text { (animal vs } \\
\text { human) }\end{array}$ & Selected References \\
\hline \multirow[t]{3}{*}{$\begin{array}{l}\text { Congenital } \\
\text { muscular } \\
\text { dystrophy- } \\
\text { dystroglycanopat } \\
\text { hy with brain and } \\
\text { eye anomalies } \\
\text { (type A), which } \\
\text { includes both the } \\
\text { more severe } \\
\text { Walker-Warburg } \\
\text { syndrome } \\
\text { (WWS) and the } \\
\text { slightly less } \\
\text { severe muscle- } \\
\text { eye-brain disease } \\
\text { (MEB) }\end{array}$} & $\begin{array}{l}D A G 1 \\
(* 128239)\end{array}$ & $\mathrm{AR}$ & $3 \mathrm{p} 21.31$ & $\begin{array}{l}2 \text { different forms of } \\
\text { muscular dystrophy- } \\
\text { dystroglycanopathy } \\
\text { (MDDG): } \\
\text { - type A19: a severe } \\
\text { form with brain and } \\
\text { eye anomalies, } \\
\text { (WWS) or (MEB); } \\
\text { - type C9 a milder } \\
\text { limb-girdle form }\end{array}$ & $\begin{array}{l}\text { Classic features of } \\
\text { Walker-Warburg } \\
\text { syndrome, including } \\
\text { cobblestone } \\
\text { lissencephaly, enlarged } \\
\text { ventricles/ hydrocephalus, } \\
\text { cerebellar and brainstem } \\
\text { hypoplasia } \\
\text { Bilateral multicystic white } \\
\text { matter disease with } \\
\text { macrocephaly }\end{array}$ & $\begin{array}{l}\text { Dystroglycan, } \\
\text { component of } \\
\text { dystrophin- } \\
\text { glycoprotein complex } \\
\text { that links the } \\
\text { extracellular matrix } \\
\text { and the cytoskeleton, } \\
\text { especially in skeletal } \\
\text { muscle. After O- and } \\
\text { N-glycosylation, and } \\
\text { proteolytic processing } \\
\text { generates alpha and } \\
\text { beta subunits. Involved } \\
\text { in laminin and BM } \\
\text { assembly, sarcolemmal } \\
\text { stability, cell survival, } \\
\text { peripheral nerve } \\
\text { myelination, nodal } \\
\text { structure, cell } \\
\text { migration, and } \\
\text { epithelial polarization }\end{array}$ & $\begin{array}{l}\text { GFAP }{ }^{-\mathrm{Cre}} / \mathrm{DAG} 1^{\text {lox/- }} \\
\text { GFAP-Cre, } \\
\text { Dagl } 1^{\text {lox/lox }} \\
\text { mouse }\end{array}$ & $\begin{array}{l}\text { Embryonic lethal } \\
\text { No structural brain } \\
\text { abnormalities } \\
\text { Neuromuscular } \\
\text { abnormalities } \\
\text { KO: resembles } \\
\text { COB LIS. } \\
\text { Macrocephaly. } \\
\text { Heterotopia and } \\
\text { other abnormalities } \\
\text { in several brain } \\
\text { regions (e.g. } \\
\text { cerebellum) } \\
\text { Axon guidance } \\
\text { defects, } \\
\text { fragmentation of } \\
\text { the BM }\end{array}$ & {$[208,209,230,343]$} \\
\hline & $\begin{array}{l}\text { POMT1 } \\
(* 607423) \\
P O M T 2 \\
(* 607439)\end{array}$ & AR & $\begin{array}{l}9 \mathrm{q} 34.13 \\
14 \mathrm{q} 24.3\end{array}$ & $\begin{array}{l}3 \text { different forms of } \\
\text { MDDG }^{1} \text { - } \\
\text { - type A1, a severe } \\
\text { form with brain and } \\
\text { eye anomalies } \\
\text { formerly designated } \\
\text { Walker-Warburg } \\
\text { syndrome (WWS) or } \\
\text { muscle-eye-brain } \\
\text { disease (MEB); } \\
\text { - type B1, a less severe } \\
\text { form with ID; } \\
\text { - type C1, a milder } \\
\text { limb-girdle form, } \\
\text { previously } \\
\text { designated } \\
\text { LGMD2K }\end{array}$ & $\begin{array}{l}\text { Classic features of } \\
\text { Walker-Warburg } \\
\text { syndrome, including } \\
\text { cobblestone } \\
\text { lissencephaly, enlarged } \\
\text { ventricles, cerebellar } \\
\text { hypoplasia } \\
\text { Classic features of MEB: } \\
\text { pachygyria-type cortical } \\
\text { malformation, septal and } \\
\text { CC defects, } \\
\text { leukoencephalopathy, } \\
\text { cerebellar dysplasia with } \\
\text { cysts and severe } \\
\text { hypoplasia of the pons }\end{array}$ & $\begin{array}{l}\text { Protein O- } \\
\text { Mannosyltransferase } 1 \\
\text { and 2, requires } \\
\text { interaction with each } \\
\text { other for enzymatic } \\
\text { function }\end{array}$ & Pomt1 KO mouse & Embryonic lethal & $\begin{array}{l}{[69,215,216,218,296,} \\
344]\end{array}$ \\
\hline & $\begin{array}{l}\text { FKRP } \\
(* 606596)\end{array}$ & $\mathrm{AR}$ & $19 q 13.32$ & $\begin{array}{l}3 \text { different forms of } \\
\text { MDDG: } \\
\text { - type A5, a severe } \\
\text { form with brain and } \\
\text { eye anomalies } \\
\text { formerly designated } \\
\text { Walker-Warburg } \\
\text { syndrome (WWS) or } \\
\text { muscle-eye-brain } \\
\text { disease (MEB); } \\
\text { - type B5, a less severe }\end{array}$ & $\begin{array}{l}\text { Classic features of WWS } \\
\text { Classic features of MEB }\end{array}$ & $\begin{array}{l}\text { Fukutin Related } \\
\text { Protein, targets medial } \\
\text { Golgi apparatus and is } \\
\text { necessary for } \\
\text { posttranslational } \\
\text { modification of } \\
\text { dystroglycan }\end{array}$ & $\begin{array}{l}\text { Fkrp KD MO } \\
\text { Zebrafish } \\
\text { Fkrp-Neo Tyr307Asn/ } \\
\text { Tyr307Asn mutant } \\
\text { mouse } \\
\text { Fkrp KD mouse }\end{array}$ & $\begin{array}{l}\text { Hydrocephalus } \\
\text { Perinatal lethal } \\
\text { Completely } \\
\text { disorganized } \\
\text { cortex. Incomplete } \\
\text { formation of the } \\
\text { interhemispheric }\end{array}$ & $\begin{array}{l}{[210,218,225,232,} \\
345]\end{array}$ \\
\hline
\end{tabular}




\begin{tabular}{|c|c|c|c|c|c|c|c|c|}
\hline & & & $\begin{array}{l}\text { form with or without } \\
\text { ID; } \\
\text { - type C5, a milder } \\
\text { limb-girdle form, } \\
\text { previously } \\
\text { designated } \\
\text { LGMD2K }\end{array}$ & & & & $\begin{array}{l}\text { fissure. } \\
\text { Hydrocephalus. } \\
\text { Defects in the pial } \\
\text { BM. Disruption of } \\
\text { RG scaffold. } \\
\text { Mislocalization of } \\
\text { Cajal Retzius cells }\end{array}$ & \\
\hline $\begin{array}{l}\text { FKTN } \\
(* 607440)\end{array}$ & $\mathrm{AR}$ & $9 \mathrm{q} 31.2$ & $\begin{array}{l}3 \text { different forms of } \\
\text { MDDG: } \\
\text { - Type A4: a severe } \\
\text { congenital form with } \\
\text { brain and eye } \\
\text { anomalies formerly } \\
\text { designated } \\
\text { Fukuyama congenital } \\
\text { muscular dystrophy } \\
\text { (FCMD), (WWS), or } \\
\text { (MEB); } \\
\text { - Type B4: a less } \\
\text { severe form without } \\
\text { ID; } \\
\text { Type C4: a milder } \\
\text { limb-girdle form, } \\
\text { previously } \\
\text { designated } \\
\text { LGMD2M }\end{array}$ & $\begin{array}{l}\text { Classic features of WWS } \\
\text { Classic features of MEB }\end{array}$ & $\begin{array}{l}\text { Fukutin, putative } \\
\text { transmembrane } \\
\text { protein, localized in } \\
\text { cis-Golgi apparatus } \\
\text { where it may be } \\
\text { involved in the } \\
\text { glycosylation of alpha- } \\
\text { dystroglycan }\end{array}$ & $\begin{array}{l}\text { Fktn KD MO } \\
\text { Zebrafish }\end{array}$ & Hydrocephalus & {$[212,218,225]$} \\
\hline $\begin{array}{l}\text { POMGNT1 } \\
(* 606822)\end{array}$ & $\mathrm{AR}$ & $1 \mathrm{p} 34.1$ & $\begin{array}{l}3 \text { different forms of } \\
\text { MDDG: } \\
\text { - type A3: a severe } \\
\text { congenital form with } \\
\text { brain and eye } \\
\text { anomalies, (WWS) } \\
\text { or (MEB); } \\
\text { - type B3: a less severe } \\
\text { congenital form with } \\
\text { ID; } \\
\text { - type C3 a milder } \\
\text { limb-girdle form }\end{array}$ & $\begin{array}{l}\text { Classic features of WWS } \\
\text { Classic features of MEB }\end{array}$ & $\begin{array}{l}\text { Protein O-Linked } \\
\text { Mannose N- } \\
\text { Acetylglucosaminyl } \\
\text { transferase } 1 \text { located in } \\
\text { the Golgi apparatus }\end{array}$ & Pomgnt1 KO mouse & $\begin{array}{l}\text { COB-like } \\
\text { phenotype } \\
\text { including } \\
\text { extracortical layer } \\
\text { (with ectopic } \\
\text { neurons and glial } \\
\text { cells), disorganized } \\
\text { lateral cortex, } \\
\text { ventricular dilation } \\
\text { (hydrocephalus), } \\
\text { defects in the pial } \\
\text { BM, disruption of } \\
\text { the radial glial } \\
\text { scaffold, } \\
\text { mislocalized Cajal } \\
\text { Retzius cells. }\end{array}$ & {$[210,213,215,218]$} \\
\hline $\begin{array}{l}\text { POMGNT2 } \\
(* 614828)\end{array}$ & $\mathrm{AR}$ & $3 \mathrm{p} 22.1$ & $\begin{array}{l}\text { MDDG: } \\
\text { - type A8: a severe } \\
\text { congenital form with } \\
\text { brain and eye } \\
\text { anomalies, (WWS) }\end{array}$ & $\begin{array}{l}\text { Classic features of WWS, } \\
\text { including cobblestone } \\
\text { lissencephaly, enlarged } \\
\text { ventricles, cerebellar } \\
\text { hypoplasia }\end{array}$ & $\begin{array}{l}\text { Protein O-Linked } \\
\text { Mannose N- } \\
\text { Acetylglucosaminyl } \\
\text { transferase 2, involved } \\
\text { in the biosynthesis of } \\
\text { the phosphorylated O- } \\
\text { mannosyl } \\
\text { trisaccharide, a } \\
\text { carbohydrate structure } \\
\text { present in alpha- } \\
\text { dystroglycan (DAG1) }\end{array}$ & Pomgnt $2 \mathrm{KO}$ mouse & $\begin{array}{l}\text { Perinatal death. } \\
\text { Embryos with pial } \\
\text { basement } \\
\text { membrane } \\
\text { disruption. Ectopic } \\
\text { clusters of subplate } \\
\text { neurons and Cajal } \\
\text { Retzius cells, lost } \\
\text { polarity and } \\
\text { misoriented } \\
\text { neurons. }\end{array}$ & {$[223,235,346]$} \\
\hline
\end{tabular}




\begin{tabular}{|c|c|c|c|c|c|c|c|c|}
\hline & & & & & & $\begin{array}{l}\text { Pomgnt } 2 \text { KD MO } \\
\text { Zebrafish }\end{array}$ & $\begin{array}{l}\text { Embryos with short } \\
\text { body, thick and } \\
\text { poorly developed } \\
\text { tail, and no } \\
\text { discernible eyes or } \\
\text { head structures }\end{array}$ & \\
\hline $\begin{array}{l}\text { LARGE } \\
(* 613154)\end{array}$ & $\mathrm{AR}$ & $22 q 12.3$ & $\begin{array}{l}\text { MDDG: } \\
\text { - type A6: a severe } \\
\text { congenital form with } \\
\text { brain and eye } \\
\text { anomalies, (WWS) } \\
\text { or (MEB) }\end{array}$ & $\begin{array}{l}\text { Classic features of WWS } \\
\text { Classic features of MEB }\end{array}$ & $\begin{array}{l}\mathrm{N} \text {-acetylglucosaminyl- } \\
\text { transferase gene family }\end{array}$ & Large $^{\text {myd }}$ mouse & $\begin{array}{l}\text { Muscular } \\
\text { dystrophy, } \\
\text { ophthalmic and } \\
\text { retinal defects. } \\
\text { Several brain } \\
\text { abnormalities (e.g. } \\
\text { cerebellum). COB- } \\
\text { like phenotype } \\
\text { (including ectopic } \\
\text { neurons and glial } \\
\text { cell, extra cortical } \\
\text { layer, defects in the } \\
\text { pial BM, disruption } \\
\text { of the radial glial } \\
\text { scaffold, } \\
\text { mislocalized Cajal } \\
\text { Retzius cells }\end{array}$ & 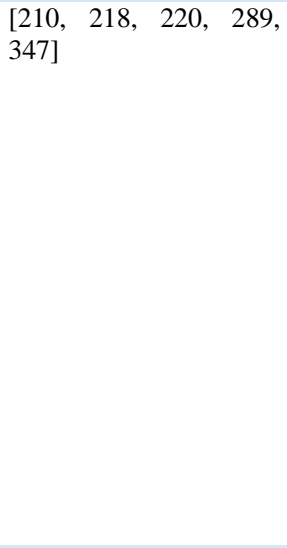 \\
\hline $\begin{array}{l}\text { TMTC3 } \\
(* 617218)\end{array}$ & AR & $12 \mathrm{q} 21.32$ & $\begin{array}{l}\text { COB with minimal eye } \\
\text { or muscle involvement } \\
\text { (normal CK levels). }\end{array}$ & Classic features of WWS & $\begin{array}{l}\text { Transmembrane and } \\
\text { tetratricopeptide } \\
\text { repeat-containing } \\
\text { protein family }\end{array}$ & Smile KO mouse & $\begin{array}{l}\text { Die after } 3 \text { PW. } \\
\text { Defects in fetal } \\
\text { lung development } \\
\text { and alveolarization } \\
\text { after birth. } \\
\text { Growth retardation }\end{array}$ & {$[215,348]$} \\
\hline $\begin{array}{l}I S P D \\
(* 614631)\end{array}$ & $\mathrm{AR}$ & $7 \mathrm{p} 21.2$ & $\begin{array}{l}2 \text { different forms of } \\
\text { MDDG: } \\
\text { - type A7: a severe } \\
\text { congenital form with } \\
\text { brain and eye } \\
\text { anomalies, (WWS) } \\
\text { or (MEB); } \\
\text { - type C7 a milder } \\
\text { limb-girdle form. }\end{array}$ & $\begin{array}{l}\text { Classic features of WWS } \\
\text { Classic features of MEB }\end{array}$ & $\begin{array}{l}\text { 4-diphosphocytidyl- } \\
2 \mathrm{C} \text {-methyl-D- } \\
\text { erythritol synthases } \\
\text { required for efficient } \\
\text { O-mannosylation of } \\
\text { alpha-dystroglycan }\end{array}$ & $\begin{array}{l}\text { Ispd }{ }^{L 79}{ }^{L} L 79_{*}(E N U- \\
\text { induced) mutant } \\
\text { mouse }\end{array}$ & $\begin{array}{l}\text { Hydrocephalus, } \\
\text { incomplete brain } \\
\text { folding, reduced } \\
\text { eye size. } \\
\text { Defects in muscle } \\
\text { Fibers } \\
\text { COB LIS-like } \\
\text { phenotype. Axon } \\
\text { guidance defects }\end{array}$ & {$[217,218,225,349]$} \\
\hline $\begin{array}{l}\text { TMEM5 } \\
(* 605862)\end{array}$ & $\mathrm{AR}$ & $12 q 14.2$ & $\begin{array}{l}\text { MDDG: } \\
\text { - type A10: a severe } \\
\text { congenital form with } \\
\text { brain and eye } \\
\text { anomalies, (WWS) }\end{array}$ & $\begin{array}{l}\text { Classic features of WWS } \\
\text { Classic features of MEB } \\
\text { Encephalocele }\end{array}$ & $\begin{array}{l}\text { Transmembrane } \\
\text { Protein } 5 \text { is thought to } \\
\text { have } \\
\text { glycosyltransferase } \\
\text { function }\end{array}$ & & & {$[218,350]$} \\
\hline $\begin{array}{l}\text { POMK } \\
(* 615247)\end{array}$ & AR & $8 \mathrm{p} 11.21$ & $\begin{array}{l}2 \text { different forms of } \\
\text { MDDG: } \\
\text { - type A12: a severe } \\
\text { congenital form with } \\
\text { brain and eye } \\
\text { anomalies, (WWS) } \\
\text { or (MEB); } \\
\text { - type C12 a milder } \\
\end{array}$ & $\begin{array}{l}\text { COB lissencephaly } \\
\text { Microcephaly } \\
\text { Hypomyelination } \\
\text { Mega cisterna magna } \\
\text { Hydrocephaly } \\
\text { Temporal lobe arachnoid } \\
\text { cyst }\end{array}$ & $\begin{array}{l}\text { Protein-O-Mannose } \\
\text { Kinase }\end{array}$ & $\begin{array}{l}\text { RIKEN cDNA } \\
4930444 \mathrm{~A} 02 \text { KO } \\
\text { mouse (ortholog of } \\
\text { the human SGK196 } \\
\text { or POMK gene) } \\
\text { Pomk KD MO }\end{array}$ & $\begin{array}{l}\text { Hydrocephalus and } \\
\text { cerebellar } \\
\text { dysplasia. } \\
\text { Abnormal neuronal } \\
\text { migration. } \\
\text { Behavioral deficits. } \\
\text { Embryos with small }\end{array}$ & {$[222,236,351]$} \\
\hline
\end{tabular}




\begin{tabular}{|c|c|c|c|c|c|c|c|c|}
\hline & & & limb-girdle form & & & Zebrafish & $\begin{array}{l}\text { head, delayed } \\
\text { ocular } \\
\text { development, } \\
\text { shortened thicker } \\
\text { tail, U-shaped } \\
\text { somites, reduced } \\
\text { motility }\end{array}$ & \\
\hline $\begin{array}{l}B 3 G N T 1 \\
(B 4 G A T 1) \\
(* 605517)\end{array}$ & AR & $11 \mathrm{q} 13.2$ & $\begin{array}{l}\text { MDDG: } \\
\text { - type A13: a severe } \\
\text { congenital form with } \\
\text { brain and eye } \\
\text { anomalies, (WWS) }\end{array}$ & $\begin{array}{l}\text { Classic features of WWS, } \\
\text { including cobblestone } \\
\text { lissencephaly, enlarged } \\
\text { ventricles/ hydrocephalus, } \\
\text { cerebellar and brainstem } \\
\text { hypoplasia } \\
\text { Anencephaly }\end{array}$ & $\begin{array}{l}\text { Beta-1,3-N- } \\
\text { acetylglucosa- } \\
\text { minyltransferase } \\
\text { family, transmembrane } \\
\text { protein, essential for } \\
\text { the synthesis of poly- } \\
\mathrm{N} \text {-acetyllactosa- } \\
\text { mine, a determinant } \\
\text { for the blood group i } \\
\text { antigen. Involved in O- } \\
\text { mannosylation of } \\
\text { alpha-dystroglycan } \\
\text { (DAG1) }\end{array}$ & $\begin{array}{l}\text { B3gnt1 KD MO } \\
\text { Zebrafish } \\
\\
\text { B3gnt1 LacZ/LacZ } \\
\text { KO mutant mouse } \\
\text { B3gntI LacZ/M155T } \\
\text { (ENU-induced) } \\
\text { mutant mouse }\end{array}$ & $\begin{array}{l}\text { Muscle fibre } \\
\text { organization } \\
\text { disrupted, } \\
\text { hypoglycosylation } \\
\text { of alpha-DG } \\
\text { Embryonic lethal } \\
\text { (E9.5) } \\
\text { Majority die } \\
\text { perinatally, axon } \\
\text { guidance defects. } \\
\text { MDDG phenotype, } \\
\text { COB LIS -like } \\
\text { phenotype and } \\
\text { hydrocephaly } \\
\text { Heterotopia and } \\
\text { other abnormalities } \\
\text { in several brain } \\
\text { regions (e.g. } \\
\text { cerebellum and } \\
\text { hippocampus). }\end{array}$ & {$[224,349,352]$} \\
\hline $\begin{array}{l}\text { B3GALNT2 } \\
(* 610194)\end{array}$ & AR & $1 \mathrm{q} 42.3$ & $\begin{array}{l}\text { MDDG: } \\
\text { - type A11: a severe } \\
\text { congenital form with } \\
\text { brain and eye } \\
\text { anomalies, (WWS) }\end{array}$ & $\begin{array}{l}\text { Classic features of WWS, } \\
\text { including cobblestone } \\
\text { lissencephaly, enlarged } \\
\text { ventricles/ hydrocephalus, } \\
\text { cerebellar and brainstem } \\
\text { hypoplasia } \\
\text { PMG, } \\
\text { leukoencephalopathy and } \\
\text { cerebellar cyst }\end{array}$ & $\begin{array}{l}\text { Beta-1,3-N- } \\
\text { Acetylgalactosaminyltr } \\
\text { ansferase } 2 \text { that } \\
\text { synthesizes a unique } \\
\text { carbohydrate structure, } \\
\text { GalNAc-beta-1- } \\
\text { 3GlcNAc, on } \mathrm{N} \text { - and } \\
\text { O-glycans. Involved } \\
\text { DAG1 glycosylation }\end{array}$ & $\begin{array}{l}\text { B3galnt2 KD MO } \\
\text { Zebrafish }\end{array}$ & $\begin{array}{l}\text { Embryos with } \\
\text { curved body, mild } \\
\text { retinal } \\
\text { degeneration, } \\
\text { severely impaired } \\
\text { motility and } \\
\text { hydrocephalus }\end{array}$ & [221] \\
\hline
\end{tabular}

${ }^{1}$ Eyes anomalies in MDDG, including bilateral retinal dystrophia, severe myopia, cataract, optic nerve hypoplasia, glaucoma, microphthalmia, corneal clouding, and coloboma. 


\begin{tabular}{|c|c|c|c|c|c|c|c|c|c|}
\hline Table 5. & $\begin{array}{l}\text { Gene } \\
\text { (OMIM) }\end{array}$ & Inheritance & $\begin{array}{l}\text { Human } \\
\text { Locus }\end{array}$ & $\begin{array}{l}\text { Main clinical } \\
\text { characteristics/ } \\
\text { Syndromes }\end{array}$ & $\begin{array}{l}\text { Cortical malformation } \\
\text { (and other brain } \\
\text { abnormalities) }\end{array}$ & Protein function & Animal model & $\begin{array}{l}\text { CM phenotype } \\
\text { correlation (animal } \\
\text { vs human) }\end{array}$ & $\begin{array}{l}\text { Selected } \\
\text { References }\end{array}$ \\
\hline \multirow[t]{6}{*}{$\begin{array}{l}\text { Polymicrogyria } \\
\text { (PMG) and } \\
\text { microcephaly }\end{array}$} & $\begin{array}{l}\text { GPR56 } \\
(A D G R G 1) \\
(* 604110)\end{array}$ & $\mathrm{AR}$ & $16 \mathrm{q} 21$ & $\begin{array}{l}\text { ID / Developmental delay } \\
\text { Epilepsy } \\
\text { Non progressive cerebellar } \\
\text { ataxia } \\
\text { Spasticity } \\
\text { Dysconjugate } \\
\text { gaze, variably as esotropia, } \\
\text { nystagmus, exotropia, or } \\
\text { strabismus }\end{array}$ & $\begin{array}{l}\text { Bilateral bifrontoparietal } \\
\text { PMG (BFPP) and/or } \\
\text { cobblestone LIS } \\
\text { Brainstem and cerebellar } \\
\text { hypoplasia / dysplasia + } \\
\text { cysts } \\
\text { White matter abnormalities }\end{array}$ & $\begin{array}{l}\text { Heterotrimeric G- } \\
\text { protein-coupled receptor } \\
\text { family member, receptor } \\
\text { for collagen } \\
\text { III/COL3A1, involved in } \\
\text { cell adhesion. } \\
\text { Controls proliferation of } \\
\text { progenitors in the } \\
\text { neocortex }\end{array}$ & Gpr56 KO mouse & $\begin{array}{l}\text { Overmigration of } \\
\text { neurons through } \\
\text { breached pial BM or } \\
\text { undermigration forming } \\
\text { irregular cortical layers } \\
\text { (and neuronal ectopia) } \\
\text { and disorganization of } \\
\text { the glial scaffold. } \\
\text { Mislocalized Cajal- } \\
\text { Retzius cells. } \\
\text { Cerebellum } \\
\text { abnormalities }\end{array}$ & {$[227,252-254,353]$} \\
\hline & & & & & & & $\begin{array}{l}\text { Human GPR56 } \\
\text { transgenic }(\mathrm{Tg}) \\
\text { mouse mutant } \\
\text { (15-bp deletion in } \\
\text { Cis- regulatory } \\
\text { element) }\end{array}$ & $\begin{array}{l}\text { Lateral, cortex or lateral } \\
\text { ganglionic eminence } \\
\text { decreased expression of } \\
\text { GPR56 }\end{array}$ & \\
\hline & $\begin{array}{l}\text { RTTN } \\
(* 610436)\end{array}$ & $\mathrm{AR}$ & $18 \mathrm{q} 22.2$ & $\begin{array}{l}\text { ID/ DD } \\
\text { Microcephalic primordial } \\
\text { dwarfism } \\
\text { Epilepsy }\end{array}$ & $\begin{array}{l}\text { PMG / simplified gyral } \\
\text { pattern } \\
\text { Microcephaly }\end{array}$ & $\begin{array}{l}\text { Rotatin, colocalized with } \\
\text { basal bodies at the } \\
\text { primary cilium in human } \\
\text { fibroblasts, with a } \\
\text { predicted role in its } \\
\text { structure and function }\end{array}$ & Rttn KO mouse & Embryonic lethal & {$[238,241,242]$} \\
\hline & $\begin{array}{l}P I K 3 R 2 \\
(* 603157)\end{array}$ & $\begin{array}{l}\text { De novol } \\
\text { dominant }\end{array}$ & $19 \mathrm{p} 13.11$ & $\begin{array}{l}\text { Overgrowth syndromes } \\
\text { Megalencephaly- } \\
\text { Polymicrogyria- } \\
\text { Polydactyly- } \\
\text { Hydrocephalus (MPPH) }^{\text {syndrome }}{ }^{1} \\
\text { Megalencephaly-capillary } \\
\text { malformation (MCAP) }^{2}\end{array}$ & $\begin{array}{l}\text { Megalencephaly (MEG) } \\
\text { PMG } \\
\text { Hydrocephalus } \\
\text { Mega CC. } \\
\text { Cerebellar tonsillar ectopia } \\
\text { (Chiari malformation) } \\
\text { Perisylvian bilateral PMG }\end{array}$ & $\begin{array}{l}\text { Phosphatidylinositol 3- } \\
\text { kinase (PI3K), lipid } \\
\text { kinase that } \\
\text { phosphorylates the } \\
\text { inositol ring of PI and } \\
\text { related compounds at the } \\
\text { 3-prime position (second } \\
\text { messengers in growth } \\
\text { signaling pathways) }\end{array}$ & Pik3r2 KO mouse & $\begin{array}{l}\text { Smaller body size } \\
\text { tendency }\end{array}$ & {$[244,247,354]$} \\
\hline & $\begin{array}{l}\text { AKT3 } \\
(* 611223)\end{array}$ & $\begin{array}{l}\text { De novol } \\
\text { dominant }\end{array}$ & $1 \mathrm{q} 44$ & $\begin{array}{l}\text { Overgrowth syndromes } \\
\text { Megalencephaly- } \\
\text { Polymicrogyria- } \\
\text { Polydactyly- } \\
\text { Hydrocephalus (MPPH) }_{\text {syndrome }}{ }^{1} \\
\text { Megalencephaly-capillary }_{\text {malformation (MCAP) }}^{2}\end{array}$ & $\begin{array}{l}\text { Megalencephaly (MEG) / } \\
\text { Hemimegalencephaly } \\
\text { (HMEG)/ PMG } \\
\text { Enlarged ventricles/ } \\
\text { Hydrocephalus } \\
\text { Mega CC. } \\
\text { Cerebellar tonsillar ectopia } \\
\text { (Chiari malformation) }\end{array}$ & $\begin{array}{l}\text { Member of a } \\
\text { serine/threoonine protein } \\
\text { kinase family. } \\
\text { Implicated in many } \\
\text { biological processes, } \\
\text { including cell signaling } \\
\text { in response to insulin } \\
\text { and growth factors, } \\
\text { apoptosis, glycogen and } \\
\text { fatty acid synthesis, } \\
\text { cellular proliferation, } \\
\text { differentiation, among } \\
\text { others }\end{array}$ & $\begin{array}{l}\text { Akt3 KO mouse } \\
A k t 3^{N m f 350 / N m f 350} \\
\text { and } A k t 3^{N m f 350 /+} \\
\text { ENU-induced } \\
\text { mice mutant }\end{array}$ & $\begin{array}{l}\text { Reduced brain size } \\
\text { Seizures and agenesis } \\
\text { CC observed. Larger } \\
\text { brains in adulthood, } \\
\text { enlarged hippocampus }\end{array}$ & $\begin{array}{l}{[242-244,247,} \\
355-357]\end{array}$ \\
\hline & $\begin{array}{l}\text { MTOR } \\
(* 601231)\end{array}$ & $\begin{array}{l}\text { Post zygotic/ } \\
\text { mosaic }\end{array}$ & $1 \mathrm{p} 36.22$ & $\begin{array}{l}\text { ID/DD } \\
\text { Can include: Autism }\end{array}$ & $\begin{array}{l}\text { FCD type } 2 a^{3} \text { to diffuse } \\
\text { MEG/ PMG }\end{array}$ & $\begin{array}{l}\text { Mechanistic Target Of } \\
\text { Rapamycin, member of } \\
\text { the PIK-related kinases }\end{array}$ & Mtor KO mouse & Embryonic lethal & {$[243,245,249,358]$} \\
\hline
\end{tabular}




\begin{tabular}{|c|c|c|c|c|c|c|c|c|}
\hline & & & $\begin{array}{l}\text { Epilepsy } \\
\text { Can include: } \\
\text { Cutaneous pigmentary } \\
\text { mosaicism } 5\end{array}$ & & $\begin{array}{l}\text { family, involved in } \\
\text { cellular metabolism, } \\
\text { growth and survival in } \\
\text { response to hormones, } \\
\text { growth factors, cellular } \\
\text { responses to stresses, e.g. } \\
\text { DNA damage and } \\
\text { nutrient deprivation }\end{array}$ & & & \\
\hline $\begin{array}{l}\text { PIK3CA } \\
(* 171834)\end{array}$ & $\begin{array}{l}\text { De novol } \\
\text { dominant }\end{array}$ & $3 q 26.32$ & $\begin{array}{l}\text { PIK3CA-related } \\
\text { overgrowth spectrum } \\
\text { (PROS) }^{3}\end{array}$ & $\begin{array}{l}\text { MEG / HMEG/ PMG } \\
\text { Enlarged ventricles/ } \\
\text { Hydrocephalus } \\
\text { Mega CC. } \\
\text { Cerebellar tonsillar ectopia } \\
\text { (Chiari malformation) }\end{array}$ & $\begin{array}{l}\text { PIK3-kinase subunit } \\
\text { alpha, phosphorylates PI } \\
\text { to generate PIP3, which } \\
\text { plays a role by recruiting } \\
\text { PH domain-containing } \\
\text { proteins to the } \\
\text { membrane, including } \\
\text { AKT1 and PDPK1, } \\
\text { activating signaling } \\
\text { cascades involved in cell } \\
\text { growth, survival, } \\
\text { proliferation, motility } \\
\text { and morphology }\end{array}$ & & & {$[243,244]$} \\
\hline $\begin{array}{l}C C N D 2 \\
(* 123833)\end{array}$ & $\begin{array}{l}\text { De novol } \\
\text { dominant }\end{array}$ & $12 \mathrm{p} 13.32$ & $\begin{array}{l}\text { Overgrowth syndromes } \\
\text { Megalencephaly- } \\
\text { Polymicrogyria- } \\
\text { Polydactyly- } \\
\text { Hydrocephalus (MPPH) }^{\text {syndrome }}{ }^{1} \\
\text { Megalencephaly-capillary }_{\text {malformation (MCAP) }}^{2}\end{array}$ & $\begin{array}{l}\text { MEG/ HMEG/ PMG } \\
\text { Enlarged ventricles/ } \\
\text { Hydrocephalus } \\
\text { Mega CC. } \\
\text { Cerebellar tonsillar ectopia } \\
\text { (Chiari malformation) }\end{array}$ & $\begin{array}{l}\text { Cyclin D1, cyclins } \\
\text { function as regulators of } \\
\text { CDK kinases, in cell } \\
\text { cycle progression (e.g. } \\
\text { G1/S transition) }\end{array}$ & $\begin{array}{l}C_{\mathrm{P} 281 \mathrm{R}}{ }^{\mathrm{T} 280 \mathrm{~A}} \text { and } \\
\text { mutations } \\
\text { (IUE E13.5 mouse } \\
\text { neocortex) }\end{array}$ & $\begin{array}{l}\text { No obvious } \\
\text { malformation reported. } \\
\text { Lack of adult } \\
\text { neurogenesis. } \\
\text { Indistinguishable from } \\
\text { WT. Females sterile. } \\
\text { Memory impairment, } \\
\text { learning difficulties } \\
\text { Increased numbers of } \\
\text { actively dividing cells in } \\
\text { the CP and decreased cell } \\
\text { cycle exit }\end{array}$ & {$[246,248,359]$} \\
\hline $\begin{array}{l}\text { PAX6 } \\
(* 607108)\end{array}$ & $\begin{array}{l}\text { De novol } \\
\text { dominant }\end{array}$ & $11 \mathrm{p} 13$ & $\begin{array}{l}\text { Aniridia } \\
\text { Can include: } \\
\text { ID, ataxia } \\
\text { Anterior Segment } \\
\text { Dysgenesis and/or Foveal } \\
\text { Hypoplasia } \\
\text { Keratitis (corneal } \\
\text { opacification and } \\
\text { vascularization and by } \\
\text { foveal hypoplasia) } \\
\text { Rare ocular phenotypes } \\
\text { (coloboma, morning glory } \\
\text { disc anomaly, optic nerve } \\
\text { hypoplasia/aplasia and } \\
\text { persistent hyperplastic } \\
\text { primary vitreous) }\end{array}$ & $\begin{array}{l}\text { Unilateral PMG and } \\
\text { absence of pineal gland } \\
\text { CC agenesis and brainstem } \\
\text { hypoplasia }\end{array}$ & $\begin{array}{l}\text { Transcription factor } \\
\text { involved in neural } \\
\text { development (forebrain } \\
\text { patterning and cerebral } \\
\text { cortical arealization) and } \\
\text { eye development. } \\
\text { RG cells precursors }\end{array}$ & $\begin{array}{l}\text { Pax6 KO mouse } \\
\operatorname{Pax}^{\text {Sey/Sey/ }} \\
\operatorname{Pax}^{\text {Sey/Neu }} \text { and } \\
\operatorname{Pax}^{\text {Sey/Neu/t }} \\
\text { mutant mice }\end{array}$ & $\begin{array}{l}\text { Embryonic lethal } \\
\text { Die at birth. } \\
\text { Absence of eyes } \\
\text { (homozygous) or } \\
\text { abnormally small eyes } \\
\text { (Het.), impaired radial } \\
\text { cell migration and } \\
\text { progenitor proliferation } \\
\text { (neocortex), smaller } \\
\text { cortices, thin CP and } \\
\text { thickened SVZ } \\
\text { presenting clusters of } \\
\text { cells towards the IZ. } \\
\text { Cerebellum } \\
\text { abnormalities } \\
\text { Thinner cortical wall, } \\
\text { lamination defects, } \\
\text { enlarged ventricles }\end{array}$ & {$[251,360-364]$} \\
\hline
\end{tabular}




\begin{tabular}{|c|c|c|c|c|c|c|c|c|}
\hline & & & & & & $\begin{array}{l}\text { Pax6 mutant } \\
\text { Xenopus }\end{array}$ & $\begin{array}{l}\text { Embryos with eye } \\
\text { defects, persistent eye- } \\
\text { like structure with an } \\
\text { abnormal retina and no } \\
\text { lens. Axial defects, some } \\
\text { death after stage } 46\end{array}$ & \\
\hline $\begin{array}{l}\text { RAB3GAPI } \\
\text { (* 602536) } \\
\#\end{array}$ & $\mathrm{AR}$ & $2 \mathrm{q} 21.3$ & $\begin{array}{l}\text { Warburg Micro Syndrome } \\
\text { (WMS) } \\
\text { Martsolf syndrome }\end{array}$ & $\begin{array}{l}\text { PMG } \\
\text { Microcephaly } \\
\text { CC hypoplasia, } \\
\text { Can include cerebellar } \\
\text { hypoplasia }\end{array}$ & $\begin{array}{l}\text { Catalytic subunit (p130) } \\
\text { of a Rab GTPase } \\
\text { activating protein, } \\
\text { regulator of vesicle } \\
\text { trafficking and synaptic } \\
\text { vesicle release }\end{array}$ & $\begin{array}{l}\text { p130 KO mouse } \\
\text { Rab3-GAP mutant } \\
\text { Drosophila }\end{array}$ & $\begin{array}{l}\text { Non morphological } \\
\text { abnormalities in the } \\
\text { neocortex and } \\
\text { hippocampus. } \\
\text { Synaptic dysfunction } \\
\text { (necessary for normal } \\
\text { morphological synapses) } \\
\text { and disrupted } \\
\text { neurotransmitter release }\end{array}$ & {$[240,365-368]$} \\
\hline $\begin{array}{l}R A B 3 G A P 2 \\
(* 609275)\end{array}$ & AR & $1 \mathrm{q} 41$ & $\begin{array}{l}\text { WMS }{ }^{6} \\
\text { Martsolf syndrome }\end{array}$ & $\begin{array}{l}\text { PMG } \\
\text { Microcephaly } \\
\text { CC hypoplasia, } \\
\text { Can include cerebellar } \\
\text { hypoplasia }\end{array}$ & $\begin{array}{l}\text { Non-catalytic regulatory } \\
\text { subunit (p150) of a Rab } \\
\text { GTPase activating } \\
\text { protein, role in } \\
\text { neurodevelopment }\end{array}$ & & & {$[240,369]$} \\
\hline $\begin{array}{l}\text { RAB18 } \\
(* 602207)\end{array}$ & $\mathrm{AR}$ & $10 \mathrm{p} 12.1$ & $\begin{array}{l}\text { WMS }{ }^{6} \\
\text { Martsolf syndrome }\end{array}$ & $\begin{array}{l}\text { PMG } \\
\text { Microcephaly } \\
\text { CC hypoplasia, } \\
\text { Can include cerebellar } \\
\text { hypoplasia }\end{array}$ & $\begin{array}{l}\text { Small GTPase family } \\
\text { that inhibits secretory } \\
\text { activity in vertebrate } \\
\text { neuroendocrine cells }\end{array}$ & Rab18 KO mouse & $\begin{array}{l}\text { Congenital nuclear } \\
\text { cataracts and atonic } \\
\text { pupils. Neuronal } \\
\text { cytoskeleton disruption. } \\
\text { Progressive hind limb } \\
\text { weakness. }\end{array}$ & {$[240,370,371]$} \\
\hline $\begin{array}{l}\text { WDR62 } \\
(* 613583)\end{array}$ & AR & 19q13.1 & $\begin{array}{l}\text { ID/ DD } \\
\text { Seizures }\end{array}$ & $\begin{array}{l}\text { Primary, autosomal } \\
\text { recessive microcephaly, } \\
\text { with or without cortical } \\
\text { malformations } \\
\text { Cortical malformations } \\
\text { include simplified gyral } \\
\text { pattern } \\
\text { PMG / schizencephaly } \\
\text { Microlissencephaly } \\
\text { Unilateral cerebellar } \\
\text { hypoplasia. Unilateral } \\
\text { brainstem atrophy. } \\
\text { Abnormal CC }\end{array}$ & $\begin{array}{l}\text { Centrosome/spindle } \\
\text { localization and nucleus, } \\
\text { depending on the cell } \\
\text { phase and on the cell } \\
\text { type }\end{array}$ & $\begin{array}{l}\text { Wdr62 KD MO } \\
\text { Zebrafish } \\
\text { Wdr62 KO mutant } \\
\text { mouse } \\
\begin{array}{l}\text { Wdr62 } \\
\text { mutant mouse }\end{array}\end{array}$ & $\begin{array}{l}\text { Reduced head and retina } \\
\text { size } \\
\text { Dwarfism and } \\
\text { microcephaly. Disrupted } \\
\text { apical complexes } \\
\text { Smaller body size only at } \\
\text { early postnatal stages. } \\
\text { Sterile. Smaller brain } \\
\text { than normal } \\
\text { Neuronal migration } \\
\text { defects, progenitor } \\
\text { spindle and mitotic } \\
\text { defects. Depletion of } \\
\text { progenitors }\end{array}$ & {$[258-260,372-375]$} \\
\hline $\begin{array}{l}N D E 1 \\
(* 609449)\end{array}$ & $\mathrm{AR}$ & $16 \mathrm{p} 13.11$ & $\begin{array}{l}\text { ID/ DD } \\
\text { Seizures }\end{array}$ & $\begin{array}{l}\text { Microlissencephaly } \\
\text { Microhydranencephaly }\end{array}$ & $\begin{array}{l}\text { Centrosome/spindle } \\
\text { localization. Expressed } \\
\text { in progenitors. } \\
\text { Role in microtubule } \\
\text { organization, mitosis and } \\
\text { neuronal migration }\end{array}$ & Ndel KO mouse & $\begin{array}{l}\text { Reduced brain size, } \\
\text { mainly the cortex, } \\
\text { normal overall } \\
\text { patterning. Defects of } \\
\text { neuronal migration and } \\
\text { neurogenesis. } \\
\text { Progressive decrease in } \\
\text { progenitor number. } \\
\text { Mitotic defects }\end{array}$ & {$[77-79,376]$} \\
\hline
\end{tabular}




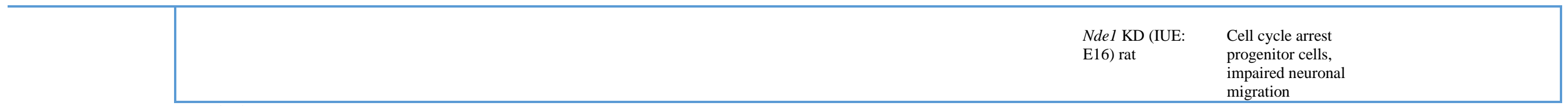

\# mutations in all RAB3GAP1 / 2 / RAB18 cause an indistinguishable phenotype ranging from WMS to Martsolf, making it likely that there is some overlap.

${ }^{1} \mathrm{MPPH}$

${ }^{2}$ MCAP syndrome

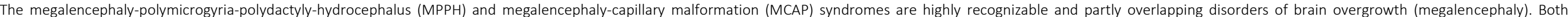
syndromes are characterized by congenital or early postnatal megalencephaly, ID/DD, epilepsy, tone abnormalities

with a high risk for progressive ventriculomegaly leading to hydrocephalus and cerebellar tonsillar ectopia leading to Chiari malformation, and cortical brain abnormalities, specifically polymicrogyria.

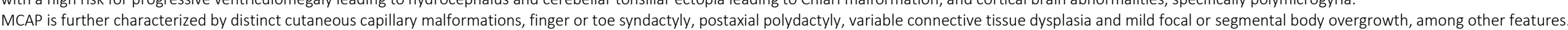

$\mathrm{MPPH}$, lacks consistent vascular or somatic manifestations besides postaxial polydactyly in almost half of reported individuals. Postaxial polydactyly, MEG

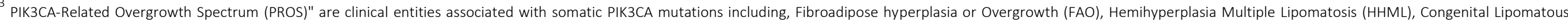

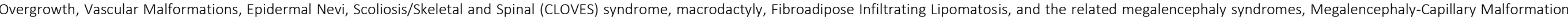
(MCAP or M-CM) and Dysplastic Megalencephaly (DMEG).

${ }^{4}$ FCD type II include cortical dyslamination and large dysmorphic neurons without (type 2a) or with (type 2b) balloon cells

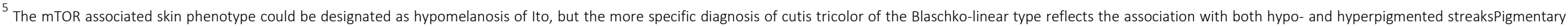
mosaicism in skin (cutis tricolor).

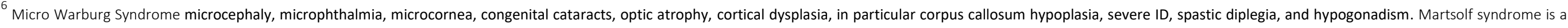
clinically overlapping with Micro Warburg but milder disorder with severe ID, cataracts, short stature, primary hypogonadism, and minor digital abnormalities 


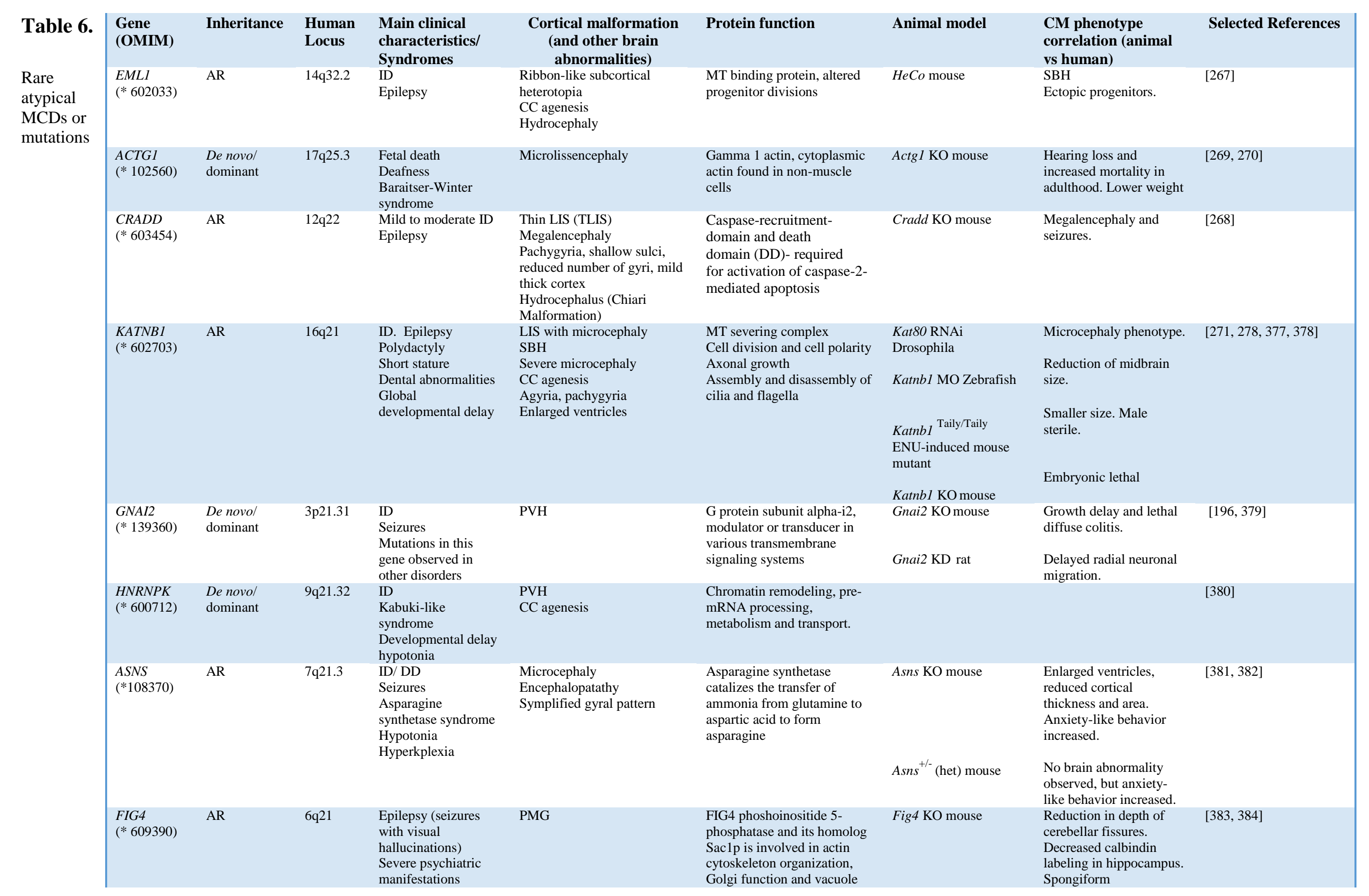




\begin{tabular}{|c|c|c|c|c|c|c|c|c|}
\hline & & & $\begin{array}{l}\text { Charcot-Marie-Tooth } \\
\text { Disease (Type 4J) } \\
\text { Yunis-Varón } \\
\text { syndrome }\end{array}$ & & morphology & & degeneration. & \\
\hline $\begin{array}{l}L A M C 3 \\
(* 604349)\end{array}$ & $\mathrm{AR}$ & $9 \mathrm{q} 34.12$ & $\begin{array}{l}\text { Seizures } \\
\text { Ocular abnormalities } \\
\text { Psychomotor delayed }\end{array}$ & $\begin{array}{l}\text { Occipital pachygyria } \\
\text { Regions with PMG, LIS } \\
\text { Thickened occipital cortex }\end{array}$ & $\begin{array}{l}\text { Laminin Subunit Gamma } 3 \text {, } \\
\text { family member of } \\
\text { extracellular matrix } \\
\text { glycoproteins, may mediate } \\
\text { attachment, migration and } \\
\text { organization of cells into } \\
\text { tissues during embryonic } \\
\text { development }\end{array}$ & Lamc3 KO mouse & $\begin{array}{l}\text { Cortical abnormalities } \\
\text { not determined. }\end{array}$ & {$[385,386]$} \\
\hline $\begin{array}{l}\text { CENPF } \\
(* 600236)\end{array}$ & AR & $1 \mathrm{q} 41$ & $\begin{array}{l}\text { ID } \\
\text { Stromme syndrome } \\
\text { Ocular abnormalities } \\
\text { Intestinal atresia } \\
\text { Xiphoid cleft } \\
\text { Cleft palate } \\
\text { Micrognathia }\end{array}$ & $\begin{array}{l}\text { Microcephaly } \\
\text { Hydrocephalus } \\
\text { Cerebellar hypoplasia } \\
\text { CC agenesis }\end{array}$ & $\begin{array}{l}\text { Centromere protein } F \\
\text { associates with the } \\
\text { centromere-kinetochore } \\
\text { complex, may play a role in } \\
\text { chromosome segregation } \\
\text { during mitosis }\end{array}$ & $\begin{array}{l}\text { Cenpf KD MO } \\
\text { Zebrafish }\end{array}$ & $\begin{array}{l}\text { Hydrocephalus, heart } \\
\text { defects, axis curvature } \\
\text { defects, laterality } \\
\text { malformations, } \\
\text { pronephric cysts. }\end{array}$ & {$[387,388]$} \\
\hline $\begin{array}{l}\text { IER3IP1 } \\
(* 609382)\end{array}$ & $\mathrm{AR}$ & $18 \mathrm{q} 21.1$ & $\begin{array}{l}\text { Epilepsy } \\
\text { Diabetes syndrome } \\
\text { DD } \\
\text { Hypotonia Obesity }\end{array}$ & $\begin{array}{l}\text { Microcephaly (severe in } \\
\text { some patients with LIS) }\end{array}$ & $\begin{array}{l}\text { Immediate Early Response } 3 \\
\text { Interacting Protein } 1 \text { is } \\
\text { localized to the endoplasmic } \\
\text { reticulum (ER) and may play } \\
\text { a role in ER stress response } \\
\text { by mediating cell } \\
\text { differentiation and apoptosis }\end{array}$ & & & {$[389,390]$} \\
\hline $\begin{array}{l}\text { PRICKLE1 } \\
(* 608500)\end{array}$ & $\mathrm{AR}$ & $12 \mathrm{q} 12$ & $\begin{array}{l}\text { Progressive } \\
\text { myoclonus epilepsy- } \\
\text { ataxia syndrome }\end{array}$ & $\begin{array}{l}\text { Microcephaly } \\
\text { PMG } \\
\text { CC agenesis } \\
\text { Mild enlarged ventricles }\end{array}$ & $\begin{array}{l}\text { Prickle Planar Cell Polarity } \\
\text { Protein } 1 \text { is involved in } \\
\text { planar cell polarity pathway } \\
\text { that controls convergent } \\
\text { extension during gastrulation } \\
\text { and neural tube closure }\end{array}$ & 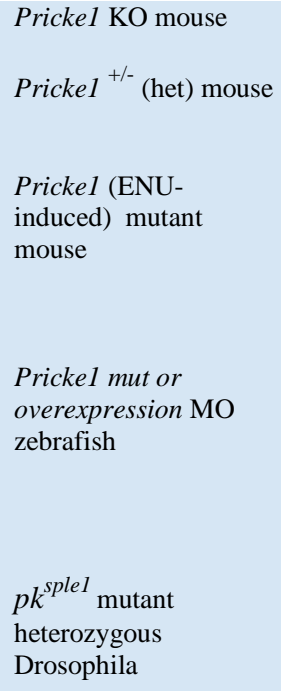 & $\begin{array}{l}\text { Embryonic lethal. } \\
\text { Decreased seizure } \\
\text { threshold. } \\
\text { Decreased seizure } \\
\text { threshold. } \\
\text { No cortical abnormalities } \\
\text { reported. } \\
\text { Decreased gastrulation } \\
\text { effects, morphology } \\
\text { abnormalities, reduced } \\
\text { anterior-posterior length. } \\
\\
\text { Planar cell polarity } \\
\text { abnormalities, anomalies } \\
\text { in the body epidermis } \\
\text { and legs. Seizures. }\end{array}$ & {$[239,391,392]$} \\
\hline $\begin{array}{l}\text { SRPX2 } \\
(* 300642)\end{array}$ & $\mathrm{X}$-linked & $\mathrm{Xq} 22.1$ & $\begin{array}{l}\text { ID } \\
\text { Epilepsy } \\
\text { Speech } \\
\text { dyspraxia }\end{array}$ & $\begin{array}{l}\text { PMG } \\
\text { Bilateral perisylvian } \\
\text { polymicrogyria (BPP) }\end{array}$ & $\begin{array}{l}\text { Sushi Repeat Containing } \\
\text { Protein, X-Linked 2, ligand } \\
\text { for the urokinase } \\
\text { plasminogen activator surface } \\
\text { receptor. Involved in cellular }\end{array}$ & $\begin{array}{l}\text { Srpx2 KD(IUE: E15) } \\
\text { rat }\end{array}$ & $\begin{array}{l}\text { Altered positioning of } \\
\text { projection neurons }\end{array}$ & {$[279,393,394]$} \\
\hline
\end{tabular}




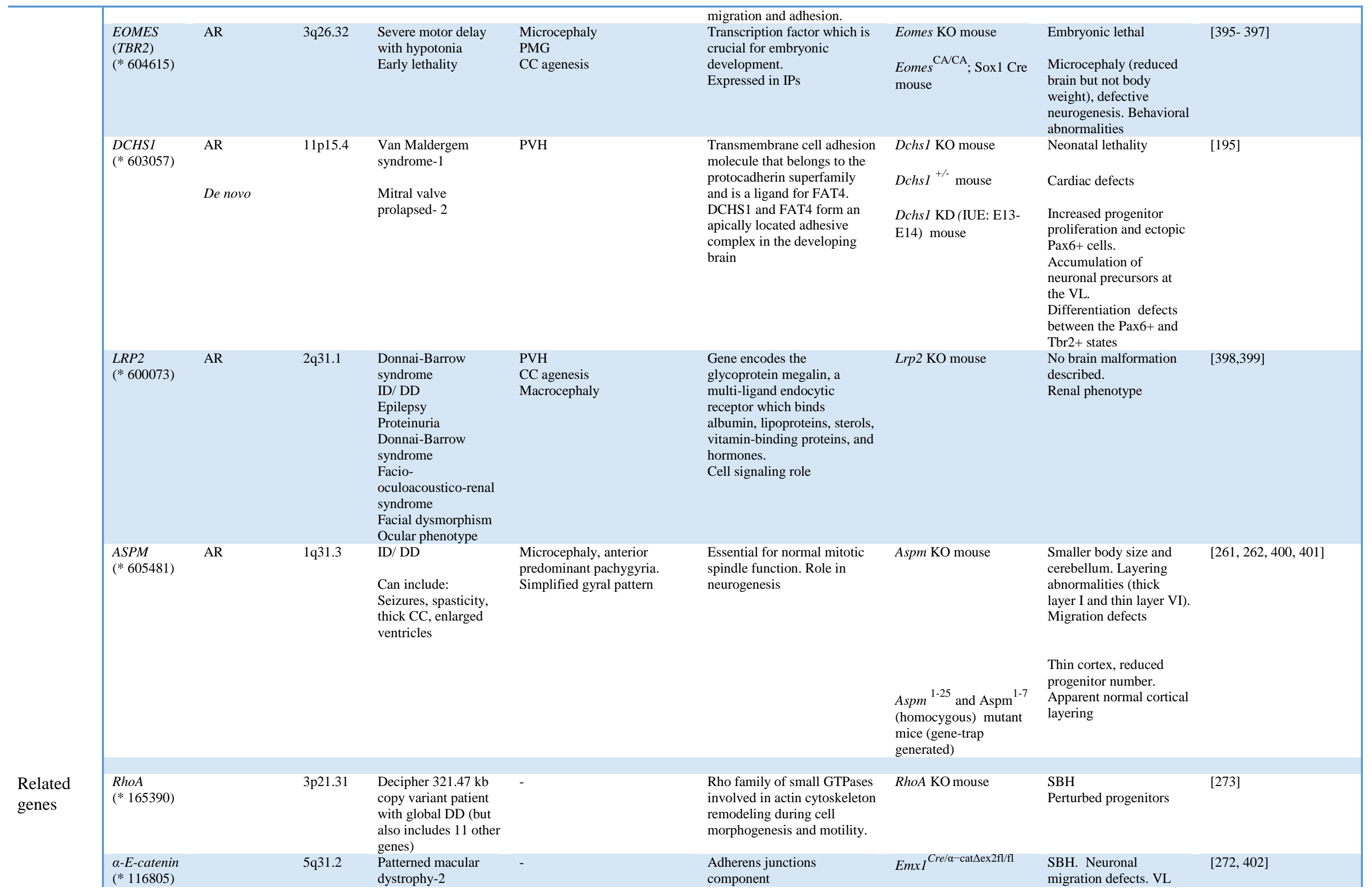




\begin{tabular}{|c|c|c|c|c|c|c|c|}
\hline & & & & & mouse & $\begin{array}{l}\text { defects. RGC phenotype. } \\
\text { Perinatal lethal }\end{array}$ & \\
\hline & & & & & $\begin{array}{l}\alpha \text {-E-catenin } \mathrm{KO} \\
\text { mouse }\end{array}$ & & \\
\hline $\begin{array}{l}\text { MAP3K4 } \\
(* 602425)\end{array}$ & $6 \mathrm{q} 26$ & - & - & $\begin{array}{l}\text { Mitogen-Activated Protein } \\
\text { Kinase Kinase Kinase } 4 \text { that } \\
\text { phosphorilates MAPKK } \\
\text { signal transduction cascade }\end{array}$ & Mekk4 KO mice & $\begin{array}{l}\text { PVH, neuronal migration } \\
\text { defects }\end{array}$ & [201] \\
\hline $\begin{array}{l}\text { NDEL1 } \\
(* 607538)\end{array}$ & $17 \mathrm{p} 13.1$ & $\begin{array}{l}\text { Association with } \\
\text { schizophrenia }\end{array}$ & - & $\begin{array}{l}\text { NudE Neurodevelopment } \\
\text { Protein } 1 \text { Like } 1 \text { is involved } \\
\text { in MT organization during } \\
\text { neurite extension. } \\
\text { Actin reorganization } \\
\text { Cilium dynamics and cell } \\
\text { cycle progression }\end{array}$ & $\begin{array}{l}\text { Ndell KO mouse } \\
\text { Ndell }{ }^{h} \text { cKO mouse } \\
\begin{array}{l}\text { Ndell KD (IUE: E16) } \\
\text { rat }\end{array}\end{array}$ & $\begin{array}{l}\text { Embryonic lethal. } \\
\text { Thinner cortical upper } \\
\text { layers. Neuronal } \\
\text { migration defects } \\
\text { Neuronal migration } \\
\text { defects }\end{array}$ & {$[264,403-405]$} \\
\hline $\begin{array}{l}\text { AF6 } \\
(\text { Mllt4) } \\
(* 159559)\end{array}$ & $6 \mathrm{q} 27$ & $\begin{array}{l}\text { Linked to acute } \\
\text { lymphoblastic } \\
\text { leukemias and acute } \\
\text { myeloid leukemias }\end{array}$ & - & $\begin{array}{l}\text { Actin binding protein that } \\
\text { regulates cell-cell adhesions } \\
\text { downstream of Ras activation }\end{array}$ & $\begin{array}{l}\text { Af6 KO mouse } \\
\text { Af6 floxflox (nestin-Cre } \\
\text { cKO mouse) } \\
\text { Af6 flox/flox; Emxl Cre/+ } \\
\text { (cKO mouse induced at } \\
\text { E10.5) }\end{array}$ & $\begin{array}{l}\text { Embryonic lethal (E10). } \\
\text { General architecture } \\
\text { apparently distorted and } \\
\text { reduced in size. Embryos } \\
\text { with major defects in the } \\
\text { embryonic ectoderm } \\
\text { Perinatal lethal (P3 or } \\
\text { P21 depending on the } \\
\text { genetic background). } \\
\text { Enlarged ventricles, } \\
\text { hydrocephalus. Thinner } \\
\text { cortex. Mislocalized } \\
\text { progenitors and neurons } \\
\text { SBH and rosette-like } \\
\text { structures (Tuj1+ cells) } \\
\text { close to the ventricles. } \\
\text { Increased size and } \\
\text { severely disorganized } \\
\text { neocortex. Disruption of } \\
\text { adherens junctions. } \\
\text { Mislocalized progenitors } \\
\text { and proliferation defects }\end{array}$ & {$[275,406,407]$} \\
\hline $\begin{array}{l}\text { RAPGEF2 } \\
(* 609530)\end{array}$ & $4 q 32.1$ & - & - & $\begin{array}{l}\text { Member of the RAS } \\
\text { subfamily of GTPases. Link } \\
\text { between cell surface } \\
\text { receptors and Rap/Ras } \\
\text { GTPases in intracellular } \\
\text { signaling cascades. Guanine } \\
\text { nucleotide exchange factors } \\
\text { (like RAPGEF2), serve as } \\
\text { RAS activators }\end{array}$ & $\begin{array}{l}\text { Rapgef2 } \mathrm{KO} \text { mouse } \\
\text { Rapgef2 }{ }^{\text {flox/flox; }} \\
\text { Emxl }^{\text {Cre/+ }} \text { cKO mouse }\end{array}$ & $\begin{array}{l}\text { Embryonic lethal, } \\
\text { Impaired cell } \\
\text { proliferation and } \\
\text { migration. Defective } \\
\text { yolk sac vascularization. } \\
\text { SBH, disruption of the } \\
\text { adherens junctions at the } \\
\text { apical surface, abnormal } \\
\text { distribution of } \\
\text { progenitors. }\end{array}$ & {$[276,408]$} \\
\hline
\end{tabular}


hydrocephalus and

unction of RGCs in the wall

subcortical heterotopias.

of lateral ventricles in the

Ependymal agenesis 